\title{
Republic of Montenegro: Selected Issues
}

This Selected Issues paper for the Republic of Montenegro was prepared by a staff team of the International Monetary Fund as background documentation for the periodic consultation with the member country. It is based on the information available at the time it was completed on January 2 , 2008. The views expressed in this document are those of the staff team and do not necessarily reflect the views of the government of the Republic of Montenegro or the Executive Board of the IMF.

The policy of publication of staff reports and other documents by the IMF allows for the deletion of market-sensitive information.

To assist the IMF in evaluating the publication policy, reader comments are invited and may be sent by e-mail to publicationpolicy@imf.org.

Copies of this report are available to the public from

International Monetary Fund $\bullet$ Publication Services

700 19th Street, N.W. • Washington, D.C. 20431

Telephone: (202) 6237430 • Telefax: (202) 6237201

E-mail: publications@imf.org • Internet: http://www.imf.org

Price: $\$ 18.00$ a copy

\section{International Monetary Fund Washington, D.C.}





\section{INTERNATIONAL MONETARY FUND}

\section{REPUBLIC OF MONTENEGRO}

\section{Selected Issues}

Prepared by Anastassios Gagales, Magnus Alvesson (both EUR), Jung Kim (PDR), and Christian Capuano (MCM)

Approved by the European Department

January 2, 2008

Contents

I. Convergence and Euroization in Montenegro ……............................................................

A. An Eclectic Snapshot of the Montenegrin Economy ............................................

B. The Anatomy of the Upswing..............................................................................

C. Should the Current Account Deficit be of Concern in a Euroized Economy? .......21

D. How Could the FDI and Credit Stimuli Unwind? ...............................................24

Boxes

I.1. The Transmission of Shocks in Montenegro ……..................................................

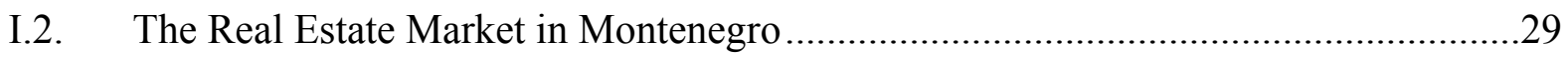

I.3. A Simple Model of Internal and External Adjustment ................................................30

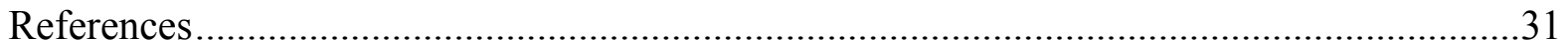

Appendix

I.1. Milestones in the History of Montenegro .................................................................

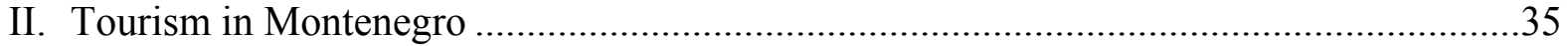

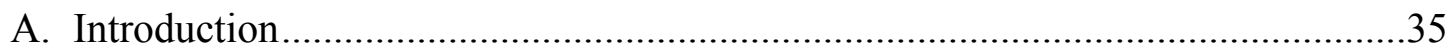

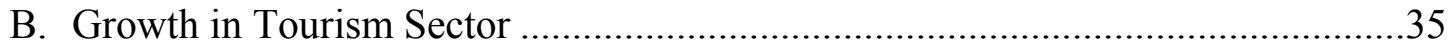

C. Structural Factors Affecting the Development of Tourism ......................................37

D. Competitiveness of Montenegro's Tourism Sector ……….....................................39

E. Sustainability of Tourism Sector ……………………......................................42

Tables

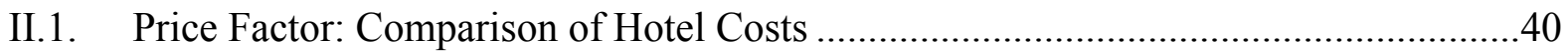

II.2. Perception-based Indicator of Competitiveness in Tourism Sector..............................42 
Figures

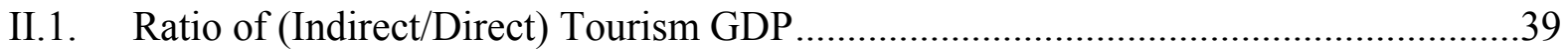

II.2. Comparison of New Monthly Wages in the Region ..............................................40

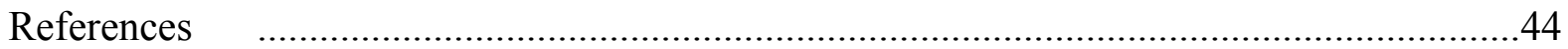

III. Fiscal Policy Implementation at Dawn of Independence-Supporting a Stable

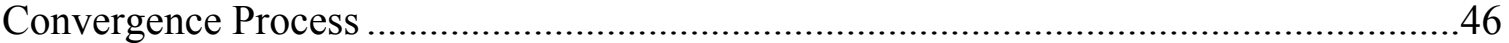

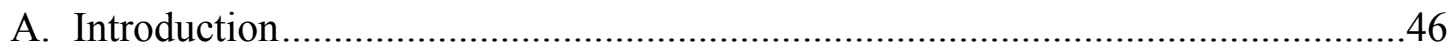

B. A Fiscal Framework for Montenegro ...........................................................46

C. Strengthening the Fiscal Framework - Conclusions and Policy Considerations ..57

Tables

III.1. Public Policy and Perception Indicators .............................................................51

III.2. Structural Budget Balance, 2003-06 ......................................................................55

Figures

III.1. Montenegro: Debt Sustainability Scenarios, 2005-26 ...........................................49

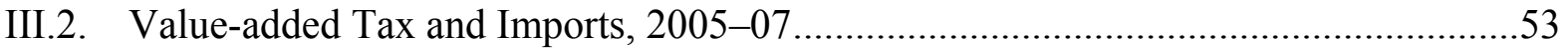

III.3. Cyclical Pressures on the Budget, 2003-06.......................................................54

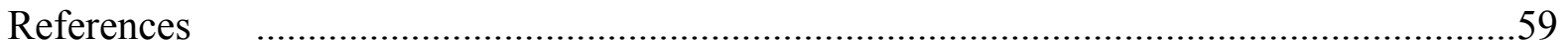

Appendices

III.1. Estimating Potential GDP and the Output Gap ...............................................61

III.2. Cyclical Impact on the Budget - Estimating the Effects of Output and Absorption Gaps

IV. The Banking Sector of Montenegro: Risks during the Transition Path Towards the EU

A. The Transition Path of Montenegro's Banking Sector .......................................65

B. Risks from Rapid Convergence in Montenegro and Policy Options ......................75

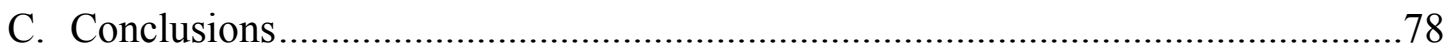

Tables

IV.1. CA Fixed and Random Effects Panel Regression..............................................73

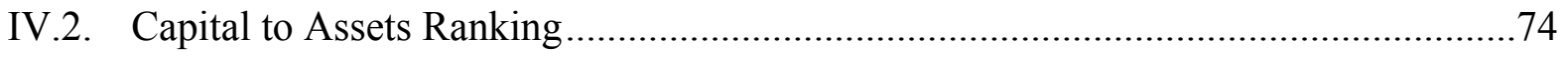

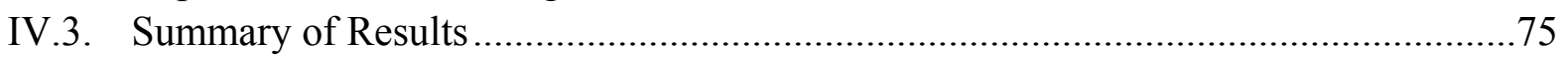


Figures

IV.1. Capital in Percent of Asset and Interest Rates Spread: GISP Countries ...................69

IV.2. Balance Sheet Developments: GISP Countries .................................................70

IV.3. Measures of Profitability: GISP Countries ............................................................. 70

IV.4. Capital in Percent of Assets: CEE Countries ............................................................. 71

IV.5 Capital to Assets Distribution for CEE Countries .................................................72

IV.6 Convergence to GISP: Capital in Percent of Assets ..............................................74

Boxes

IV.1. Credit Growth from an International Perspective...................................................66

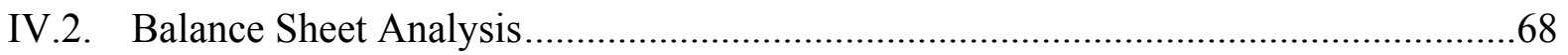

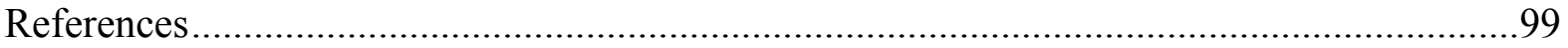

Appendices

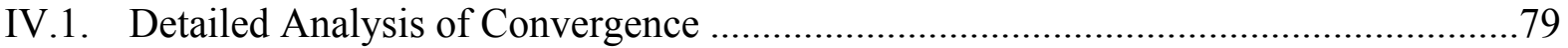

IV.2. Policy Responses to Capital Inflows in Selected European Countries .......................93 


\section{Convergence And Euroization in Montenegro ${ }^{1}$}

1. Montenegro is going through exciting times. Following bold reforms since the late 1990s and financial stabilization, the economy has finally taken off on strong tail winds from phenomenally large capital inflows and, in 2007, became the fastest growing international tourist destination. However, the takeoff has been accompanied by remarkably high external current account deficits, with credit galloping at unsustainable levels. Montenegro exhibits many similarities to other transition economies with fixed exchange rate arrangements. What sets it apart is euroization and the magnitude of the capital inflows and credit growth. This environment raises questions about the sustainability of external deficits, how to best manage the capital inflows to facilitate a soft landing, and the appropriate policy framework during this phase of rapid convergence.

\section{The main conclusions of this paper are:}

- $\quad$ The large current account deficits in Montenegro are the equilibrium response to correspondingly large private capital inflows and fast credit growth, and should be largely self correcting as the capital inflows and credit growth unwind.

- $\quad$ Large capital inflows are a mixed blessing. They stimulate growth and boost productivity but, if their pace exceeds the absorptive capacity of the economy, they could create imbalances (real exchange rate appreciation, asset bubbles etc) and undermine future growth.

- $\quad$ Rapid credit growth has been triggered by large FDI inflows and facilitated by financial deepening. Aggressive lending practices could exacerbate macroeconomic imbalances and strain the capacity of banks to manage credit risks prudently.

- $\quad$ Euroization has served Montenegro well by anchoring inflation expectations. It has also deprived the policy arsenal from monetary instruments and shifted the burden of adjustment to fiscal and structural policies. But the fiscal policy framework is ill equipped to fill in the void.

- A soft landing during the unwinding of the capital inflows cannot be assured, as the convergence process is typically neither monotonic nor smooth. Nonetheless, the probability of and repercussions from a disorderly unwinding can be minimized by countercyclical fiscal policy, making labor markets more flexible, and reforming product markets to boost the supply response.

\footnotetext{
${ }^{1}$ Prepared by Anastassios Gagales.
} 
The paper is structured as follows: it starts with a snapshot of the Montenegrin economy and the policy framework in place; examines the anatomy of the current upswing; analyzes the dynamics of the capital inflows during euroization; looks at the significance of large current account deficits; discusses possible unwinding scenarios; and concludes with policy implications.

\section{A. An Eclectic Snapshot of the Montenegrin Economy}

The economic reform effort since 1998 has been commendable, but structural weaknesses abound and the growth potential remains yet to be confirmed.

3. With its declaration of independence, in June 2006, Montenegro completed a long process of gaining full control over its territory. Until 1997/98, Montenegro was closely integrated with and dependent on Serbia. During the conflict in the FSRY, the country experienced a dramatic reduction in economic activity; a drop in the standard of living; the evaporation of financial wealth through hyperinflation and mismanagement; largescale degradation of physical and human capital; loss of traditional markets; and expansion of the underground economy accompanied by a rise in crime and corruption. In 1998, Montenegro started decoupling from economically beleaguered Serbia with a bold reform program focused economic stabilization, structural reform and privatization, and integration in the international community: ${ }^{2}$

- $\quad$ Economic stabilization focused on taming inflation and consolidating public finances.

○ To quickly insulate the economy from hyperinflation in neighboring Serbia, Montenegro introduced the deutsche mark as a parallel currency in 1999 and as sole legal tender in 2001; and replaced it with the euro in 2002. Euroization succeeded in quickly reducing and stabilizing inflation at about 3 percent per year.

- Impressive progress has also been achieved in fiscal consolidation. The general government balance improved in the past five years by 9 percentage points of GDP, posting a surplus of $4 \frac{1}{2}$ percent of GDP in 2007, and public debt was reduced to 37 percent of GDP.

- $\quad$ The shift towards a market-based economy, capital account liberalization, and large scale privatization has encouraged massive capital inflows, especially in real estate

\footnotetext{
${ }^{2}$ The Appendix at the end of this chapter lists milestones in the history of Montenegro. Vukotic (2004) outlines the reform strategy.
} 
and tourism, but also in manufacturing. A comprehensive bank restructuring has spurred the development of the sector and has led to rapid financial deepening.

- Integration into the international community has been accelerated since independence and is guided by Euroization and Atlanticism. In this regard, Montenegro concluded a Stabilization and Association Agreement (SAA) with the EU, ratified the agreement for the South East Europe Free Trade Area (SEEFTA), became part of the enlarged Central European Free Trade Agreement (CEFTA), has put in place an open trade regime, and is actively pursuing membership in the World Trade Organization (WTO). As part of its Atlantic orientation, Montenegro has joined NATO's Partnership for Peace program.

\section{Salient features of the economy}

4. Despite the recent upswing, production remains below pre-conflict levels. The synergy between the reorientation of economic policy and a favorable external environment raised average GDP growth to a respectable 6 percent per year in 2005-07. However, GDP still remains 15 percent below pre-conflict levels. ${ }^{3}$ At 4,700 dollars, per capita GDP is also low from an international perspective. In purchasing power terms it is at par with Serbia's but 36 percent below Croatia's, 50 percent below the CEE average and about 70 percent below the euro area average (Eurostat, 2007). This suggests a large catching up potential as economic slack is eliminated and convergence takes hold.

Despite the recent uptick, economic activity remains well below pre-conflict levels in the 1980s.

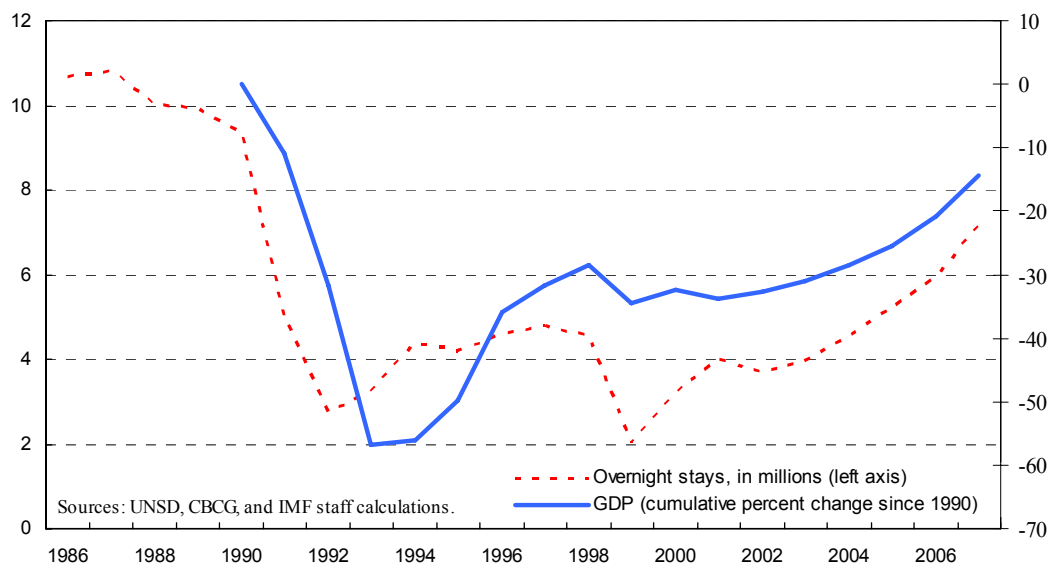

${ }^{3}$ GDP comparisons are plagued by an apparently large and difficult to measure underground economy (amounting to $1 / 4$ of recorded GDP according to rough unofficial estimates). National accounts are currently being revised. 
5. Poverty is widespread and regional income disparities large. In 2001 (the last year for which data are available), almost

10 percent of the population lived in extreme poverty and another 25 percent was just above the poverty line (UNDP, 2003). There are also large regional inequalities between the more prosperous coastline and the less developed mountainous hinterland, where poverty and unemployment are more pronounced.

Widespread poverty and the lack of a reliable social safety net have been an impediment to structural reforms, especially in the electricity sector where tariffs are below cost recovery levels (Silva, 2007). Setting up an adequate social safety net would be essential for overcoming resistance to needed reforms, especially enterprise restructuring.

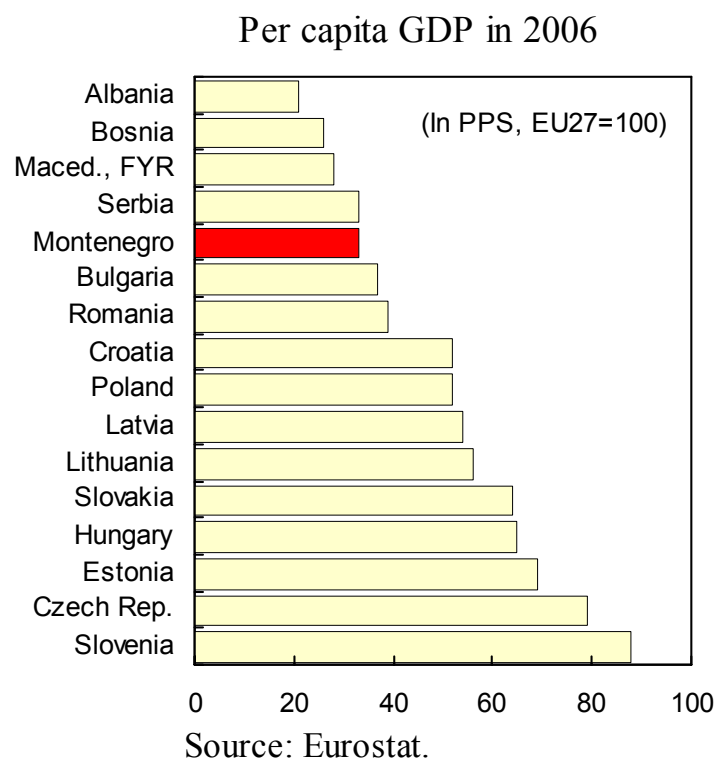

6. The production base is diversified but weak. With a population of just over 600,000 , Montenegro is the smallest Balkan country and about the same size as Malta and Cyprus. A mountainous country, Montenegro has few natural resources (mainly bauxite, lignite and hydropower), aging production structures and former state/collective enterprises needing restructuring. The production base is undergoing rapid transformation, largely with the help of imported capital and expertise, and resources are being shifted from the declining manufacturing, agriculture and state sectors towards tourism, trade and construction. The banking sector has been rehabilitated. Tourist and real estate development are seen as the drivers of future growth. However, there are notable weaknesses:

- A dilapidated electricity sector (the result of using pricing and employment in the sector as social policy instruments). This is causing frequent power outages and is a drag on economic activity, and tourism in particular.

- Quasi-enclave sectors that rely heavily on imported inputs with weak inter-industry linkages, and are mostly foreign owned. The expansion of these sectors (e.g., the aluminum factory and high-end resort complexes) cannot be relied upon to trigger broad-based growth. ${ }^{4}$

- $\quad$ Economic resources are shifting from production to trade (mainly imports) thereby weakening the supply response, notwithstanding extensive slack. This reflects high

\footnotetext{
${ }^{4}$ See chapter II on tourism development.
} 
returns on trade as opposed to production, impediments to entrepreneurship, obsolescence of skills, and coordination failures. This shift puts the economy in a poor position to weather the unwinding of the current demand shock.

These weaknesses suggest that growth cannot be sustained only with strong demand and parametric reforms, but needs to be supported by structural reforms aiming at improving the supply response and broadening diversification of production.

\begin{tabular}{|c|c|c|c|c|c|c|c|c|}
\hline & alue & $\begin{array}{l}\text { ed an } \\
\text { perce }\end{array}$ & $\begin{array}{l}\text { Emplc } \\
\text { of tot }\end{array}$ & nent by & & & & \\
\hline & \multicolumn{4}{|c|}{ Gross value added } & \multicolumn{4}{|c|}{ Employment } \\
\hline & \multirow{2}{*}{$\begin{array}{r}2004 \\
10.8\end{array}$} & \multirow{2}{*}{$\begin{array}{r}2005 \\
9.9\end{array}$} & \multicolumn{2}{|c|}{2006 Average } & \multirow{2}{*}{$\begin{array}{r}2004 \\
2.1\end{array}$} & \multirow{2}{*}{$\begin{array}{r}2005 \\
2.0\end{array}$} & \multicolumn{2}{|c|}{2006 Average } \\
\hline Agriculture and fishing & & & $\ldots$ & 10.3 & & & 1.8 & 2.0 \\
\hline Mining & 1.9 & 1.8 & $\ldots$ & 1.8 & 3.2 & 2.8 & 2.8 & 2.9 \\
\hline Manufacturing & 10.3 & 9.9 & $\ldots$ & 10.1 & 18.3 & 18.0 & 17.3 & 17.9 \\
\hline Electricity & 6.8 & 5.7 & $\ldots$ & 6.3 & 3.8 & 3.8 & 3.7 & 3.8 \\
\hline Construction & 3.3 & 3.6 & $\ldots$ & 3.4 & 4.8 & 5.2 & 4.5 & 4.9 \\
\hline Trade & 12.1 & 12.8 & $\ldots$ & 12.4 & 16.8 & 16.5 & 19.6 & 17.6 \\
\hline Hotels and restaurants & 3.2 & 3.5 & $\ldots$ & 3.3 & 6.7 & 7.7 & 7.2 & 7.2 \\
\hline Transport and communication & 11.6 & 11.4 & $\ldots$ & 11.5 & 9.9 & 9.5 & 8.0 & 9.1 \\
\hline Financial intermediation & 2.2 & 2.0 & $\ldots$ & 2.1 & 2.3 & 2.1 & 2.1 & 2.2 \\
\hline Real estate and business services & 15.0 & 14.5 & $\ldots$ & 14.8 & 3.3 & 3.5 & 3.9 & 3.6 \\
\hline Public administration & 22.8 & 24.9 & $\ldots$ & 23.8 & 28.9 & 28.8 & 29.0 & 28.9 \\
\hline
\end{tabular}

Source: Monstat

\section{Foreign trade is fairly concentrated.}

The foreign trade regime is liberal, import duties are low, and trade flows (exports plus imports) averaged 132 percent of GDP in 2005-07, which is mid-range for transition economies. Not uncommon for a small country, the export base is narrow consisting mainly of tourism and aluminum. However, what is unfavorable for Montenegro is the high import content of its main exports: (i) electricity consumption in aluminum production corresponds roughly to electricity imports; ${ }^{5}$ and (ii) the tourism sector

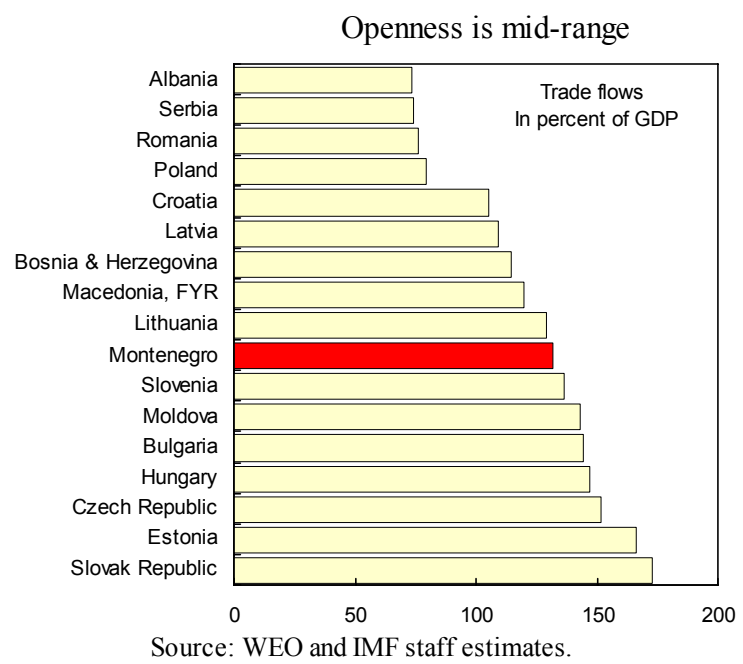
(especially at the high end) relies heavily on

\footnotetext{
${ }^{5}$ Currently, electricity is supplied to KAP at below the cost of electricity imports (which, owing to the energy deficit, corresponds to the marginal cost of electricity). The agreement with EPCG stipulates the phasing out of this subsidy. However, reports raise doubts about the profitability of KAP at current international prices for electricity and aluminum.
} 
imports, including skilled labor. The direction of trade is determined by proximity, and more than half of tourism revenues originate in Serbia, although the share of tourists from the EU is rising rapidly. Significant trade relations with countries not linked to the euro poses an exchange rate risk, and the limited diversification of the export base could magnify the volatility of GDP growth, strengthening the case for structural reforms, especially in product and labor markets.

Montenegro: Trade structure, Jan-June 2007

\begin{tabular}{lclr}
\hline \multicolumn{2}{c}{ Exports } & \multicolumn{2}{c}{ Imports } \\
\hline \multicolumn{3}{c}{ I. Composition of trade (in percent of total goods and services) } \\
Aluminum & 30.9 & Machines and transport equipment & 15.9 \\
Iron/steel and steel products & 7.6 & Vehicles & 11.0 \\
Fruit, beverages, tobacco & 6.0 & Oil and gas & 10.1 \\
Mineral fuel, mineral oil & 4.5 & Iron/steel and steel products & 6.7 \\
Other goods & 12.7 & Electricity & 4.4 \\
& & Furniture & 3.2 \\
& & Other goods & 38.6 \\
Tourism 1/ & 18.9 & Construction services & 1.9 \\
Other services & 19.4 & Other services & 8.3 \\
& & & \\
Italy & & Sir. Direction of trade (in percent of total merchandise trade) & 26.6 \\
Serbia & 30.2 & Italy & 10.7 \\
Hungary & 26.1 & Germany & 10.1 \\
Greece & 5.6 & Croatia & 4.1 \\
Bosnia and Herzegovina & 3.8 & Slovenia & 3.8 \\
Others & 1.8 & Others & 44.7 \\
\hline Source: Central Bank of Montenegro and IMF estimates. & & \\
1/ Tourism receipts are very seasonal. Historically, the first six & months account for 17 percent of annual receipts.
\end{tabular}

8. The labor market is stifled by rigidities.

Non-wage costs are relatively low, but the legislative framework is focused on protecting existing jobs with strict firing conditions, restrictions in atypical employment (e.g., part-time and temporary), and rigidities in collective bargaining. These hamper enterprise restructuring, depress the participation rate, and contribute to the large underground economy, which according to unofficial estimates employs at least $1 / 4$ of the labor force. On the other hand, an open attitude towards foreign employment, especially temporary, has supported the development of the seasonal tourism

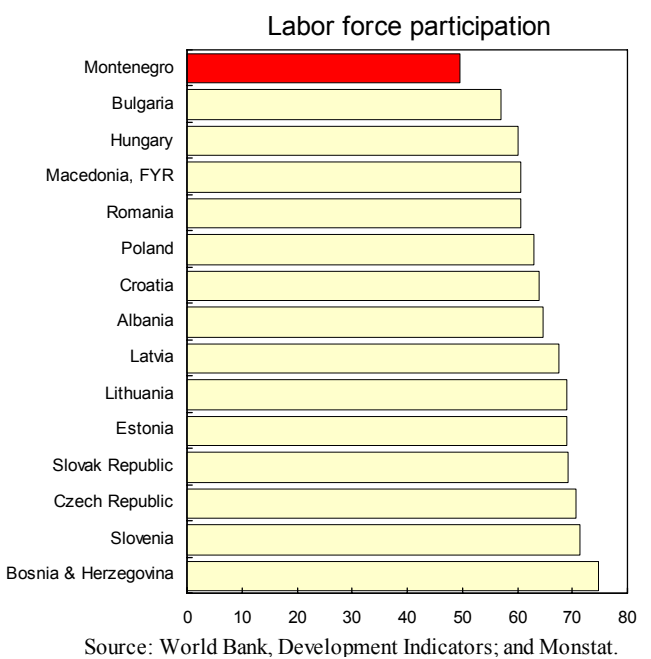
and construction sectors and has helped alleviate skill shortages. The combination of labor market rigidities and euroization can make it costly to improve cost competitiveness. For example, an improvement in cost competitiveness by 5 percentage points would require a 
year long nominal wage freeze, which is difficult to achieve without slowing down the economy. ${ }^{6}$
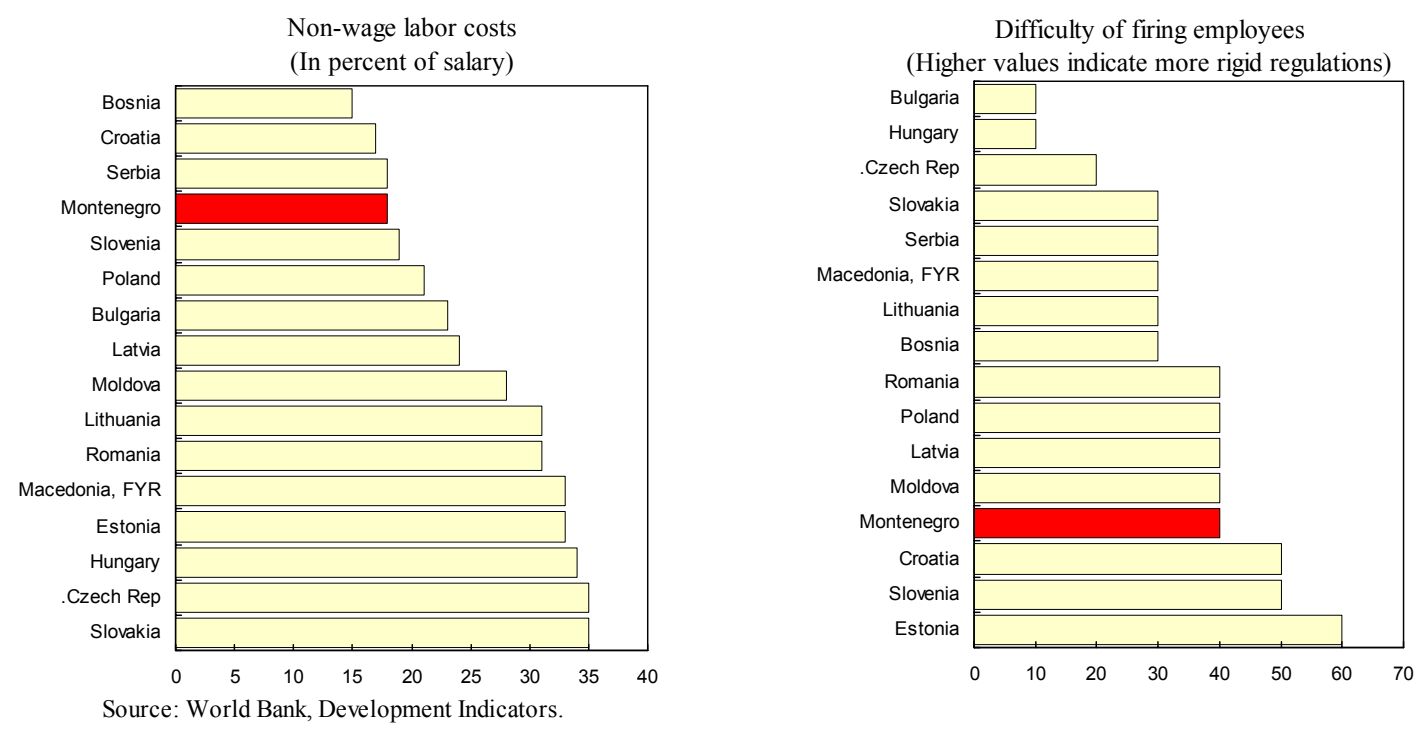

9. The economy is supported by a dynamic and rapidly expanding banking sector. The financial system is bank dominated. Large foreign participation (banks with more than 85 percent foreign participation have a market share of 80 percent) has facilitated the transfer of expertise and the integration of banks into the international financial system; it also provides some insurance against liquidity risks. Credit has been growing very fast, fueled by low interest rates and aggressive competition for market share in the sector. Although prudential supervision is being strengthened, very rapid credit growth (at 190 percent per year in September 2007) could become problematic if it exceeds banks' capacity to underwrite loans prudently and exacerbates asset price inflation. With the recent recovery based in large part on credit growth, bank soundness is important for the macroeconomic outlook. A sharp brake in bank lending could trigger a demand shock, depressing asset prices and eroding confidence.

\footnotetext{
${ }^{6}$ The calculation assumes that productivity remains on its current trend and wage moderation continues in the rest of the euro area. In this scenario nominal wages take the brunt of the adjustment. Supportive structural policies can take off some pressure from wages. For example, if structural reforms raise productivity growth by 1 percentage point, the adjustment period will be shortened by 3 months.
} 


\section{Policy framework}

Macroeconomic policy is guided by euroization and the medium term objective of fiscal consolidation.

10. Euroization in Montenegro was unilateral. The euro was adopted in 2002 as sole legal tender without the explicit consent of the ECB and, thus, without the benefits deriving from EMU participation. ${ }^{7}$ In particular, the Central bank of Montenegro (CBM) does not issue currency and cannot count on liquidity support by the ECB. Unilateral euroization differs from the formal introduction of the euro, which is reserved for EU countries, is regulated by EU treaties, envisages a specific procedure, and presupposes observance of the Maastricht criteria. ${ }^{8}$

\section{Euroization has brought significant benefits...}

- $\quad$ Price stability and the anchoring of expectations, which has helped the quick remonetization of the economy after protracted financial instability in the 1990s, punctuated with hyperinflation.

- $\quad$ The elimination of the currency risk premium and the attendant drop of domestic interest rates towards euro area levels.

- Lower transaction costs that encourage integration with euro area financial and goods markets.

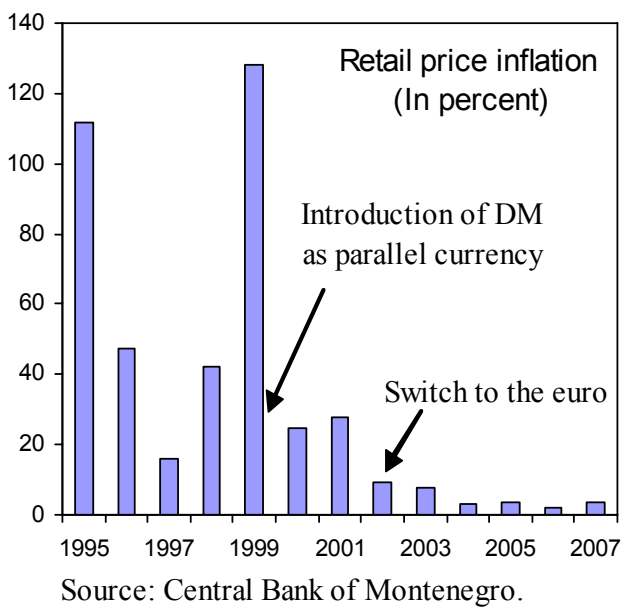

\footnotetext{
${ }^{7}$ The euroization of Montenegro is discussed in Fabris et. al. (2004). ECB (2003a,b) and Bratkowski and Rostowski (2002) discuss the EU attitude towards unilateral euroization, and Levasseur (2004) argues the case for euroization in CEECs on the grounds that conditions have changed radically since the drafting of the Maastricht Treaty. Montenegro is not the only economy outside the EMU that is using the euro. There is also Kosovo (a territory under UN administration) and four states: Andorra, Monaco, Vatican City, and San Marino. Due to their historical ties with EMU member countries, these four states are considered part of the euro area.

${ }^{8}$ The Maastricht criteria comprise price stability, convergence of long-term interest rates, good fiscal performance, a ceiling on public debt, and exchange rate stability.
} 
... and costs

- $\quad$ Loss of seigniorage revenue, as there is no revenue sharing agreement with ECB.

- $\quad$ Limitation of monetary autonomy, with monetary conditions determined by the ECB exclusively on the basis of euro area considerations, which may be inappropriate from the vantage point of Montenegro.

- Loss of the exchange rate as a means to quickly shore up competitiveness, placing a premium on wage restraint and productivity growth.

- $\quad$ Restriction of lender of last resort (LOLR) capacity. ${ }^{9}$ As the CBM cannot issue money, the LOLR capacity is bounded by the availability of required reserves, resources of the deposit insurance agency, and government deposits.

12. Weakened LOLR capacity could undermine public confidence during episodes of banking or liquidity stress. This vulnerability could be mitigated by raising liquidity ratios and capital cushions in banks, arranging precautionary credit lines with euro area commercial banks, and strengthening supervision to safeguard bank soundness.

13. The loss of monetary sovereignty leaves fiscal policy as the sole instrument for demand management; it also raises the specter of procyclical monetary conditions when cyclical conditions in Montenegro and the euro area happen to be out of phase.

Monetary conditions are set by the ECB, exclusively on euro area considerations, and only by chance will they be appropriate from Montenegro's vantage point. During the unfolding upswing, for example, monetary conditions are unnecessarily loose. In this environment, fiscal policy and the management of public sector deposits have a role to play in safeguarding competitiveness by offsetting procyclical monetary conditions as needed. The CBM can, say, raise reserves requirements and liquidity ratios above those in the euro area. ${ }^{10}$ Such actions are not expected to have lasting effects on aggregate demand as they will induce, probably after some lag, the substitution of foreign for domestic borrowing.

\section{The fiscal framework is not adequately designed to address the need for} countercyclical policy. Still in a formative stage, the framework is guided by the mediumterm objectives of (i) reducing public debt; (ii) reducing taxation to internationally competitive levels; and (iii) creating a lean and efficient public administration while allowing room for infrastructure investment and nation building. These objectives, however, are

\footnotetext{
${ }^{9}$ The weakening of LOLR capacity is not the result of euroization as such but of unilateralism, which deprives CBM of access to ECB facilities.

${ }^{10}$ In this respect, CBM has more room for maneuver than euro area central banks.
} 
defined loosely. Moreover, the use of demand management for smoothing economic fluctuations (including pressures on inflation and competitiveness) is not explicitly included among the tasks of fiscal policy, notwithstanding the lack of monetary instruments in the policy arsenal.

\section{Recent success in fiscal consolidation has revealed weaknesses in the fiscal}

framework. Bold fiscal consolidation and favorable economic conditions have generated large fiscal surpluses: at end-2007, net public debt is projected at 32 percent of GDP and the general government surplus at 51/2 percent of GDP. However, these achievements are presenting challenges that the current framework is ill equipped to handle: ${ }^{11}$

- The fiscal framework does not take into account that a significant part of tax revenue (and the improvement in fiscal accounts) is of a temporary nature. This could lead to the overestimation of future tax revenue. Moreover,

- The fiscal surpluses are generating political-economy-related spending pressures and (in the absence of a longer term planning/budgeting horizon) create temptations for commitments that the budget will not be able to afford when the temporary component eventually disappears.

\section{This environment blunts the effect of automatic fiscal stabilizers and has led to procyclical fiscal behavior:}

- $\quad$ Spending pressures triggered by the fiscal surpluses and the placement of large public sector deposits with domestic banks (7 percent of GDP, primarily the result of lumpy privatization revenue) dent the effect of automatic stabilizers, and inhibit fiscal policy from mitigating cyclical fluctuations and preventing the build up of imbalances.

- $\quad$ Longer-term commitments (e.g., tax cuts, large infrastructure projects) based on overestimated revenues could be disruptive if they necessitate a fiscal adjustment when temporary revenues eventually disappear. Procyclicality could be exacerbated if, at the time of a fiscal contraction, monetary conditions in the euro area happen to be tight.

17. Is there a solution? Saving part of the temporary surge in tax revenue would ease cyclical pressures and also prevent an unsustainable build-up of expenditures; and temporarily parking public sector deposits aboard would vent some steam off credit expansion and domestic demand. As a general principle, effective medium-term budgeting

${ }^{11}$ Chapter III discusses in more detail the fiscal framework. 
requires that the authorities smooth recurrent expenditures while providing funds for key lumpy expenditures.

\section{The present policy framework lacks strong incentives for short term}

stabilization. Euroization has decoupled monetary policy from domestic economic conditions while the anchoring of inflation expectations has created complacency and benign neglect towards overheating and competitiveness erosion. In fact, cost competitiveness indicators have yet to be developed and the competitiveness issue has not, so far, featured prominently in the public debate on the budget (the only available demand management instrument). Moreover, municipalities, which enjoy considerable autonomy, tend to behave procyclicaly and the decision to place public sector deposits with domestic banks or abroad is not guided by conjunctural considerations and has provided a procyclical boost to credit expansion. This policy environment could result in significant welfare losses given the traditional volatility of FDI inflows, the reliance of future growth on only two and rather cyclical sectors (tourism and real estate development), and rigidities in product and labor markets.

\section{B. The Anatomy of the Upswing}

19. The upswing has been driven primarily by large FDI inflows and, increasingly, by fast credit growth. FDI inflows shot up to around 23 percent in the past three years (see table below). Credit expansion took off in the past two years, averaging 39 percentage points of GDP per year, supported increasingly by banks' rising net foreign liabilities. These are massive stimuli. FDI exceeds by far levels observed in other transition economies. The credit shock (measured by the increase of bank lending to the private sector in percent of GDP) is already at par with Estonia's and Latvia's, and well above the peak during Portugal's run up to EMU.

\section{Montenegro benefits from increasingly large stimuli ...}

\begin{tabular}{lrrrr}
\hline & 2004 & 2005 & 2006 & 2007 \\
\cline { 2 - 5 } & \multicolumn{4}{c}{ (In percent of GDP) } \\
FDI net inflows & 3.4 & 21.3 & 23.6 & 24.5 \\
Banks' net foreign borrowing & 1.9 & -3.4 & 3.7 & 10.6 \\
Credit expansion to the private sector & 4.5 & 4.6 & 22.9 & 56.1 \\
Total stimulus 1/ & $\mathbf{1 . 2}$ & $\mathbf{2 1 . 8}$ & $\mathbf{3 6 . 7}$ & $\mathbf{6 6 . 6}$ \\
\hline
\end{tabular}

Sources: CBM and IMF staff estimates.

$1 /$ Corrected for the double counting of foreign participation in banks' recapitalization (included in FDI) and banks' external borrowing. 
... whose scale is high relative to other transition economies.
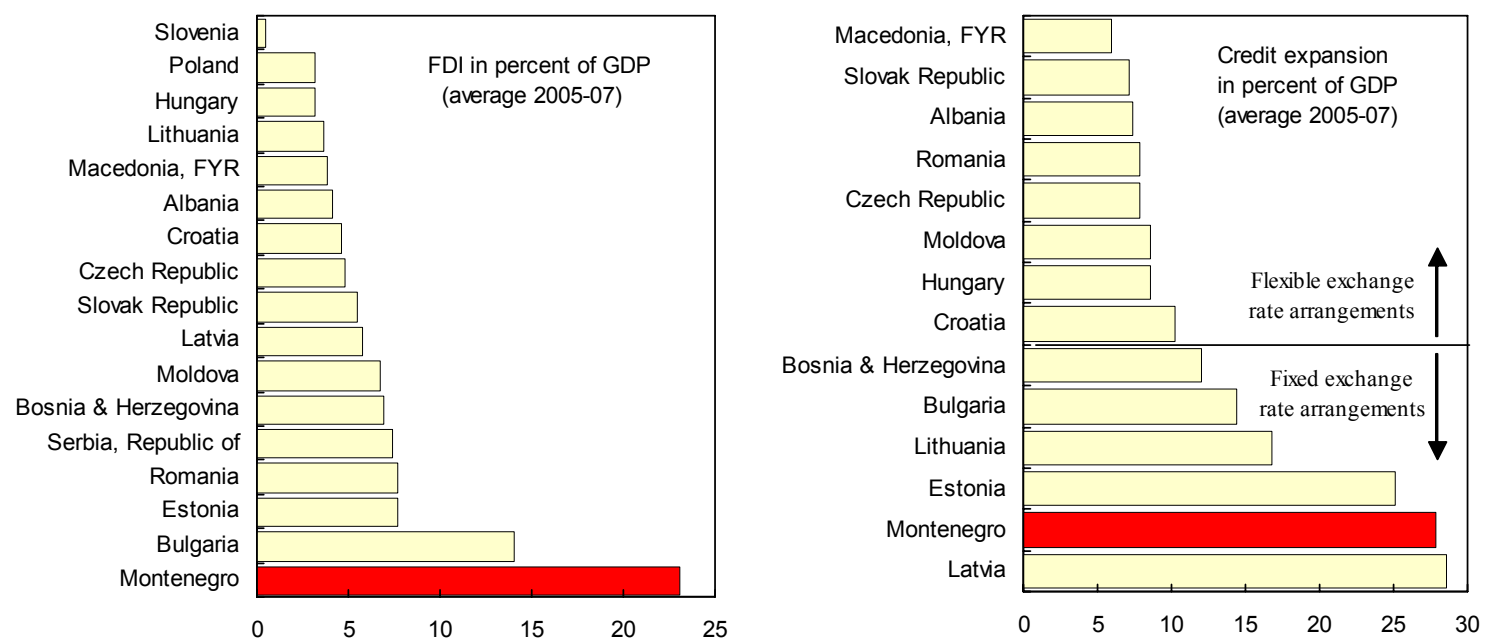

Sources: WEO, IFS and IMF staff estimates.

\section{The two shocks are positively correlated, which implies that the aggregate is}

smaller than the sum of the components. First, the shocks are not primary but derived ones, driven by common factors (e.g. good policies, optimistic growth outlook, expansionary monetary conditions, global liquidity glut) that are themselves positively correlated. ${ }^{12}$ Second, there is an element of double counting: injections in banks' capital from their foreign parent institutions raises both FDI and credit growth; and the sale of real estate to non-residents raises FDI and stimulates bank lending (through deposits from the proceeds of real estate sales). ${ }^{13}$ Finally, by practically eliminating the capacity of the CBM to sterilize the inflows, euroization has exogenized the monetary base.

${ }^{12}$ Data limitations make it impossible to estimate primary shocks econometrically.

${ }^{13}$ The relation between credit expansion and capital inflows depends (negatively) on how much of the latter is spent on imports. As a first approximation, one can formalize the relation as follows:

$$
\begin{aligned}
& \Delta L=(1-\rho)^{-1} \rho \cdot \Delta R+\Delta N F L+\Delta K_{B}+\Delta K_{B}^{*} \quad \text { (banks' balance sheet) } \\
& \Delta R=\rho \cdot(1-\xi) \cdot(A S+O I) \quad \text { (required reserves depend on proceeds from sale of assets) } \\
& C I=\Delta N F L+\Delta K_{B}{ }^{*}+A S+O I \quad \text { (capital inflows breakdown) }
\end{aligned}
$$

where $L, R, N F L$, and $K_{B}$ denote respectively bank lending, required reserves, net foreign liabilities, and bank capital (the superscript * stands for foreign ownership); $C I, A S$ and $O I$ stand for total capital inflows, asset sales to non-residents and other capital inflows; and $\rho$ and $\xi \xi$ stand for the required reserves rate and the share of the proceeds from the sale of assets and other inflows that is ultimately spent on imports. High values of $\xi$ and $\rho$ weaken the link between capital inflows and credit expansion. The CBM can manipulate the correlation between capital inflows and credit expansion by controlling the required reserves ratio, $\rho$, and capital adequacy, $K_{B} / L$. 
21. The shocks have been triggered by a combination of good luck and good policies. Good luck in the form of expansionary monetary conditions in the euro area and world-wide, which have fueled international liquidity, boosted asset markets, and raised the demand for secondary residences in international resort destinations. Amidst this favorable external environment, Montenegro has undertaken bold privatization, opened up its economy, took charge of its future by engineering a consensual separation from Serbia, and deepened its EU and Atlantic orientation, creating an inviting environment for capital inflows.

22. FDI inflows reflect convergence play. They have been attracted by the large untapped potential for tourist and real estate development in Montenegro, and arbitrage opportunities from undervalued assets. The opening of the economy to foreign investment and large scale privatization catalyzed and accelerated the process. In fact, more than half of FDI during the past two years has been directed to real estate (especially in the coastal area) and almost 40 percent to enterprises and banks (mostly for the recapitalization of the latter). On the other hand, green field investment, which is instrumental for expanding the productive base, accounted for a meager 10 percent of total FDI. Weak local capacity means that FDI (especially in upscale tourist and real estate developments) has a very high import content (in terms of both materials and labor).

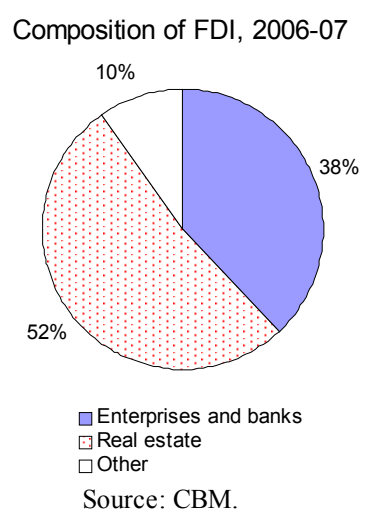

\section{The rapid credit growth reflects convergence play and cyclical factors:}

- Convergence has (i) fueled deposit growth (mainly with proceeds from privatization and large sales of real estate to non-residents), and energized the economy (especially trade, construction and tourism) expanding lending opportunities for banks;

(ii) induced banks to aggressively extend credit in their quest for market share; (iii) reduced the interest rate differential visà-vis the euro area; and (iv) relaxed liquidity constraints and generated wealth effects, providing a further boost to the demand for credit. With
Counterparts to credit growth (In percent of end-of last period's credit)

\begin{tabular}{lrrrr}
\hline & 2004 & 2005 & 2006 & $2007^{1}$ \\
\cline { 2 - 5 } Bank lending & 43 & 33 & 139 & 161 \\
Deposits & 24 & 75 & 147 & 110 \\
Net foreign liabilities & 19 & -25 & 22 & 43 \\
CBM & 2 & 25 & 41 & 9 \\
Bank capital & 9 & 5 & 13 & 19 \\
\hline
\end{tabular}

Sources: CBM and IMF staff estimates

1/ Annualized estimates based on Jan.-Sept. figures. 
convergence play intensifying, credit expansion overtook deposit growth and banks started to bridge the gap, initially, by running down their NFA and, increasingly, by foreign borrowing. ${ }^{14}$

- Cyclical factors, namely expansionary monetary conditions world-wide, have provided a further boost to the demand for assets (especially real estate). Domestic banks have joined the rush and have rapidly expanded mortgage lending and, to a lesser extent, lending for the purchase of shares feeding an upward spiral of asset prices. Soaring asset prices have also generated strong wealth effects (stimulating credit demand as part of intertemporal consumption smoothing).

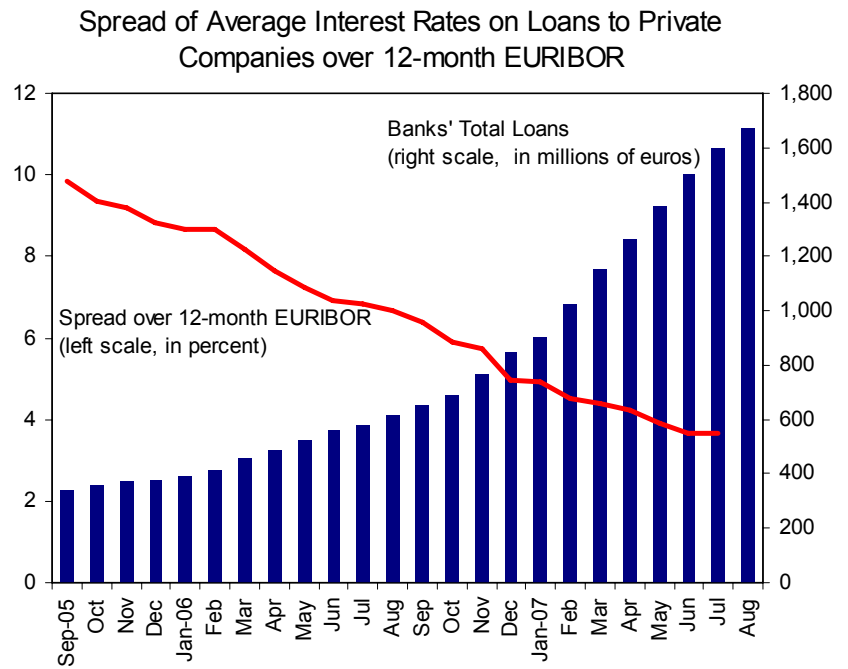

Source: Central Bank of Montenegro.

${ }^{14}$ Chapter IV examines the impact of financial convergence on banks' balance sheets. 


\section{Box I.1: The Transmission of Shocks in Montenegro}

The capital inflow shock is propagated through three channels: investment, wealth and credit:

- In the investment channel, FDI raises productive capacity. High import content (typical for a small transition economy) implies correspondingly high current account deficits, a small contemporaneous impact on output, and a lagged increase in potential output (time to build effect).

- $\quad$ The wealth channel is fed by (i) the sale of domestic assets to non-residents, an operation involving the switch from real assets to financial wealth and, typically, significant capital gains; and (ii) expectations of improving economic prospects that expand intertemporal budget constraints and net worth in present value terms. These fuel consumption (putting pressure on inflation and the current account if the supply response is weak) and demand for domestic assets (boosting asset prices). But growth potential has yet to be confirmed. Failure to live up to expectations would trigger a correction in asset valuations and consumption.

- The credit channel magnifies the effects of the wealth channel through money creation. The availability of foreign financing and the uncontrollability of the money base has led to very fast credit expansion.

In Montenegro's small euroized economy, the combined effect of the FDI and the related credit shock are high current account deficits (which take off the pressure from inflation) and soaring asset prices. A weak supply response exacerbates the pressure on the current account deficit while openness blunts the effect on inflation. The impact on potential growth is constrained by the low share (10 percent) of greenfield investment in FDI.

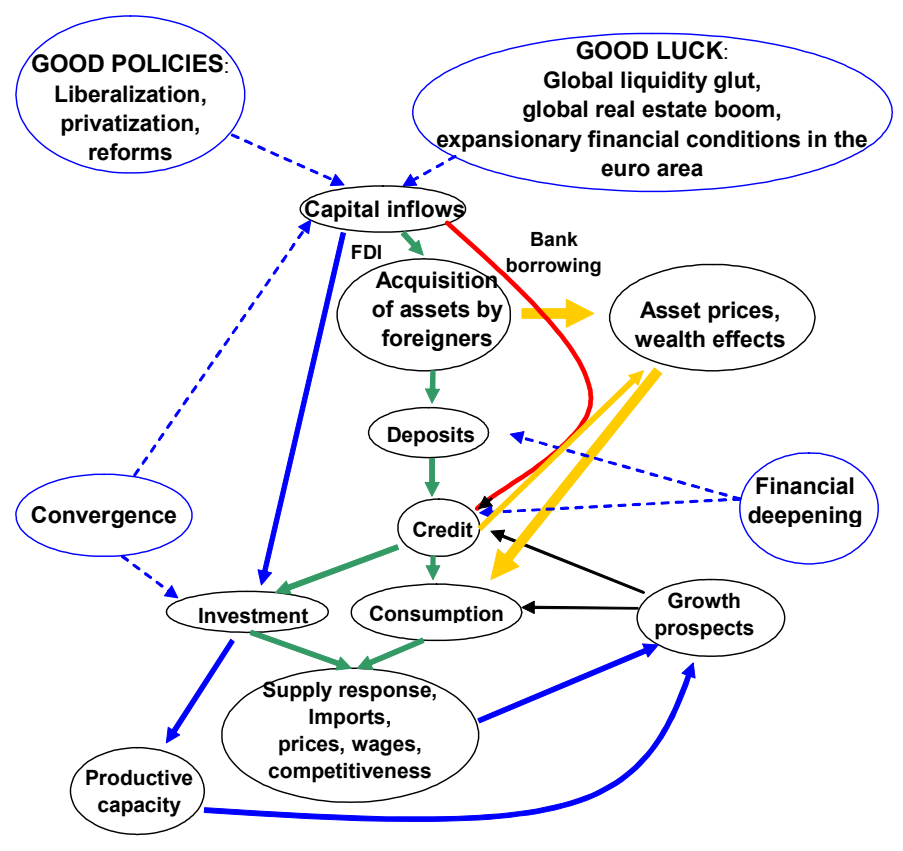




\section{As a result, the current account deficit and asset valuations have soared and}

\section{inflation has picked up:}

- $\quad$ The external deficit reached 37 percent of GDP in 2007, the highest among transition economies in Europe. ${ }^{15}$ The top of the list is populated with countries having fixed exchange rate regimes (the Baltics, Bulgaria, Bosnia, shaded in the table beside), interestingly, countries that are also experiencing credit booms, inflation pressures and eroding external competitiveness.

- $\quad$ Asset prices have soared and, together with the increase in deposits, have led to a more than doubling of financial wealth.

Real estate prices doubled in the past three years and, in some instances, prices are reported to exceed levels in comparable neighboring countries (Box I.2). Equity prices have also more than doubled, not withstanding a significant correction in the second half of 2007.
Current Account Deficits in Transition Economies (In percent of GDP)

\begin{tabular}{lrr}
\hline & 2007 & $2005-07$ \\
\cline { 2 - 3 } Montenegro & 37 & 25 \\
Latvia & 25 & 20 \\
Bulgaria & 20 & 16 \\
Estonia & 17 & 14 \\
Bosnia \& Herzegovina & 15 & 16 \\
Serbia & 15 & 12 \\
Lithuania & 14 & 11 \\
Romania & 14 & 11 \\
Croatia & 8 & 8 \\
Moldova & 8 & 10 \\
Albania & 7 & 7 \\
Hungary & 6 & 6 \\
Slovak Republic & 5 & 7 \\
Poland & 4 & 3 \\
Slovenia & 3 & 3 \\
Czech Republic & 3 & 3 \\
Macedonia, FYR & 3 & 1 \\
\hline Source: WEO & &
\end{tabular}

Financial wealth has more than doubled (In percent of GDP)

\begin{tabular}{lrrr}
\hline & 2005 & 2006 & 2007 \\
\cline { 2 - 4 } Deposits & 23 & 45 & 94 \\
Value of real estate & 179 & 275 & 375 \\
Market capitalization & 50 & 84 & 184 \\
Total financial wealth & $\mathbf{2 5 2}$ & $\mathbf{4 0 5}$ & $\mathbf{6 5 3}$
\end{tabular}

Sources: CBM, MOSTE, Monstat and IMF staff estimates.

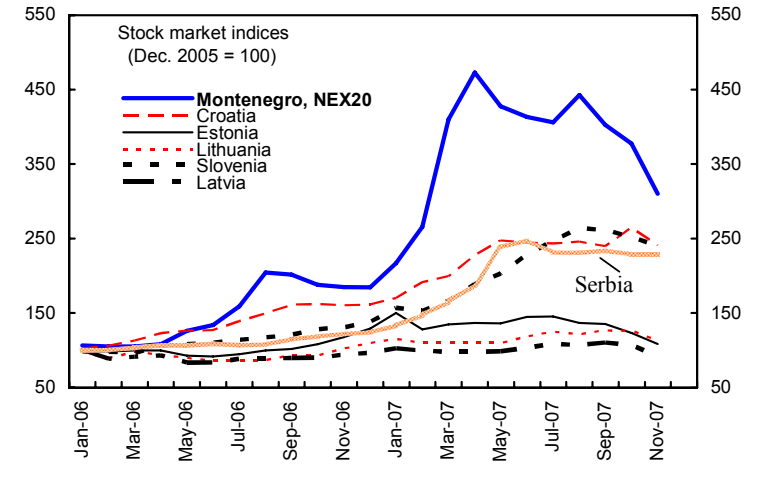

Source: Bloomberg

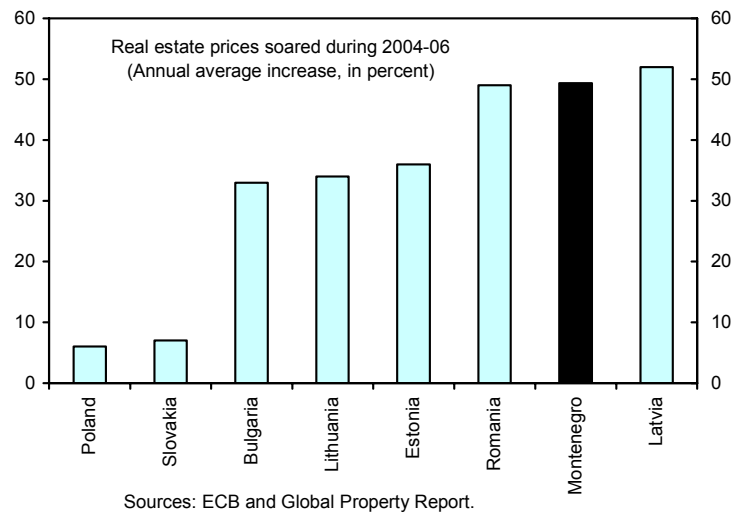

\footnotetext{
${ }^{15}$ Persistent high current account deficits are not uncommon in small economies. For instance, in the six states that use the East Caribbean dollar, which is pegged to the U.S. dollar with a currency board arrangement, and have a population comparable to Montenegro, the deficit averaged 19 percent of GDP during 1996-2005. In St. Kitts and Nevis it averaged 26 percent.
} 
- Wage growth averaged 15 percent per year in 2006-07, which is well above productivity growth and euro area inflation, thereby eroding competitiveness and enterprise profitability. However, there is no indication of real exchange rate overvaluation (IMF Country Report No. 08/48). To some extent, these rapid increases are the result of nominal convergence and reflect the low starting level of wages. The latter are currently at mid-range compared to neighboring countries.
Gross Monthly Wages, 2007 (In euros)

\begin{tabular}{ll}
\hline Croatia & 964 \\
Montenegro & 493 \\
Bosnia Herzegovina & 483 \\
Serbia & 482 \\
Romania & 428 \\
Macedonia, FYR & 233 \\
Bulgaria & 209 \\
\hline
\end{tabular}

Source: CBM.

- $\quad$ Nonetheless, retail price inflation has remained relatively subdued hovering around $3 \frac{1}{2}$ percent (excluding the effect of administrative price adjustments) since the current account has acted as the main shock absorber. Moreover, increasing competition in retail trade and the appreciation of the euro have had a tempering effect on inflation.

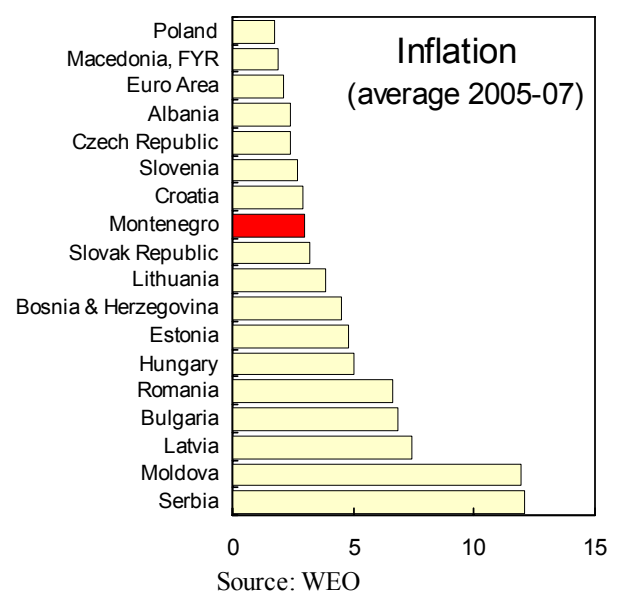

Policy reaction to the shocks

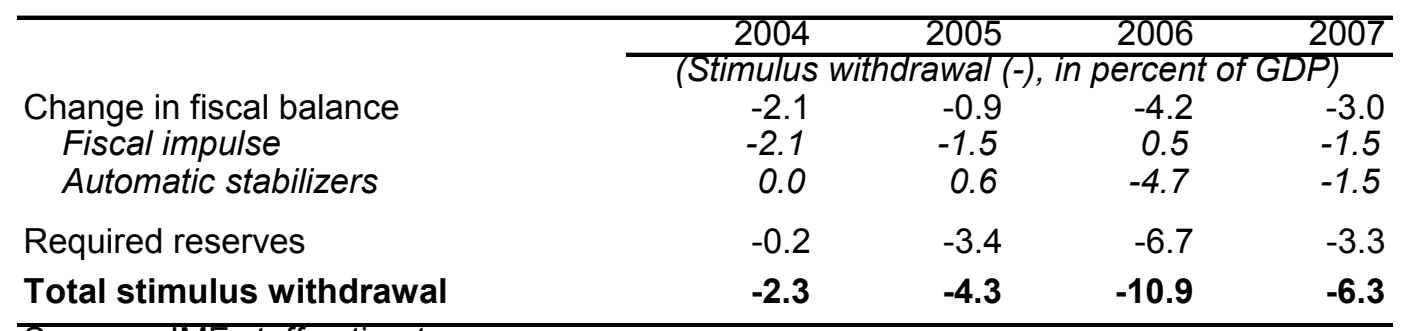

Sources: IMF staff estimates.

25. The policy response has been dwarfed by the size of the shocks. Fiscal policy withdrew stimulus in 2004-07 with discretionary measures (as part of the ongoing fiscal consolidation) and by allowing automatic stabilizers to operate. The CBM withdrew additional stimulus in 2006 by broadening the base of calculation of reserve requirements (thereby raising the effective rate) and tightening prudential supervision. With the fiscal surplus rising to $5 \frac{1}{2}$ percent in 2007 , and average reserve requirements at 14 percent, the policy tightening has been significant but no match for the size of the shock. And from the political economy viewpoint, there was not much more that macroeconomic policy could have done to sterilize the shocks. However, the policy mix was tilted in late 2007: fiscal policy provided a procyclical stimulus (through increases in public sector salaries and tax 
cuts), whose full impact will be felt in 2008 with a projected fiscal stimulus of $3 \frac{1}{2}$ percentage points of GDP. On the other hand, the CBM recently imposed a temporary speed limit on credit expansion that should slow down credit growth to about 40 percent in $2008 .^{16}$ This is projected to reduce the credit stimulus from 57 to 33 percent of GDP.

\section{Should the Current Account Deficit be of Concern in a Eurorized Economy?}

\section{Euroization has reduced the significance of current account deficits and external} indebtedness as risk factors. By greatly reducing transaction costs and eliminating country specific exchange rate risk, euroization helps the integration of goods and financial markets into the global economy. Increased goods market integration raises the elasticity of demand for domestic goods by making them closer substitutes. Financial integration invigorates the convergence process by facilitating finance. Moreover, the elimination of country specific exchange rate risk and capital mobility make the supply of foreign financing elastic. In such an environment, economies with above-average returns to capital should experience an investment boom, while the catching up process creates prospects for higher future income growth, relaxes liquidity constraints and lowers savings. This widening of the savingsinvestment gap raises external financing needs and its mirror image, the current account deficit. To the extent that the economy is free of distortions - external borrowing is contracted mainly by the private sector and is based on capacity to repay, risks are correctly priced, prices are flexible, and the corporate and household balance sheets are sound - the current account deficit and external indebtedness are equilibrium outcomes that reflect time preferences and income expectations.

\section{Such convergence related current account deficits are temporary and largely} self-correcting. As FDI inflows expand the capital stock and exhaust arbitrage opportunities, rates of return on investment decline, cooling FDI inflows, and scaling down investment demand. Moreover, as income rises and pent up demand during the initial phase of transition dissipates, savings increase. This process of declining investment and rising savings helps deflate current account deficits and FDI inflows towards sustainable levels. ${ }^{17}$

\footnotetext{
${ }^{16}$ The package, effective as from 1.1.2008, has four components: (i) extends the application of the high (19 percent) reserve requirement to all public sectors deposits and all deposits with 90-180 days maturity; (ii) broadens the base (albeit at a reduced rate of 2 percent) to deposits with maturity between 180 days and two years; (iii) raises the minimum capital adequacy rate from 8 to 10 percent for banks with credit growth faster than 60 percent, and to 12 percent for those with credit growth in excess of 100 percent; and (iv) caps annual credit growth to 30, 40 and 60 percent respectively for banks with outstanding loans above 200 million, between 100 and 200 million, and below 100 million euros. The ceilings on credit growth are intended to be temporary and do not apply to new banks.

${ }^{17}$ Provisional estimates - based on economic fundamentals such as the fiscal balance, old-age dependency, relative income and NFA in percent of GDP — suggest that the equilibrium level of the current account deficit is
} 


\section{The high current account deficits in Montenegro have not so far been the result}

of expansionary domestic polices or distortions. In fact, as argued in the preceding section, domestic fiscal and monetary policies have withdrawn some demand stimulus in recent years. Moreover, there is no evidence of trade restrictions or distortions with a bias towards current account deficits. On the other hand, there are informational weaknesses (lack of credit histories, irregular releasing of financial information, and agency problems) that complicate the assessment and pricing of risks and make it difficult to harness risk taking amidst the euphoria that typically accompanies large capital inflows. Such behavior could magnify the macroeconomic impact of FDI shocks and lead to overshooting. From the savings-investment perspective, the high current account deficits reflect low savings due to strong wealth effects and the relaxation of liquidity constraints. Investment, on the other hand, has been below average relative to other transition economies, as half of the very high FDI relates to real estate transactions. Interestingly, low savings is not a common feature of transition economies with fixed exchange rates arrangements. Under these circumstances, the closing of the current account deficit in Montenegro will rely essentially on the recovery of the savings rate.

Investment has been below average ...

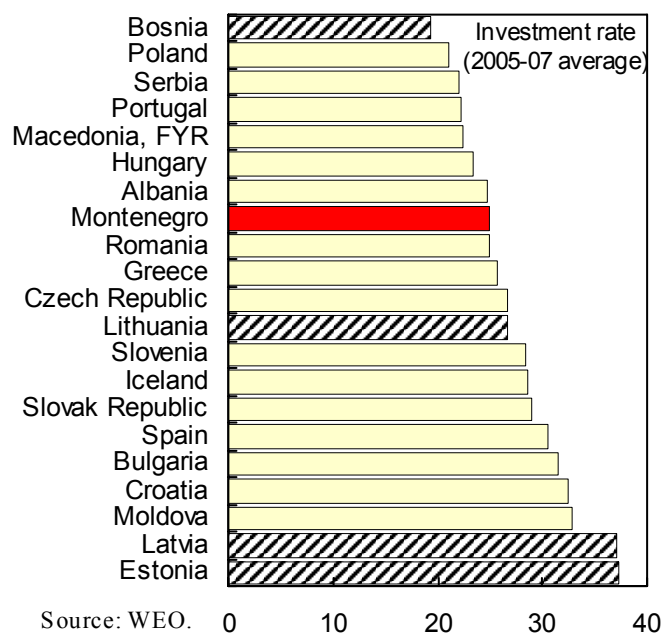

... and savings extremely low.

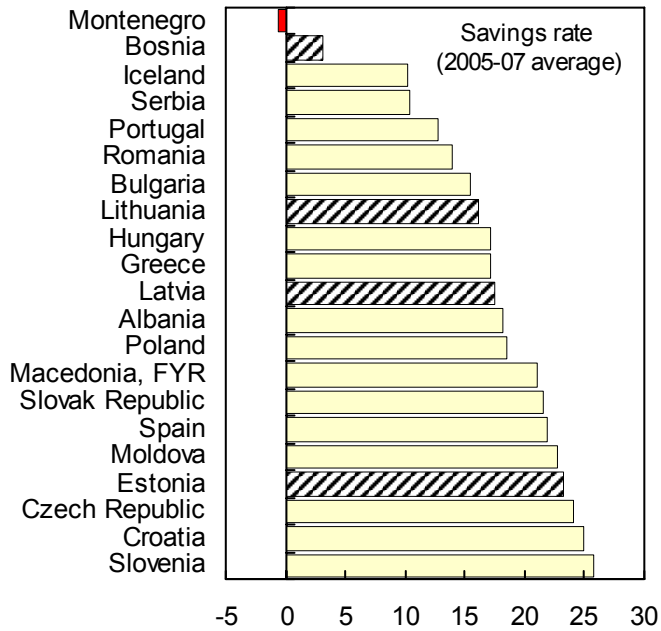

about 5 percent of GDP (IMF Country Report No. 08/48). However, such estimates are characterized by considerable uncertainty, especially in transition economies. 
29. Notably, Montenegro's high current account deficits have not encountered financing problems. About 70 percent of the deficits in 2005-07 were covered with non-debt creating FDI as assets (real estate and state property) were run down to finance mainly consumption (e.g., automobiles and consumer durables). Private sector external borrowing (mainly banks) is estimated to have increased by 12 percentage points of GDP in 2007. At 30 percent of GDP at end-2007, private debt is not high for a transition economy but the pace of build-up is a concern if it continues unabated.
Correlation between FDI and the current account deficit, 2005-07

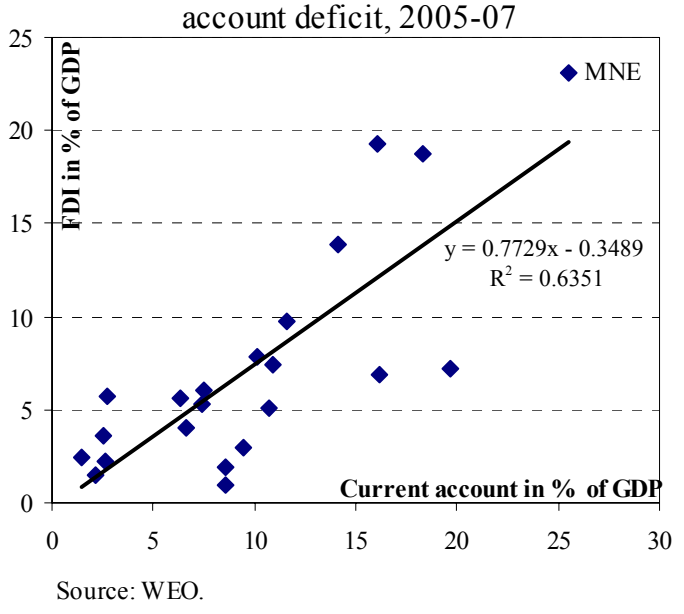

30. While in a euroized environment high current account deficits are not problematic in themselves, they could nonetheless be symptomatic of growing imbalances, mainly overheating, asset overvaluation, and balance sheet fragility.

- Overheating. The degree of overheating depends on the extent to which the capital inflows are spent on non-traded goods. ${ }^{18}$ Rising wages are part of the macroeconomic adjustment process as they facilitate the transfer of resources to the booming nontraded goods sector. If, however, rapid wage increases during the upswing result in a significant real appreciation, they will render macroeconomic adjustment costly when the capital inflows start unwinding. At that stage, the export sector will not have the torque to pick up the slack released by the downsizing of the non-traded goods sector. And with exchange rate realignment not an option, a real depreciation may necessitate significant wage restraint that could trigger a recession.

- Asset overvaluation. To a large extent, the rapid increases in asset prices reflect low starting levels and expectations of rapid growth in the foreseeable future. But unrealistic expectations cannot be ruled out, as evidenced by the 40 percent correction in equity prices during the second half of 2007.

- Balance sheet fragility. Increasing reliance on debt instruments for the financing of large current account deficits could impair balance sheets and make the economy vulnerable to large swings in market conditions. In fact, over indebtedness and very

\footnotetext{
${ }^{18}$ If spent entirely on traded goods, FDI will have no effect on GDP as it will increase equally aggregate demand and imports. It will still expand productive capacity and future income, if spent on imported investment goods.
} 
rapid credit growth are, empirically, early warnings indicators of financial distress, albeit with a low signal to noise ratio.

31. Large FDI inflows do not come without costs. Two issues in a small economy like Montenegro are overdevelopment and affordability.

- Overdevelopment without appropriate infrastructure, and without respect for the environment, could generate strong negative externalities, irreversibly change the landscape and undermine further real estate and tourist development. Moreover, a fast pace of development, well above the capacity of the construction sector, will confer limited macroeconomic benefits as it will rely disproportionately on imported inputs, including labor. Zoning regulations, capital gains and transaction taxes to slow down inflows, and taxes to help internalize these externalities, could ameliorate overdevelopment problems.

- $\quad$ Affordability is already a problem for the average household in Montenegro and could create resistance to liberalization. A CBM survey estimates the market value of an average-sized apartment at $€ 100,000$. If fully financed at prevailing interest rates, this implies a monthly interest service of $€ 630$, which exceeds by far the average monthly salary. Under these circumstances, new housing is affordable only to those who can either make a large down payment or borrow with a grace period (in the expectation that they will be able to resell at a capital gain before the expiration of the grace period. The second strategy leaves buyers (and banks) vulnerable to a downward correction in real estate valuations.

\section{How Could the FDI and Credit Stimuli Unwind?}

32. The demand stimuli are running their course. In particular, as the supply of prime land is limited, investment opportunities will gradually diminish, although back of the envelop calculations suggest that real estate related FDI could be sustained for some time if favorable conditions in the international real estate market persist. ${ }^{19}$ Significant additional stimulus would be provided by large infrastructure projects (roads, electricity etc). The situation is less clear-cut in the case of the credit shock. Taking EU economies as a benchmark, there is scope for some further increase of the leverage ratio; but banks are likely to attempt to consolidate their portfolios, and probably also their operations, building on

\footnotetext{
${ }^{19}$ The construction of, say, four high-end resorts and 2,000 secondary residences over the next five years could generate FDI inflows of 12 percent of GDP annually.
} 
experience gained during the past two years of very fast expansion; the credit tightening (see paragraph 25) and weakened international financial markets should also contribute. ${ }^{20}$

33. The unwinding of the demand stimuli will dent GDP growth. Several factors will be interacting during the adjustment but their main impact, given the negative savings and below average investment rate, will be to raise the savings rate. First, declining sales of real estate to non-residents will take some steam off asset valuations and credit growth and, ultimately, wealth and consumption. Declining FDI does not necessarily imply lower investment as the share of greenfield FDI could increase. Second, a possible downward revision of expectations about economic prospects would dent consumption further. Such a revision would also weaken bank balance sheets by rendering loans, which had been extended on the basis of more optimistic prospects, non-performing. The degree of the revision and the robustness of borrowers are the main "known unknowns" in the adjustment process. Finally, as the initial pent up consumption demand dissipates and households' indebtedness stabilizes, consumption growth will decelerate towards its new steady-state level, trimming GDP growth. The smaller the share of non-traded goods in demand, the smaller the slump in GDP.

34. The decline in growth can be mitigated by replacing faltering domestic demand with exports. But this will require a reduction in the relative price of nontradables to (i) facilitate the transfer of productive resources to the export sector and (ii) strengthen the competitiveness of the export sector. Flexible product and labor markets and support from automatic fiscal stabilizers could facilitate the process. Box I.3 sketches the adjustment process in a small open economy. ${ }^{21}$

\section{Thus, depending on the constellation of policies and luck, adjustment might follow three alternative scenarios:}

- In the good scenario, competitiveness is strengthened without the economy having to go through a recession. This presupposes preservation of competitiveness during the upswing, gradual unwinding of the demand stimuli and a strong policy bundle comprising fiscal space, structural reforms, wage moderation, and strong financial oversight.

- The bad scenario involves a hard landing triggered by a sudden unwinding of the demand stimuli and accumulated vulnerabilities, both due to unfulfilled expectations.

\footnotetext{
${ }^{20}$ An increase of the leverage rate by 15 percent of GDP over the next three years would sustain average credit growth at 16 percent per year and provide a credit stimulus of 14 percent of GDP per year. This is less than half the ceiling on credit expansion in the credit package.

${ }^{21}$ See Blanchard (2006a) for a similar analysis based on an optimizing model.
} 
A weak fiscal situation would limit the scope for automatic stabilizers while overvaluation and structural rigidities would hamper an offsetting increase in exports.

- In the ugly scenario, the hard landing is exacerbated by systemic financial sector problems. A sudden economic slowdown might reveal extensive banking-sector vulnerabilities that had been masked by strong growth (these are hypothetical, as the Montenegrin banking sector appears to be in a relatively comfortable position, in forthcoming IMF Country Report). A resulting contraction of credit would accentuate the downturn.

36. What can we learn from other countries? Two relevant and instructive episodes from Europe are the recent hard landing of the Portuguese economy and the relentless growth in Ireland. In diametrically opposite ways these episodes show the importance of investment in the tradable sector and wage moderation for sustainable growth. In Ireland, large FDI inflows in the tradables sector boosted productivity growth, and a combination of low taxes and wage moderation (wage growth below productivity) improved competitiveness and led to prolonged export-led growth (71/2 on average for 13 consecutive years). In Portugal, a sharp drop in interest rates and expectations that growth with permanently accelerate-both triggered by the prospects of EMU accession - led to a credit boom, a decrease in private savings and an investment boom, mainly in housing. ${ }^{22}$ These were accompanied by excessive wage increases, real appreciation, and widening current account deficits. However, as the expectation of higher growth did not materialize, the private sector and banks tried to correct the imbalances of the boom years, the investment boom came to an end and savings increased. Downward wage rigidity, slow productivity growth, and limited fiscal space triggered a protracted slump. The main lessons from the Portuguese experience are the importance of (i) having a strong fiscal position to allow automatic stabilizers to operate fully when the demand stimulus unwinds, (ii) withdrawing some stimulus during the "lending boom" phase of the cycle to temper the subsequent size of adjustment, and (iii) pursuing structural reform. It also demonstrates the importance of strong supervision that enabled banks to weather the slump.

\section{The growth cycle in Montenegro shares common elements with the Portuguese}

one. Important similarities include the rapid growth in credit and domestic demand, the significance of real estate for the upswing, and the widening current account deficit. However, other factors work to Montenegro's advantage. A fundamentally sound fiscal situation (the structural fiscal position is roughly on balance) and the absence of Maastricht type constraints leave room for countercyclical policy. Moreover, the CBM has greater room for maneuver at the margin relative to EMU central banks. These considerations provide hope that the soft landing scenario will prevail over the medium term.

\footnotetext{
${ }^{22}$ See also Blanchard (2006, 2006a), Fagan and Gaspar (2005), and IMF (2007).
} 


\section{Long periods of uninterrupted strong growth were not uncommon among CEE} economies during 1994-2006: on average, they lasted for 7 years and delivered annual growth of $5 \frac{1}{2}$ percent. They were supported by buoyant FDI ( $6 \frac{1}{2}$ percent of GDP), strong investment ( 24 percent of GDP) and high productivity growth ( $4 \frac{1}{2}$ percent) ${ }^{23}$ However, slowdowns are an inescapable and unpredictable ingredient of business cycles. They blunted the average performance during the entire 1994-2006 period: growth of $4 \frac{1}{4}$ percent, FDI of $3 \frac{3}{4}$ percent of GDP, and productivity growth of $31 / 2$ percent.

Macroeconomic indicators of selected emerging market economies, 1994-2006

\begin{tabular}{|c|c|c|c|c|c|c|c|c|c|c|}
\hline \multirow{4}{*}{$\begin{array}{l}\text { Average } \\
50 \% \text { Trimmed mean } \\
\text { Median }\end{array}$} & \begin{tabular}{|l} 
GDP \\
growth
\end{tabular} & $\begin{array}{l}\text { Labor } \\
\text { productivity } \\
\text { growth }\end{array}$ & $\begin{array}{l}\text { Export } \\
\text { growth }\end{array}$ & $\begin{array}{l}\text { Investment } \\
\text { rate }\end{array}$ & $\begin{array}{l}\text { FDI/ } \\
\text { GDP }\end{array}$ & $\begin{array}{l}\text { Fiscal } \\
\text { balance/ } \\
\text { GDP } \\
\end{array}$ & \begin{tabular}{|l} 
GDP \\
growth \\
during \\
upswings \\
\end{tabular} & $\begin{array}{l}\text { Years of } \\
\text { uninterrupte } \\
\text { d upswings } \\
\end{array}$ & $\begin{array}{l}\text { FDI/Y during } \\
\text { uninterrupted } \\
\text { upswings }\end{array}$ & $\begin{array}{l}\text { Duration of } \\
\text { uninterrupted } \\
\text { FDI cycles } \\
\end{array}$ \\
\hline & 4.2 & 3.5 & 8.9 & 23.2 & 3.7 & -3.0 & 5.7 & 7.2 & 6.4 & 6.8 \\
\hline & 4.1 & 3.3 & 8.5 & 22.3 & 3.6 & -2.9 & 5.5 & 6.5 & 6.4 & 5.8 \\
\hline & 4.0 & 3.3 & 8.5 & 22.0 & 3.6 & -3.1 & 5.4 & 7.0 & 6.3 & 5.0 \\
\hline Min & 1.8 & -0.4 & 3.8 & 16.2 & 0.6 & -7.7 & 3.5 & 3.0 & & \\
\hline Q1 & 3.3 & 2.0 & 5.9 & 21.2 & 2.6 & -4.1 & 4.6 & 4.0 & 4.8 & 4.0 \\
\hline Q3 & 4.8 & 4.7 & 11.2 & 24.2 & 4.5 & -1.2 & 6.8 & 9.5 & 8.3 & 9.0 \\
\hline Max & 7.4 & 8.6 & 15.7 & 32.4 & 8.2 & 0.3 & 9.2 & 15.0 & & \\
\hline
\end{tabular}

Source: IMF, WEO databank and IMF staff calculations.

39. Large capital inflows present both an opportunity and a challenge. They can help develop the potential of the country and put Montenegro on a fast convergence track. But they need careful management to ensure that convergence is monotonic. Policy action is needed on several fronts:

- $\quad$ Medium term fiscal framework, to serve the combined needs of fiscal consolidation, nation building and countercyclical policy. Fiscal policy, the only demand management instrument, needs to alleviate appreciation pressures during the upswing and allow room for automatic stabilizers to operate fully when the demand shock dissipates.

- Competitiveness, to enhance growth and temper fluctuations in economic activity. Need to monitor and assess competitiveness and coordinate on a continuous basis macroeconomic and structural policies to support it.

\footnotetext{
${ }^{23}$ Strictly speaking, this experience is of limited relevance because these economies have not completed their cycle (and the resilience of their economies to the unwinding has not been tested), the statistics are biased because of the generally favorable external environment that may not be representative of future conditions and, finally, the intensity of the shocks has been weaker than in Montenegro.
} 
- Wage restraint, especially in the public sector, which sets the tone for national wage negotiations. Income convergence needs to be based on productivity growth. Wage increases in excess of productivity growth plus inflation erode competitiveness.

- Structural reform, to improve flexibility in labor and product markets (to compensate for the loss of monetary sovereignty), and boost competitiveness and growth.

- $\quad$ Proactive and forward looking prudential oversight, to safeguard financial stability.

- Capital inflows, to ensure that they remain within the absorptive capacity of the country and mitigate negative externalities.

These issues are addressed in more detail in the ensuing chapters. 


\section{Box I.2. The Real Estate Market in Montenegro}

Real estate in Montenegro, especially along coastal areas, has long enjoyed a privileged position. The market was kick started during the $80 \mathrm{~s}$ by the Montenegrin diaspora and picked up further in the early $90 \mathrm{~s}$ with the arrival of the first non-Montenegrin investors, but fell into hibernation during the armed conflict in the FSRY. Following the opening up of the country and massive privatization, the real estate market was invigorated again in 2002 with the arrival of a large and growing number of foreign investors, initially from Russia and subsequently from the UK, Ireland and Norway. Since 2004, several foreign companies, mostly from the UK and Ireland, have started building ready-to-rent housing and small colonies/communities, and more recently significant hotel complexes have been stared. In addition, improving economic prospects, low interest rates and credit availability have stirred residents' demand for housing.

Benefiting from the global property boom, ambitious plans for tourist development of the country, and the open attitude toward foreign investors, real estate prices have been soaring. Agents report increases of 20 percent per year in 2005-06 and over 60 percent in 2007 (boosted by one-off demand for embassies following independence) and listed prices appear to be approaching rapidly levels in comparable locations in the Adriatic. A CBM survey suggests that apartment prices in Podgorica are not very different from prices in other capitals in the region. The recent correction in the global real estate market and the turmoil in international financial markets have not had a perceptible effect in Montenegro.

House price increases, 2001-06

(Cumulative increases, in percent)

\begin{tabular}{lr}
\hline Estonia & 246 \\
Spain & 101 \\
UK & 86 \\
France & 78 \\
Ireland & 71 \\
Greece & 59 \\
Sweden & 56 \\
Italy & 53 \\
Portugal & 17 \\
\hline
\end{tabular}

Source: Global Property Guide

Average House prices, 2005

The legal framework imposes few restrictions on the purchase of real estate and property, and capital gains taxes are practically nil. However, there weaknesses in the cadastre and zoning regulations can create legal ambiguities. Foreigners are treated like residents and properties are subject to a state tax equal to 2 percent of their notional value. If, however, the land does not contain buildings at the time of the purchase it needs to be registered with a company, which retains ownership until a structure is built on it. At that time, ownership can be transferred to a physical person without restrictions.

\begin{tabular}{lr}
\multicolumn{2}{c}{$\left(I n \in / m^{2}\right)$} \\
\hline Italy & 2,880 \\
Slovenia & 2,000 \\
Croatia & 1,900 \\
Austria & 1,600 \\
Montenegro & 1,550 \\
Chech Rep. & 1,500 \\
Estonia & 1,220 \\
Poland & 1,200 \\
Hungary & 1,110 \\
Lithuania & 890 \\
Bulgaria & 770 \\
\hline Sources: Egert (2007), CBM.
\end{tabular}




\section{Box I.3. A Simple Model of Internal and External Adjustment}

The gist of adjustment can be analyzed with a simple Mundell-Fleming model:

$$
y=D D(y, s)+N X(\varepsilon, y, s)
$$

where $y$ stands for output, $D D(.$.$) denotes domestic demand, and is assumed to be an increasing function$ of output and an index of fiscal policy, $g$, and a demand shock, $s ; N X(\ldots)$ is net exports, assumed to be a decreasing function of the real exchange rate, $\varepsilon$, output, and the demand shock. Internal balance requires that $y=y^{*}$, where $y^{*}$ is potential output. External balance requires $N X(\ldots)=0$. The model is closed with a Phillips curve, which stipulates that internal imbalance leads to higher inflation and to real appreciation.

The relations are plotted in the figure below, with the real exchange rate on the vertical axis and output on the horizontal axis. The $I S$ curve is drawn for given values of $g$ and $s$ and is downward sloping: an appreciation decreases the equilibrium level of output. The internal balance is vertical at $y=y^{*}$. To the right of $y^{*}$, the real exchange rate appreciates and the economy moves up along the $I S$ curve. To the left of $y^{*}$, the real exchange rate depreciates and the economy moves down along the IS curve. The external balance is given by the $N X=0$ curve and is downward sloping and flatter than the $I S$ curve (because the marginal propensity to spend is less than one). Let the economy be in internal and external equilibrium at point A.

Now suppose that a shock raises domestic demand. This will shift the IS curve to the right to IS' and the $N X=0$ locus to the left; and will bring the economy to A'. At this point, output is above potential and external trade in deficit. If the economy is left to run its course unhindered, the trade deficit will widen, inflation will increase and the real exchange rate will appreciate further widening the trade deficit. The economy will move along the $I S$ ' curve and eventually reach $\mathrm{A}$ ', At this point, output is back at potential but the real exchange rate is overvalued, the trade balance in deficit, wealth lower than in the initial equilibrium (due to the accumulation of external deficits). Declining wealth IIP will reduce disposable income, lead to a contraction of demand, reduce output below potential and put in motion a competitive disinflation. It will also reduce imports, shifting the $N X=0$ locus towards its original position. The

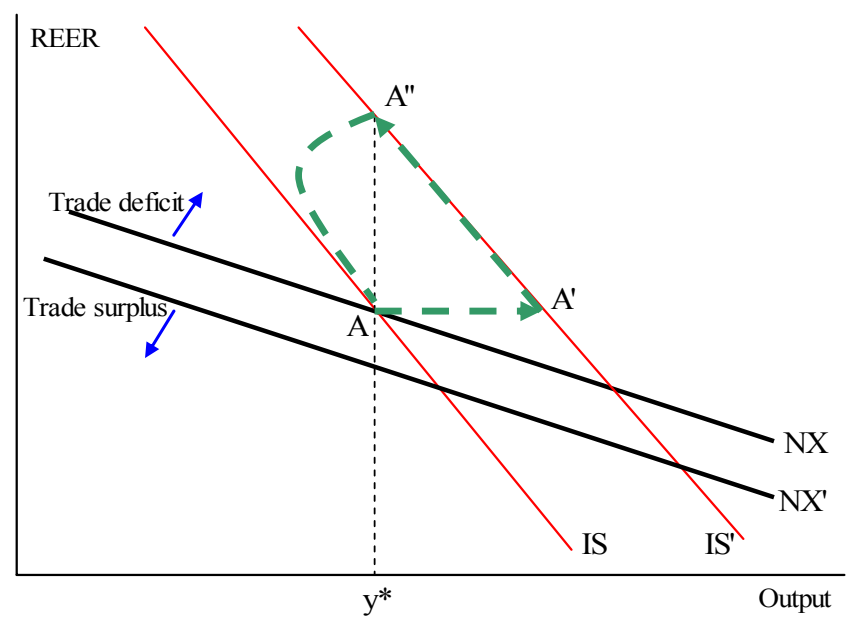
contraction of demand will eventually take the economy, along path A"A, to the original equilibrium (but with lower wealth). The adjustment will be faster if the demand shock weakens over time.

This boom-bust cycle could have been attenuated with fiscal tightening at the beginning of the cycle. Although the real appreciation is an equilibrium phenomenon, the case for policy intervention can be made on the ground that the costs of departures from potential output are not symmetric. They are higher when the economy is below potential. Also, costs are smaller when the economy is growing rapidly (the adjustment requires a growth recession) than slowly (the adjustment may require stagnation or even contraction of output). 


\section{References}

Blanchard, O., 2006, "Adjustment with the Euro: the Difficult Case of Portugal," MIT Working Paper 06-04.

— , 2006a, "Current Account Deficits in Rich Countries," Mundell-Fleming Lecture delivered at the $7^{\text {th }}$ Jacques Polak Annual Research Conference.

Bratkowski, A., and J. Rostowski, 2002, "The EU Attitude to Unilateral Euroization," Economics of Transition, Vol. 10 (2), pp. 445-468.

Calvo, G., 1998, "Capital Flows and Capital-Market Crises: The Simple Economics of Sudden Stops," Journal of Applied Economics, Vol. 1 (1), pp. 35-54.

ECB, 2003a, "Policy Position of the Governing Council of the ECB on Exchange Issues Relating to the acceding Countries," December18, available at http//:www.ecb.int.

— 2003b, "Review of the International Role of the Euro," available at http//:www.ecb.int.

Egert, B., and D. Mihaljek, 2007, "Determinants of House Prices in Central and Eastern Europe,” BIS Working Paper No. 236.

Enoch, C., and I. Ötker-Robe, 2007, Rapid Credit Growth in Central and Eastern Europe, (Palgrave Macmillan).

Eurostat, 2007, “GDP per Inhabitant in Purchasing Power Standards," News release STA/07/179.

Fabris, N., and others, 2004, "Economic Policy in Dollarized Economies with a Special Review of Montenegro," Working Paper No.1, Central Bank of Montenegro.

Fagan, G., and V. Gaspar, 2005, "Adjusting to the Euro Area: Some Issues Inspired by the Portuguese Experience," mimeo.

International Monetary Fund, 2007, Regional Economic Outlook: Europe, World Economic and Financial Surveys.

Levasseur, S., 2004, “Why Not Euroization?” Revue de l'OFCE, No. 91(5), pp. 121-156.

Lipschitz, L., T. Lane, and A. Mourmouras, 2002, "Capital Flows to Transition Economies: Master or Servant?," IMF Working Paper No. 02/11. 
Mihaljek, D., 2005, "Free Movement of Capital, the Real Estate Market and Tourism: A Blessing or Curse for Croatia on its Way to the European Union?," in Katarina Ott (ed.), 2005. "Croatian Accession to the European Union: Facing the Challenges of Negotiations," Books on Croatian accession to the European Union, Institute of Public Finance, Vol. 3, No. 3, http://ideas.repec.org/h/ipf/chaptr/3-08.html

Silva, P., I. Klytchnikova, and D. Radevic, 2007, "Poverty and Environmental Impacts of Electricity Price Reforms in Montenegro," World Bank Policy Research paper No. 4127.

Vukotic, V., 2004, "Elements for Understanding Economic Reforms in Montenegro" www.wiiw.ac.at/balkan/files/GDN_UnderstandingReform_Montenegro.pdf. 


\section{Appendix I.1.: Milestones in the History of Montenegro}

$9 \mathrm{AD} \quad$ The Romans annex the area of present day Montenegro to the province of Illyricum.

500-700 Slavs colonize the area.

700-1150 Byzantine rule. Montenegro becomes a vassal, known as Duklja or Diokletija.

1150-1389 Period of independence. Known as Principality of Zeta, Montenegro becomes virtually independent from Serbia in 1356 and gains full independence in 1371.

1389-1852 Ottoman rule.

1852 Montenegro becomes an independent principality.

1878 The Berlin Congress recognizes Montenegro as an independent state.

1906 Montenegro issues the perper (from the Greek hyperperos $=$ refined), equivalent to the French franc as part of the Latin Monetary Union (1865-1927). The currency was replaced by the dinar in 1918, when the country was annexed to the Kingdom of Serbs, Croats and Slovenes.

$1910 \quad$ Montenegro is proclaimed kingdom.

1912-13 Balkan wars. Montenegro along with Serbia, Bulgaria and Greece reclaim historic territories from the Ottoman Empire.

1918 At the end of WWI borders in the Balkans are redrawn and Croatia and Slovenia are merged with Serbia and Montenegro. A popular uprising in Montenegro fails to reverse its annexation to Serbia and King Nicolas I, who favored independence, is deposed.

1945-91 Socialist era. Centrifugal tendencies in the federation emerge during the 1980s.

1991-92 Yugoslavia is dismembered. The secession Croatia and Slovenia and later of Bosnia-Herzegovina and Macedonia triggers an armed ethnic conflict, prompting UN economic sanctions and an embargo against Serbia and Montenegro.

1998 The international community freezes Serbian and Montenegrin assets abroad in response to deteriorating conditions in Kosovo.

1998 The pro-independence coalition in Montenegro wins the election with a paper-thin majority of 50.4 percent. 
1999 More than 30,000 refugees enter Montenegro from Kosovo during the NATO campaign.

1999 The German mark is introduced as parallel currency and rapidly becomes the currency of choice for transactions and as a store of wealth.

$2000 \quad$ The EU lifts sanctions against Serbia and Montenegro.

2001 The deutsche mark becomes the sole legal tender on January $1^{\text {st }}$ and the Law on the Central Bank is adopted in March.

2002 With its introduction, the euro replaces the deutsche mark to the euro as sole legal tender.

2003 Under pressure from Montenegro, the Yugoslav parliament votes to transform the federation into a looser federation under the name "State Union Serbia and Montenegro". The new setup gives Montenegro autonomy in setting tariffs and fiscal policy, and responsibility for border control within its territory.

2005 Montenegro takes over full control over security issues.

$2006 \quad$ Following a referendum (and a majority of 55.5 percent), Montenegro reclaims its full independence, almost a century after its annexation to Yugoslavia in 1918.

2007 Signing of SAA with the EU; discussions for WTO membership. The revision of the Constitution dominates the political debate and slows legislative reforms. 


\section{TOURISM IN MONTENEGRO ${ }^{24}$}

\section{A. Introduction}

40. The potential of the tourism sector in Montenegro is impressive. For the fourth consecutive year, Montenegro has been ranked among the world's top three destinations in terms of growth over the coming decade. However, because Montenegro relies heavily on imports, its tourism industry has high leakage. There are also concerns that, despite rapid growth, tourism has weak linkage with the rest of the economy, and may not lead to significant improvements in any other sectors. By targeting high-end tourists, the industry is in danger of becoming an enclave.

\section{The paper looks at these trends and how developments in the tourism industry} have contributed to the shaping of the economy. Section B covers the growth of the sector over the last 5 years, and how it is influencing real sector activities in Montenegro.

Section $\mathrm{C}$ discusses the structural factors that undermine the contribution of the tourism sector to overall economic growth, namely high leakage, low linkage with the rest of the economy, and tourism as an enclave. Section D looks at determinants of competitiveness of Montenegro's tourism sector and Section E concludes with a discussion of the way forward, including an analysis of the productivity gains needed to meet the goals adopted by the Ministry of Tourism and Environmental Protection (MTEP).

\section{B. Growth in Tourism Sector}

42. Tourism has been the pillar of Montenegro's real economic growth. After a complete halt during the 1990s due to the Balkan conflict, the sector expanded by over 7 percent per annum, ranking $9^{\text {th }}$ position in the world in terms of annual real growth.
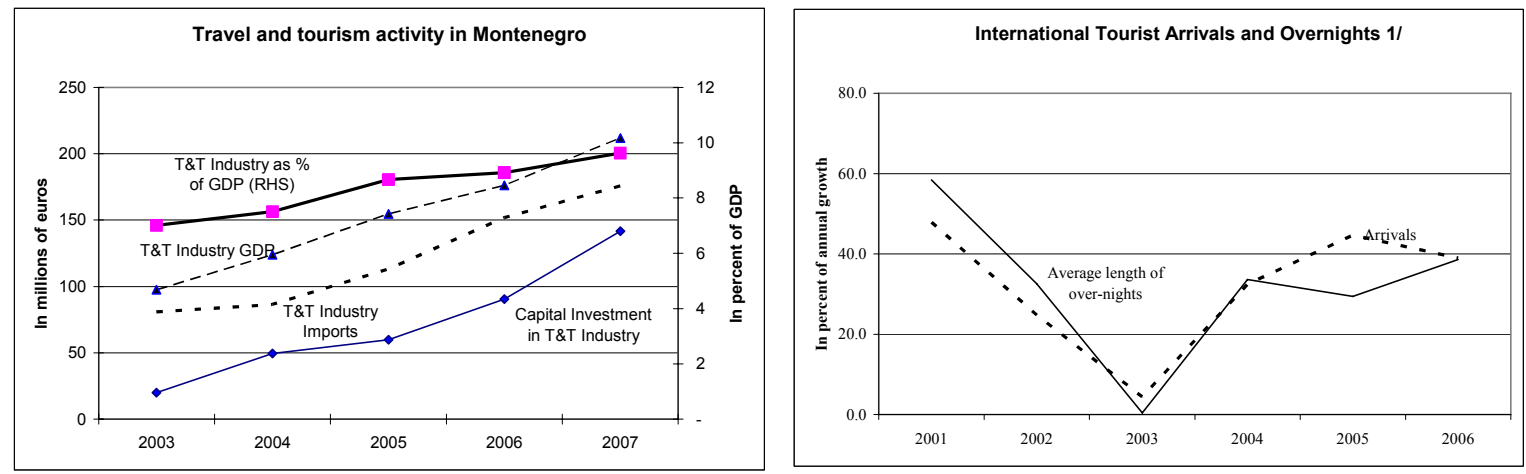

Sources: Ministry of Tourism and Environmental Protection (MTEP); and World Travel and Tourism Council (WTTC). 1/ Slowdown in 2003 was due to the introduction of VAT which discouraged tourist operators, and the electricity and water shortages in the previous year which had discouraged foreign visitors.

\footnotetext{
${ }^{24}$ Prepared by Jung Kim.
} 


\section{Growth has been one of the most impressive in the region, and Montenegro's} tourism potential has been widely recognized in the world. According to the World Travel and Tourism Council (WTTC), the baseline forecasts for Montenegro's Travel \& Tourism (T\&T) are extremely positive. In 2007, the T\&T economy ${ }^{25}$ is expected to contribute 21 percent of Montenegro's GDP (11 percent for T\&T industry) — as against 10.9 percent for T\&T economy in the European Union. The T\&T economy accounts for 28,900 jobs representing 19 percent of total employment (12 percent in the EU), about 34 percent of total exports of goods and services, and about 26 percent of capital investment. Over the next ten years, Travel \& Tourism in Montenegro is forecast to achieve annualized real growth of 7 percent, in terms of GDP, compared with only 3 percent in the EU.

T\&T Economy (\% of Total GDP)

\begin{tabular}{rrrrrr}
\hline Rank & 2004 \% GDP & Rank & 2007 & \% GDP \\
\hline 19 & Malta & 28.5 & 23 & Malta & 23.7 \\
21 & Cyprus & 27.6 & 25 & Cyprus & 21.5 \\
27 & Croatia & 24.2 & $\mathbf{2 7}$ & Montenegro & $\mathbf{2 0 . 7}$ \\
38 & Bulgaria & 16.8 & 33 & Croatia & 19.0 \\
$\mathbf{4 6}$ & Montenegro & $\mathbf{1 4 . 8}$ & 43 & Greece & 16.5 \\
50 & Greece & 14.3 & 50 & Slovakia & 14.9 \\
52 & Slovenia & 14.1 & 54 & Bulgaria & 14.5 \\
68 & Slovakia & 11.5 & 57 & Slovenia & 14.2 \\
83 & Turkey & 10 & 70 & Turkey & 9.1 \\
\hline Source: WTTC & & \multicolumn{4}{c}{}
\end{tabular}

Expected Growth in T\&T Economy (\%)

\begin{tabular}{rrr}
\hline Rank & $2008-2017$ & 10-yr avg real growth \\
\hline 1 & Croatia & 8.9 \\
9 & Montenegro & 7.1 \\
32 & Slovakia & 5.5 \\
70 & Bulgaria & 4.5 \\
103 & Greece & 4 \\
105 & Turkey & 3.9 \\
107 & Slovenia & 3.9 \\
108 & Cyprus & 4.6 \\
172 & Italy & 1.3 \\
\hline Source: WTTC &
\end{tabular}

44. In terms of origin of tourists, the EU accounts for about 50 percent of all arrivals, and visitors from former Yugoslavia represent about 20 percent, followed by Russia and CIS countries (18 percent). The largest group of visitors by country is from the former Yugoslavia, followed by Russia. Tourists from other western European countries are also rising rapidly, including Italy (up 55 percent a year since 2000), France (up 57 percent) and UK (up 67 percent).

\section{Montenegro's tourism is characterized by high seasonality of demand in the} coastal region. The five months from May through September account for about 90 percent of total overnights and over 80 percent of arrivals. Just two months, July and August, generate over 50 percent of arrivals and overnights. These tourists mostly favor coastal areas, with about 60 percent of arrivals and 65 percent of overnights concentrated in the popular destinations of Budva and Herceg Novi. About 95 percent of hotel bed capacity is concentrated in the coastal region of Montenegro, only 1 percent in the mountains despite their potential, and 3 percent in the capital and central region.

\footnotetext{
${ }^{25}$ T\&T economy includes direct and indirect impact of visitor activities, capital investment, exports and government services. A narrower concept is T\&T industry, which is limited to direct impact of visitor activity such as transportation, accommodation, food and beverage, recreation, entertainment and travel services.
} 


\section{Structural Factors Affecting the Development of Tourism}

\section{High Leakage}

\section{Montenegro's tourism sector is marked by high leakage and vulnerability to} sentiment of foreign investors. The country relies heavily on imports for most of its consumption goods. Hence, a significant portion of revenue from foreign tourists is spent on imports of goods and services to cater for them. Top tier hotels, the biggest contributors for growth in the tourism sector, have indicated that from total cost of sales, over 70 percent is attributed to the cost of food and beverages alone ${ }^{26}$. Should international prices of food and beverages rise further, so would costs. Moreover, because the industry has just embarked on growth, there is significant start up costs (imported building materials, etc.), hence the profit margins are reported to be quite low for top hotels. In addition, over 80 percent of 4 star and above hotels are owned by foreigners. This implies that profits are likely to be repatriated, and that investors are less attached to Montenegro and could quickly relocate to other locations if prospects for profits were to shift in the future.

Business operation in hotels

\begin{tabular}{lrrr}
\hline & & Hotel class & \\
\cline { 2 - 3 } & & $20<x<60$ euros & $>60$ euros \\
\hline Foreign visitors & & & \\
Group/allotment (\% of total) & 86.2 & 74.0 & 61.0 \\
Independent leisure travelers (\% of total) & 7.8 & 11.7 & 25.0 \\
& & & \\
Hotel operation & & & \\
Total operating revenue (euros) & $826,804.0$ & $729,879.2$ & $2,297,208.9$ \\
Total net operating revenue per room (euros) & $3,971.0$ & $8,045.0$ & $19,195.0$ \\
$\quad$ o/w from rooms (\%) & 51.5 & 47.5 & 38.4 \\
$\quad$ o/w from food and beverage (\%) & 41.5 & 41.4 & 30.2 \\
Total expenses & $3,814.1$ & $7,186.3$ & $15,114.6$ \\
$\quad$ o/w from rooms (\%) & 17.7 & 13.3 & 17.6 \\
$\quad$ o/w from food and beverage (\%) & 35.0 & 50.3 & 35.7 \\
Profit before tax (\% of net operating recenue) & -10.9 & -1.8 & 2.8 \\
\hline Source: MTEP & & &
\end{tabular}

47. There are indications that, despite strong growth, the tourism sector may be becoming less efficient. While the total numbers of arrivals, overnights and amount of tourist receipts have all shot up, growth in tourism receipts appears to be lagging behind the growth rate of total arrivals and overnights, signaling that Montenegro is earning less from individual tourists than before.

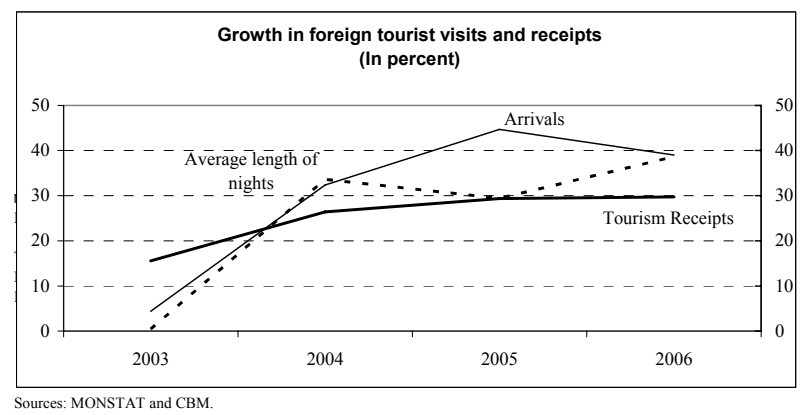

${ }^{26}$ See Horwath Hotel Industry Survey Montenegro 2006. 


\section{Low Linkage}

48. There are concerns that other sectors of the economy may not be fully benefiting from spill-over effects of tourism. From the labor market perspective, tourism-related industries are increasingly relying on foreign workers to meet rising demand. Data indicate that in 2006, employment of Montenegrin workers in construction and hotels/restaurants declined by about 5 percent, while employment of non-residents rose by 64 percent during the same period. There is strong demand for labor, but these demands are met increasingly by foreign workers rather than Montenegrins, partly due to insufficient skills. The country's current labor law also stifles competitiveness and protects resident employees, making nonresident employees a much cheaper and attractive option. This has not only contributed to a high rate of unemployment at around 18 percent, but implies a lost opportunity to build necessary human capital.

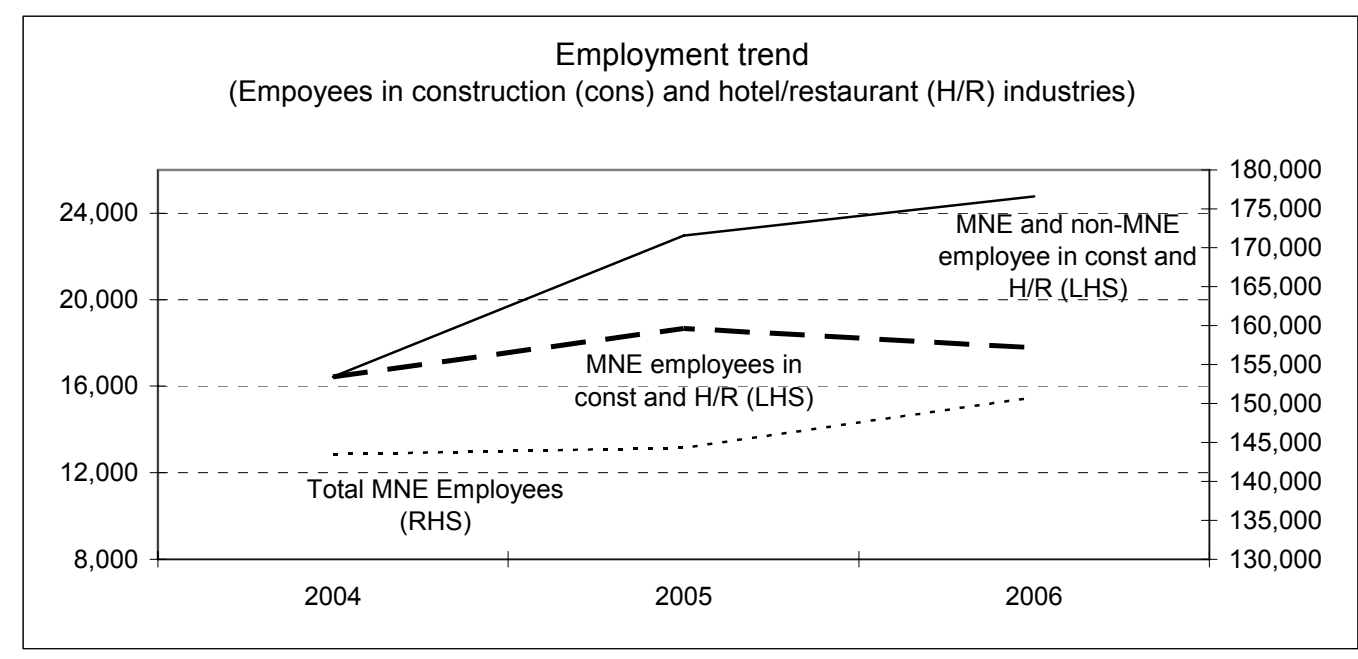

Source: Montenegrin authorities

49. The impact of tourism on the rest of the economy also appears limited. Rapid increases in tourist arrivals and overnights did not lead to any notable impact on the output of industrial sector, except for construction activities. Figure II. 1 below compares the indirect benefits of tourism in Montenegro with that of other competitor tourism countries. This is done by comparing the size of the T\&T Economy minus the T\&T Industry, which is taken to represent the indirect effect of T\&T activities in the economy. The relatively low ratio of Indirect/Direct tourism GDP in Montenegro indicates that Montenegro's tourism growth is limited to areas directly impacted by visitor activities, and has not lead to broader development of the economy through spill-overs, including the agricultural sector which continues to contract. 

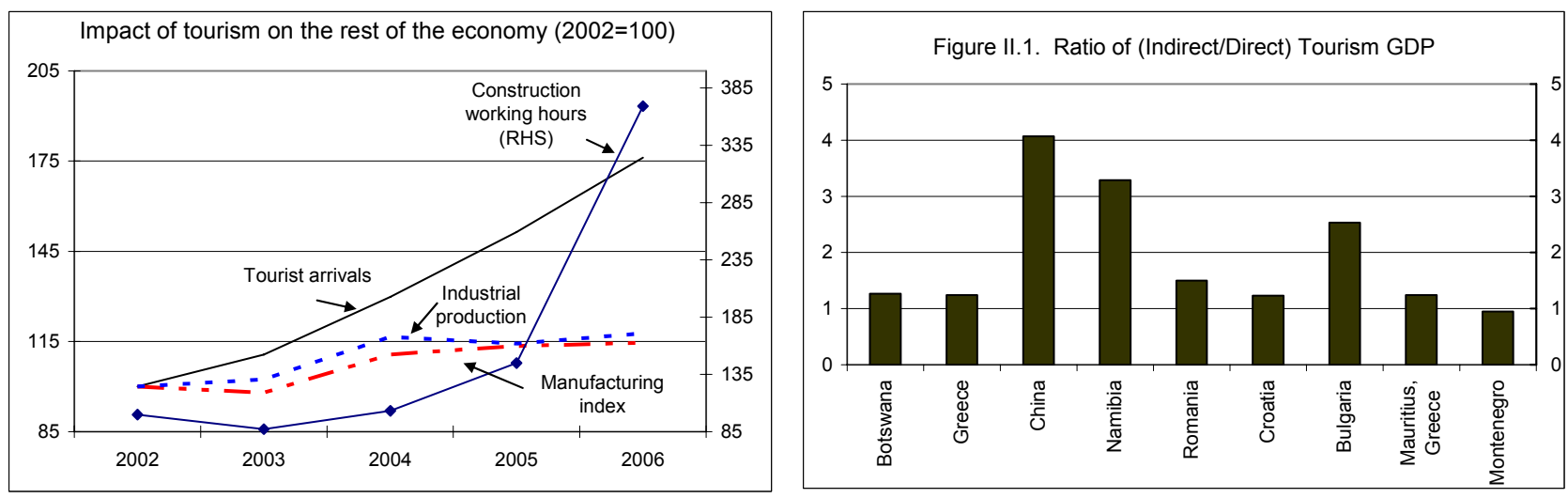

Source: WTTC, MONSTAT, and CBM

\section{Tourism Enclave}

50. There are concerns that Montenegro's tourism sector is becoming an "enclave" industry. Montenegro targets high-end tourists partly to protect its fragile environment. The majority of these high-end visitors enter through tour operators rather than as independent travelers because the country is still young and not much information is available to the tourist public compared to other competitor countries. Tourism infrastructure is also weak, hence visitors rely on tour operators rather than venturing out themselves. Tour operators often have exclusive contracts with specific restaurants or other entertainment facilities. Also, high-end tourists spend most of their time in secluded resorts, hence there are minimal effects on local businesses and spill-over to the rest of the economy. Compared to the increase in the number of visitors, the increase in the number of new restaurants and other entertainment has been negligible.

\section{Competitiveness of Montenegro's Tourism Sector}

51. The competitiveness of Montenegro's tourism industry can be viewed not only from costs but also from the tourist perception factor. ${ }^{27}$

\section{Cost Competitiveness}

52. The Figure II.2 below compares average net monthly wages of Montenegro with competing countries in the region. The average net wage is currently at mid range compared to other neighboring countries; however, it has been rising rapidly. Moreover, wages are expected to increase even further in coming months due to the impact of the hike in public wages by 28 percent on the private sector.

\footnotetext{
${ }^{27}$ See Destination Competitiveness Determinants and Indicators, Current Issues in Tourism, 2003. L Dwyer, University of New South Wales, Australia.
} 


\section{On the demand side, the cost of lodging in Montenegro is relatively high} compared to other competitor countries. Table II.1 compares lodging costs for similar class hotels for the same period offered by a popular tourism on-line vendor (Expedia.com). While a precise comparison would be difficult, the figures clearly indicate that Montenegro is a much more expensive destination than Greece or Turkey that offer a wider range of tourism activities (historical sites, shopping etc.) than Montenegro which relies mostly on nature.

\section{When the direct and indirect cost of transport and access are taken into} consideration, the total cost of tourism in Montenegro is even higher. Direct flights to Podgorica or Tivat are infrequent and much more limited compared to competing destinations such as Greece or Turkey. To accommodate increasing demand for air transport, Montenegro increased the number of airlines operating into the country to more than 40 in 2006, a significant portion of which are chartered flights into costal areas. Nevertheless, there remains a significant gap, with large capacity constraints during the summer peak seasons, and flight movements and passenger numbers fall sharply outside the peak summer season, limiting the opportunity to extend the short season.

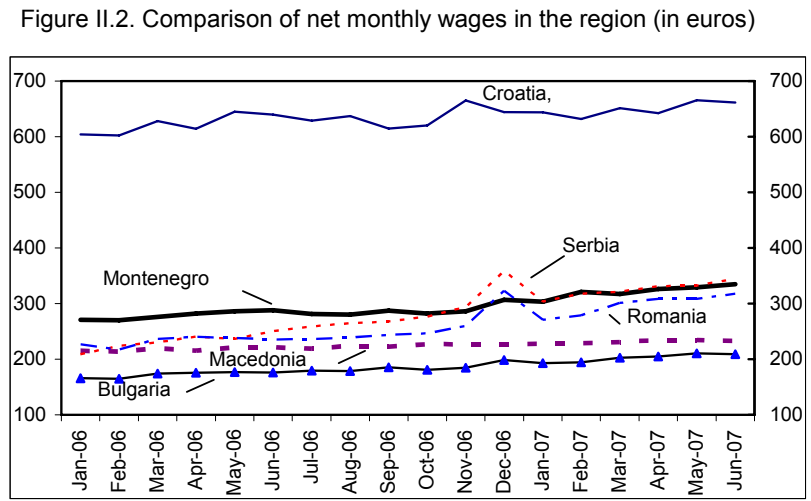

Source: ILO and Montenegrin authorities.

\begin{tabular}{|c|c|c|}
\hline Location & Hotel & In US\$ \\
\hline Bulgaria, Varna & Kempinski Hotel Grand & 211.0 \\
\hline $\begin{array}{l}\text { Budva, } \\
\text { Montenegro }\end{array}$ & $\begin{array}{l}\text { Hermitage Varna } \\
\text { Splendid }\end{array}$ & 288.0 \\
\hline $\begin{array}{l}\text { Constanta, } \\
\text { Romania }\end{array}$ & Millenium hotel & 109.2 \\
\hline Cyprus & $\begin{array}{l}\text { Palm Beach Hotel and } \\
\text { Bungalows }\end{array}$ & 98.2 \\
\hline Marmaris, Turkey & Elegance Hotel Intl'. $5^{\star}$ & 64.5 \\
\hline Santorini, Greece & Rocabella Resort \& Spa, & 185.2 \\
\hline Malta & $\begin{array}{l}\text { Le Meridien St Julians Hotel } \\
\text { and Spa } 5^{\star}\end{array}$ & 130.5 \\
\hline Malta & Hilton & 261.7 \\
\hline
\end{tabular}

55. Tourism in Montenegro appears to be related to tourism in Croatia. Tourism in Montenegro is largely concentrated in the costal region (in particular, Budva and Herceg Novi) where over 80 percent of arrivals and overnights take place. This region is located only few hours drive from Dubrovnik, a world renowned tour destination in Croatia ${ }^{28}$. Tourist operators in Dubrovnik have indicated that increasing number of tourists who visit

\footnotetext{
${ }^{28}$ Croatia has been recognized as top third travel destination in the world ( $38^{\text {th }}$ out of 124 countries) in the Tourism Competitiveness Index by World Economic Forum (2007). Croatia lags behind in terms of price competitiveness $\left(96^{\text {th }}\right)$, but is among the top countries in tourism infrastructure $\left(11^{\text {th }}\right)$. Montenegro was rated together with Serbia in $60^{\text {th }}$ in overall ranking, with $88^{\text {th }}$ in price competitiveness, $54^{\text {th }}$ in tourism infrastructure.
} 
Croatia/Dubrovnik also visit Montenegro as an extension of their holiday, and in search of a less expensive holiday destination to spend part of their vacation. WTTC reports also indicate that a sizeable share of visitors, especially those from UK, come through Dubrovnik airport and drive to Montenegro for a few hours/days. Croatia offers a larger variety of tourist destinations, and the size of the tourism market is over 20 times that of Montenegro. Cross border cooperation and strategic planning to take advantage of, rather than directly
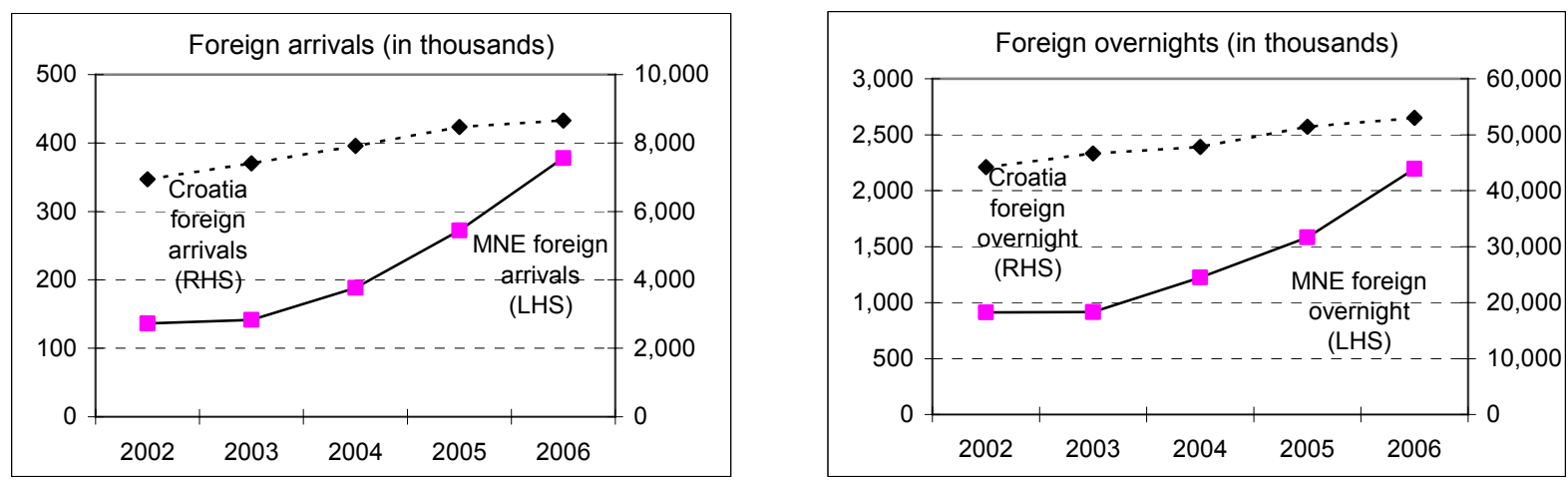

Source: Central Bureau of Statistics, Croatia and MONSTAT

competing against Croatia, could prove useful in the medium to long run.

\section{Tourist Perception Factor}

56. Safety and rule of law are important factors in attracting tourists, especially higher-end tourists who are more sensitive than young independent travelers. This is particularly important for a regime that is trying to shake off its earlier socialist image, and lingering concerns related to conflict in the region (i.e. dispute on Kosovo). The table below provides an indication of safety and rule of law in Montenegro compared with other countries, using the commonly used Corruption Perception Index (CPI) by Transparency International, Doing Business Index (DBI) by the World Bank, and Global Competitiveness Index (GCI) by World Economic Forum. All three institutional indices rank Montenegro consistently at the middle-lower end of the group. Montenegro ranked 84 out of 179 in the CPI, and 81 out of 177 in DBI, and 82 out of 131 in GCI. 
Table II.2. Perception-based Indicator of Competitiveness in Tourism Sector

\begin{tabular}{|c|c|c|c|c|c|}
\hline $\begin{array}{l}2007 \text { CPI 1/ } \\
\text { by Transparency Intl. }\end{array}$ & & $\begin{array}{l}2008 \text { Doing Business } \\
\text { by IFC }\end{array}$ & & $\begin{array}{l}2007-08 \mathrm{GCl} \\
\text { World Econo }\end{array}$ & \\
\hline Countries & rank & Countries & rank & Countries & rank \\
\hline Slovenia & 27 & Slovakia & 32 & Estonia & 27 \\
\hline Malta & 33 & Namibia & 43 & Czech Rep. & 33 \\
\hline Dubai/UAE & 34 & Bulgaria & 46 & Slovenia & 39 \\
\hline Botswana & 38 & Botswana & 51 & Slovak Rep. & 41 \\
\hline Cyprus & 39 & Slovenia & 55 & Latvia & 41 \\
\hline Slovakia & 49 & Turkey & 57 & Poland & 51 \\
\hline Greece & 56 & Belize & 59 & Turkey & 53 \\
\hline Namibia & 57 & Trinidad \& Tobago & 67 & Croatia & 57 \\
\hline Turkey & 64 & Montenegro & 81 & Greece & 65 \\
\hline Bulgaria & 64 & Vietnam & 91 & Ukraine & 72 \\
\hline Croatia & 64 & Croatia & 97 & Romania & 74 \\
\hline Trinidad \& Tobago & 79 & Greece & 100 & Botswana & 76 \\
\hline Montenegro & 84 & Dubai/UAE & $\ldots$ & Montenegro & 82 \\
\hline Belize & 99 & Malta & $\ldots$ & Serbia & 91 \\
\hline Vietnam & 123 & Cyprus & $\ldots$ & Macedonia & 94 \\
\hline
\end{tabular}

\section{E. Sustainability of the Tourism Sector}

\section{Montenegro has significant potential as the next top tourist destination in the}

world. However, some structural factors cloud the sustainability of growth over the medium term. For example, as Montenegro is a small economy of less than 700,000 citizens, it may not be economically feasible to produce a significant part of tourism-related goods domestically. High dependence on imports and high leakage of tourism industry is therefore almost unavoidable. Taking such constraints into consideration, this section provides some suggestions for ensuring sustained growth over the medium term. They include (i) reform of the labor market to boost productivity; (ii) establishment of the rule of law; and (iii) intensive government intervention to establish tourism infrastructure.

\section{Labor market reform should include a revision of the employment law and} provision of appropriate training to boost productivity. Current labor laws discourage employers from hiring Montenegrin workers due to the high cost of dismissal. It encourages employers to hire non-resident seasonal workers instead, thereby foregoing the opportunity to build up human capital. On the training side, close cooperation with industry professionals and educators is needed. Also efforts should be made to raise the perception of working in the tourism and service industry (there are reports from hoteliers of a lack of interest from Montenegrins in working in the industry, possibly due to wealth effects). Under the Tourism Master Plan developed by the MTEP, Montenegro aims to expand employment in T\&T industry by 76 percent, increase the number of beds by 141 percent, and T\&T industry output by 213 percent by 2017 . Using a standard production function with labor and capital as inputs, this would imply the need to achieve efficiency gains of 35 percent. 
Efficiency in tourism sector

Montenegro T\&T estimates and forecasts

T\&T Industry employment ('000) (L)

No. of beds ('000) (K)

T\&T Industry GDP (mil euro) (Y)

\begin{tabular}{rrr}
2007 & 2017 & \% change \\
\hline 14.9 & 26.2 & $76 \%$ \\
35.8 & 86.0 & $141 \%$ \\
212.0 & 664.0 & $213 \%$
\end{tabular}

To achieve this target, labor will need to rise by $76 \%$, capital by $141 \%$ and efficiency of labor by $35 \%$.

Source: WTTC and MTEP 2007

59. Rule of law must be firmly established. Not only to improve Montenegro's image, but also remove cumbersome urban planning procedures and reduce illegal activities in the tourism sector. Tourism providers have cited lengthy and non-transparent procedures as a major difficulty in doing business in Montenegro. Illegal construction of low economic impact residences and secondary apartments has also become widespread, threatening to endanger the fragile ecosystem, while necessary infrastructure (i.e. water and electric shortages, sewage system) remains underdeveloped. Such problems have deterred tourists and investors alike, and could pose a significant threat to the strategy of targeting high-end visitors and sustained growth.

60. Tourism has a bright future in Montenegro. However, given the numerous factors discussed above that affect Montenegro's tourism potential, government assistance is essential at this initial stage of development. This should include policies to maximize the efficiency of air-transport operations, improve the road system, and to upgrade infrastructure; measures to raise competitiveness, strengthen human resources and liberalize labor legislation; and firm action to ensure the rule of law, including urban planning. The authorities should also actively seek to improve cross-border cooperation and take advantage of tourists visiting neighboring countries to promote Montenegro as a twin destination.. 


\section{References}

Central Bank of Montenegro Chief Economist Reports, 2006.

Central Bank of Montenegro Monthly Reports, 2006-07.

Chao C., B. Hazar, J. Laffargue, M. Pasquale, and E. Yu,, 2006, Tourism, Dutch Disease and Welfare in an Open Dynamic Economy, Chinese University of Hong Kong, Deakin University, CEPREMAP City University of Hong Kong, The Japanese Economic Review, Vol. 57, No. 4.

Doing Business Report, World Bank and IFC, 2008.

Dwyer, L., and C. Kim, 2003, Destination Competitiveness Determinants and Indicators, Current Issues in Tourism, University of New South Wales, Australia, and Kyunghee University, Korea.

Edwards, J., 2005, Building the Tourism Mega-cluster: What Works and What Doesn't, University of West Indies.

Global Competitiveness Index, World Economic Forum 2007.

Global Corruption Index, Transparency International 2007.

Horwath Hotel Industry Survey Montenegro 2005 \& 2006.

Meyer, D., 2006, Caribbean Tourism, Local Sourcing and Enterprise Development-Review of the Literature, Centre for Tourism and Cultural Change, Sheffield Hallam University.

Ministry of Tourism and Environmental Protection (MTEP) and National Tourism Organization-Bulletin 65, August 2007.

MONSTAT Labor Force Survey, October 2005.

Nowak, J., 2007, Coastal Tourism and 'Dutch disease' in a Small Island Economy, Faculté de sciences économiques et sociales, EQUIPPE, Université de Lille I, Tourism Economics, 2007, 13 (1), pp. 49-65.

Tourism Competitiveness Index, World Economic Forum 2007. 
Tourism Master Plan, MTEP and German Investment and Development Company (DEG), 2001.

World Travel and Tourism Council Country Report: Montenegro, 2004 \& 2007. 


\section{FisCal Policy IMPLementation AT DAWn OF INDEPENDENCE- Supporting a Stable Convergence Process ${ }^{29}$}

\section{A. Introduction}

61. The lack of monetary and exchange rate policies in Montenegro puts a premium on a well-designed and appropriate fiscal policy. Independence has spurred intense external interest, and large capital flows have been directed towards investments in real estate and in the recovering tourism sector. Montenegro faces a steep convergence path to average European income levels, and during this process, the financial and real sectors could come under significant strains from private savings-investment imbalances, associated with large capital inflows and strong credit growth. Domestic demand is booming, and nationbuilding needs are large. In the short run, the main challenge is to contain pressures on competitiveness, and in the medium-to-long-term to provide the basis for a sustainable fiscal development. The prospect for a successful macroeconomic development, thus, depends to a large extent on a well-designed fiscal policy.

\section{B. Fiscal Framework for Montenegro}

\section{This chapter outlines some key features of an appropriate fiscal framework and} discusses its prospective implementation in the current macroeconomic context of Montenegro. The primary focus is on the role of fiscal policy in ensuring a stable financial and real sector convergence process. In this context, the adoption of an official debt target is advocated to provide an anchor for medium-to-long term policies. For such an anchor to be credible, it needs to include not only explicit public sector liabilities, but also an assessment of implicit liabilities and costs of planned reforms and age-related spending. Second, transparency in government operations will help stabilize expectations reducing country risk and strengthening the authorities' policy credibility. Regular reporting of comprehensive public sector accounts and transparency in key policy initiatives, with full disclosure of expected costs, are essential for market assessments and surveillance. Third, the budgetary impact on domestic demand and on the real exchange rate affects the stability of financial and real sector developments. A pro-cyclical fiscal stance risks eroding private sector competitiveness and will reduce the capacity to stimulate demand when the economy slows down.

\footnotetext{
${ }^{29}$ Prepared by Magnus Alvesson.
} 


\section{Debt Target: A Fiscal Policy Anchor}

\section{A well-defined public debt target consistent with fiscal sustainability provides}

the basic pre-requisite for a sound fiscal framework. Adopting a medium-term debt target bounds the fiscal framework within which the government intends to operate. However, to be credible, the government would need to be explicit regarding spending and taxation priorities over the medium term, and exhaustive concerning all existing and possible liabilities, including future demographic spending pressures. By increasing the private sector's confidence in public sector debt sustainability and liquidity, output volatility and financial sector risks would be reduced.

\section{General government debt in Montenegro remains high for the region, at around} 40 percent of GDP in 2007. Following Paris club re-scheduling in 2003 and 2006, gross public debt dipped below 40 percent of GDP in 2006, but revisions of the debt stock and the assumption of restitution liabilities reversed the debt path in 2007. This places gross government debt among the highest of neighboring countries. However, following large privatization proceeds, government deposits amount to about 10 percent of GDP; and a large share of the debt is contracted at favorable terms with low fixed interest rates and long amortization periods.

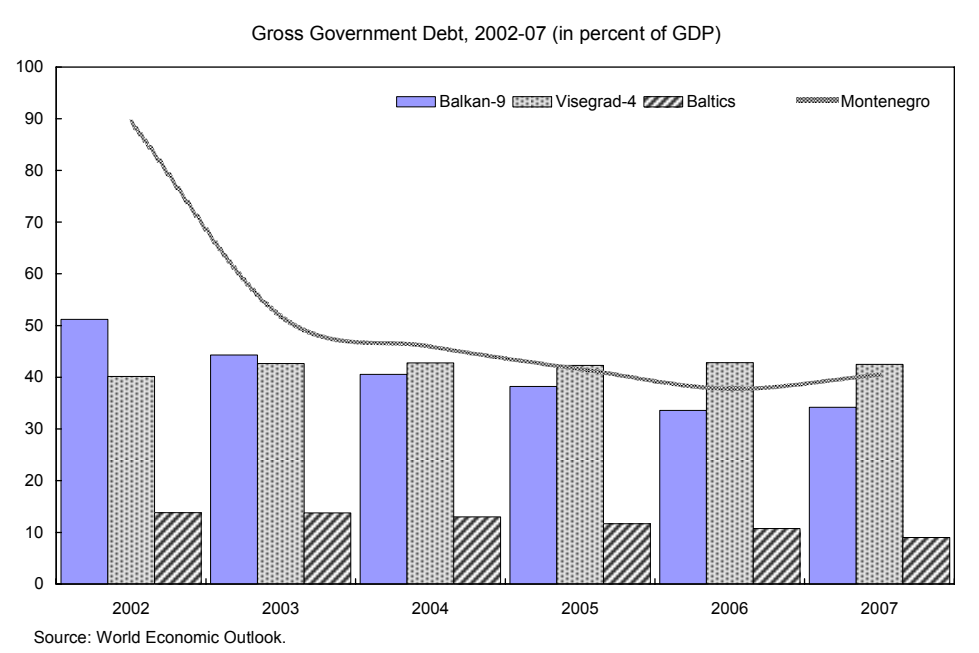

\section{Determining the optimal level of government debt depends on country-specific} factors. The primary consideration is whether, given realistic assumptions on growth, inflation and interest rates, the government can service the debt over time. In addition, factors such as the potential risk for hidden or implicit liabilities, real sector volatility, country risk assessments and planned fiscal reforms or expenditure programs need to be taken into account and, in the longer term, demographic aspects. In the case of Montenegro, the lack of monetary and exchange rate policy options reinforces the need for a cautious assessment of debt service capacity.

66. For Montenegro, standard debt sustainability analysis suggests that the current primary surplus is sufficient to stabilize debt. The debt-stabilizing primary balance is defined by the following debt dynamic equation,

$$
p b=\frac{(r-g) d}{1+g}
$$


where $p b$ denotes the primary balance as percent of GDP, $r$ is the real interest rate, $g$, the real growth rate and $d$, the debt to GDP ratio. A number of simulations are presented

(Figure III. 1). In the baseline scenario, where growth peters out and fiscal balances level off from the boom induced revenue surge, overall public debt remains markedly sustainable. However, the simulations illustrate the sensitivity to a number of adverse scenarios. A growth contraction of 25 percent compared to the baseline, a primary balance worsening by 1 percent of GDP, and a real interest hike of $2^{1} / 2$ percent all render government debt

\begin{tabular}{|l|l|}
\hline Adverse scenarios & Compared to baseline \\
\hline Growth contraction & $3 / 4$ of baseline \\
Fiscal expansion & 1 percent of GDP \\
Real interest rate hike & $2 \frac{1}{2}$ percent increase \\
\hline
\end{tabular}
unsustainable. In the longer term, in addition to fiscal pressures from addressing the gap in public infrastructure and nation-building needs, the government is going to face increasing age-related spending pressures. In a stylized scenario, assuming additional costs for health care and pension costs of a cumulative 5 percent of GDP up to 2050, all else unchanged, public debt rises to over 100 percent of GDP. ${ }^{30}$

Long-term Debt Dynamics with Age-related Spending, 2005-50 (In percent of GDP)

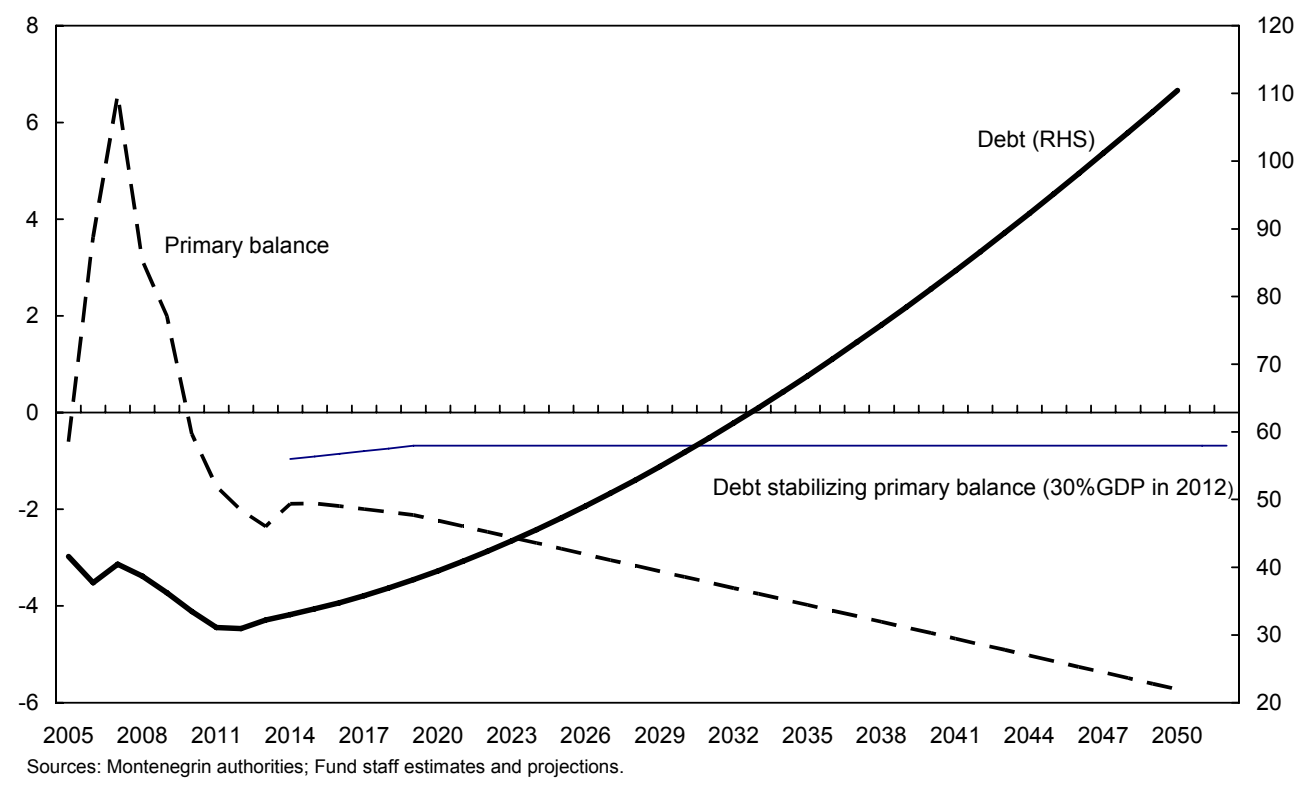

\footnotetext{
${ }^{30}$ A relative conservative estimate compared to other countries in the region (for example, for the Czech Republic the cost is estimated at 7 percent of GDP and for Estonia, at 8 percent of GDP).
} 
Figure III.1. Montenegro: Debt Sustainability Scenarios, 2005-26 (In percent of GDP)
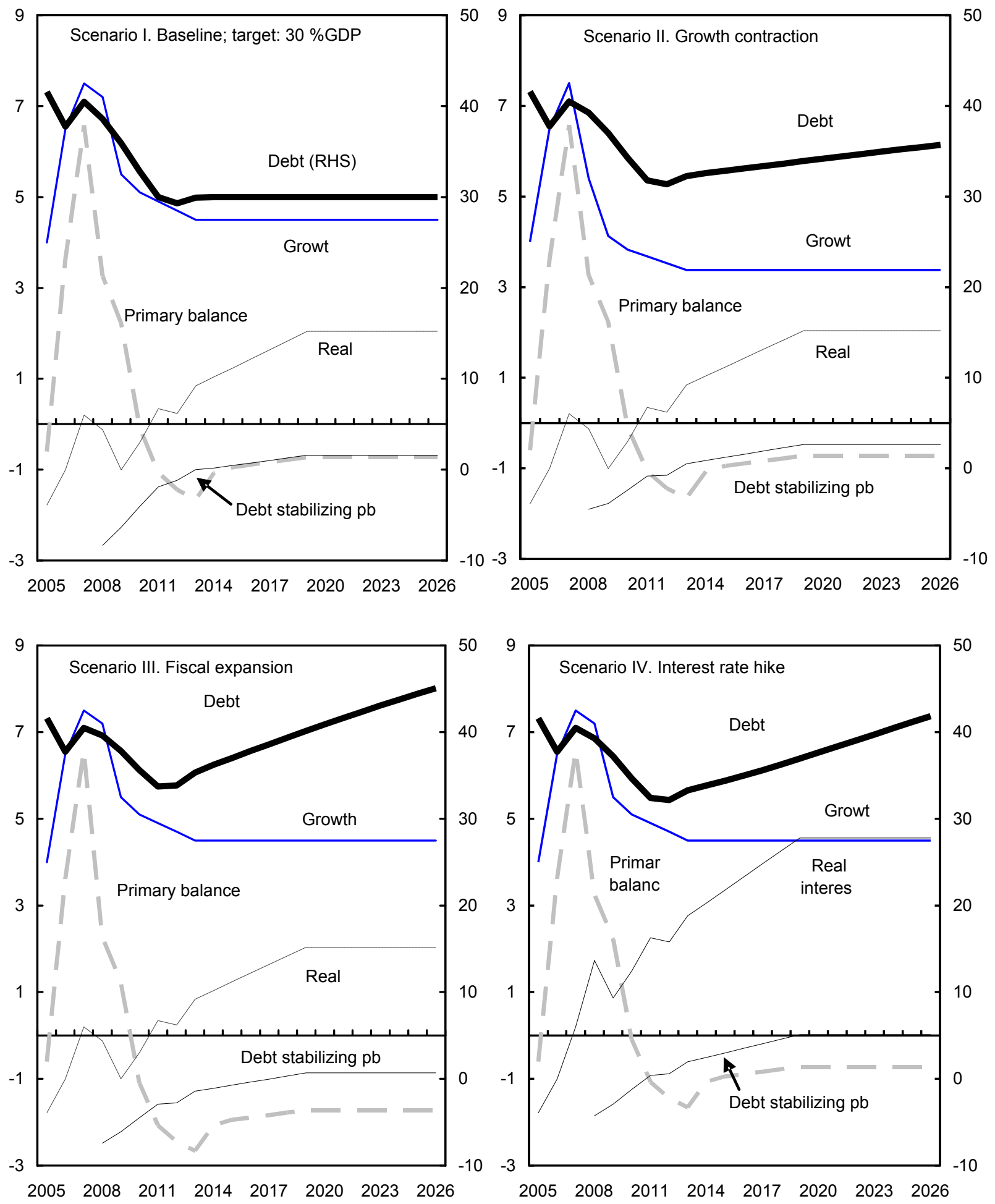

Sources: Montenegrin authorities; and Fund staff estimations and projections. 
67. Official government debt targets vary significantly across countries. The Stability and Growth Pact (SGP) stipulates that member countries should strive for a public debt level of no more than 60 percent of GDP. Research suggests, however, that the tolerance for public debt in emerging market economies is significantly lower and should range between 25-50 percent of GDP (Reinhart 2003; WEO 2003). Higher output volatility and lack of a track record in meeting debt obligations under adverse circumstances lowers the debt level the market perceives as prudent.

Public Debt Targets in Selected Countries

\begin{tabular}{ll}
\hline Stability and Growth Pact & 60 percent of GDP \\
Brasil & Net public debt to net revenues ratio cannot exceed 31/2 \\
Ecuador & 40 percent of GDP \\
Panama & 50 percent of GDP (net public debt) \\
Pakistan & 60 percent of GDP \\
Sri Lanka & 60 percent of GDP \\
UK & "Golden rule" (government should only borrow to invest), \\
& and "Sustainable investment rule" (debt assessed to be \\
& equal to 40 percent of GDP) \\
\hline
\end{tabular}

Source: IMF 2005a

68. Given Montenegro's situation as a recently independent emerging market, with little track record, an appropriate medium-term debt target should be significantly below Maastricht criteria. While the government has indicated its preference for a debt target of 30 percent of GDP over the medium term, this has not been formally adopted by the government or parliament. To enhance credibility, the debt target should be underpinned by a quantified medium-term fiscal framework and include all debt of the central and local governments, extra-budgetary funds and debts of any public or municipal enterprise not run on a strictly commercial basis.

\section{Stabilizing Expectations}

69. For a new country, it is important to establish confidence in public policy and institutional arrangements. For Montenegro, a small open economy with large investment needs, external and domestic investors' interest is all the more influenced by the perceived and real quality of public policy. Fiscal policy and a transparent and rule-based framework play important roles in underpinning expectations. More broadly, the perception of a fair and stable business climate stabilizes investment decisions, lowers country risk premiums and, in turn, would facilitate fiscal policy implementation.

70. Public policy supporting the transition to a market economy is catching up in Montenegro, although it has yet to reached peer countries. On key policy related transition indicators Montenegro is still scoring in the lower range compared to other Balkan countries, but progress was reported for 2007 in areas such as competition policy and trade (Table III.1). While Montenegro ranks above average according to doing business indicators, 
Transparency International reports that corruption is perceived to be the second worse in the region. The recent signing of the Stabilization and Association Agreement with EU is an opportunity to solidify reform efforts and enhance the confidence of investors that the current reforms will continue.

Private sector share of GDP
Large-scale privatisation
Small-scale privatisation
Governance \& enterprise
restructuring
Price liberalisation
Trade \& foreign exchange system
Competition policy
Banking reform \& interest rate
liberalisation
Securities markets \& non-bank
financial institutions
Infrastructure reform
Dealing with licenses
Employing workers
Protecting investors
Paying taxes
Average rank

Table III.1. Public Policy and Perception Indicators

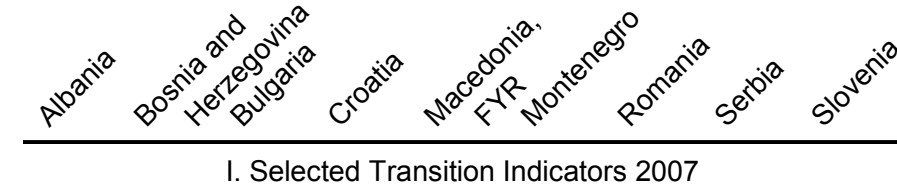

$\begin{array}{ccccccccc}75 & 60 & 75 & 70 & 65 & 65 & 70 & 55 & 70 \\ 3 & 3 & 4 & 3+ & 3+ & 3+ & 4- & 3- & 3 \\ 4 & 3 & 4 & 4+ & 4 & 4- & 4- & 4- & 4+ \\ & & & & & & & & \\ 2+ & 2 & 3- & 3 & 3- & 2 & 3- & 2+ & 3 \\ 4+ & 4 & 4+ & 4 & 4+ & 4 & 4+ & 4 & 4 \\ 4+ & 4- & 4+ & 4+ & 4+ & 4 & 4+ & 3+ & 4+ \\ 2 & 2 & 3- & 3- & 2+ & 2- & 3- & 2 & 3 \\ 3- & 3- & 4- & 4 & 3- & 3- & 3+ & 3- & 3+ \\ 2- & 2- & 3- & 3 & 2+ & 2- & 3- & 2 & 3- \\ 2+ & 2+ & 3 & 3 & 2+ & 2 & 3+ & 2 & 3\end{array}$

\begin{tabular}{cccccccccc}
\multicolumn{8}{c}{ II. Selected Doing Business Indicators } \\
2006 & 8 & 7 & 2 & 9 & 4 & 5 & 3 & 6 & 1 \\
2007 & 9 & 7 & 4 & 8 & 2 & 5 & 3 & 6 & 1 \\
2006 & 4 & 5 & 1 & 8 & 6 & 2 & 7 & 3 & 9 \\
2007 & 3 & 5 & 1 & 7 & 6 & 2 & 8 & 4 & 9 \\
2006 & 9 & 6 & 3 & 8 & 7 & 1 & 4 & 5 & 2 \\
2007 & 9 & 6 & 3 & 8 & 7 & 1 & 4 & 5 & 2 \\
2006 & 8 & 9 & 5 & 1 & 3 & 6 & 7 & 4 & 2 \\
2007 & 5 & 9 & 3 & 1 & 4 & 7 & 8 & 6 & 2 \\
2006 & 7.3 & 6.8 & 2.8 & 6.5 & 5.0 & 3.5 & 5.3 & 4.5 & 3.5 \\
2007 & 6.5 & 6.8 & 2.8 & 6.0 & 4.8 & 3.8 & 5.8 & 5.3 & 3.5 \\
& & \multicolumn{7}{c}{ III. Corruption Perception Index (rank) }
\end{tabular}

Perception of corruption

\begin{tabular}{llllllllll}
2006 & 8 & 6 & 2 & 3 & 7 & $\ldots$ & 4 & 5 & 1 \\
2007 & 9 & 6 & 2 & 3 & 7 & 8 & 4 & 5 & 1 \\
\hline
\end{tabular}

Source: EBRD 2008, IFC 2008, Transparency International 2006, 2007; and Fund staff calculations.

\section{While the coverage of fiscal accounts has improved, key areas such as local} governments and public enterprises remain underreported. The split-up of the State Union with Serbia (SCG) jolted efforts to enhance fiscal transparency. Government accounts, including public debt, are now presented on a quarterly basis and the budget documentation provides the context and assumptions for budget policy. There have been recent efforts to consolidate the financial accounts of extra-budgetary funds, with a view to include these in the single treasury account for fiscal year 2008. However, fiscal operations of local governments, in particular as regards privatization and utilities, and public enterprises should be made more transparent and rules-based. Reliable and timely information on local government and public enterprises would reduce, in large part, remaining uncertainties. 
72. The status of budget reforms still lags peer countries. Within the group,

Montenegro ranks third from last and while basic reforms of the public financial management system are on track, more advanced reforms are lagging. Furthermore, a strengthening of internal and external audit and enhanced efficiency and transparency of public procurement are key challenges (WB 2006).
Status of Public Financial Management Reforms

\begin{tabular}{|c|c|c|c|c|c|c|c|c|c|}
\hline \multicolumn{10}{|l|}{ Basic reforms } \\
\hline Complete budget classification & 3 & 2 & 2 & 2 & 1 & 2 & 1 & 2 & 2 \\
\hline Complete budget coverage & 2 & 0 & 2 & 2 & 3 & 2 & 2 & 1 & 1 \\
\hline Capital budget integration & 1 & 1 & 1 & 2 & 1 & 2 & 1 & 1 & 2 \\
\hline Consolidated TSA & 1 & 1 & 2 & 2 & 3 & 2 & 2 & 2 & 3 \\
\hline Adequate budget controls & 2 & 1 & 1 & 1 & 2 & 1 & 1 & 1 & 3 \\
\hline \multicolumn{10}{|l|}{ Advanced reforms } \\
\hline Medium-term budgeting & 1 & 1 & 2 & 1 & 2 & 1 & 1 & 1 & 2 \\
\hline Performance-oriented budgeting & 1 & 0 & 2 & 1 & 1 & 0 & 1 & 0 & 2 \\
\hline Integrated cash/debt management & 1 & 1 & 2 & 1 & 2 & 1 & 2 & 0 & 3 \\
\hline Unified accounting framework & 2 & 0 & 2 & 1 & 2 & 1 & 1 & 1 & 1 \\
\hline Fiscal transparency & 2 & 1 & 2 & 2 & 2 & 1 & 2 & 1 & 3 \\
\hline Total & 16 & 8 & 18 & 15 & 19 & 13 & 14 & 10 & 22 \\
\hline Rank & 4 & 9 & 3 & 5 & 2 & 7 & 6 & 8 & 1 \\
\hline
\end{tabular}

\section{Fiscal Stabilization-Budgetary Impact on Domestic Demand}

73. Temporary swings of the economy can often have a disruptive effect on the real sector and financial markets, and erode financial sector confidence. Absent monetary policy, fiscal policy becomes prominent in regulating the impact of economic cycles on the economy. Despite having defined a medium-term fiscal framework that is consistent with the medium-term debt target, there are instances when departing from this to stabilize developments is justified. In particular, when booms can be identified as temporary, policy makers would be well-advised to let the automatic stabilizers work; i.e. refrain from lowering tax rates or increasing discretionary spending. By letting fiscal balances improve during upswings the impact on the real and financial sectors can be dampened and the government will be in a better position to mitigate downturns and to pursue countercyclical policies.

74. The aggregate demand boom currently under way in Montenegro, generated to a large extent by capital inflows, has put pressure on the real exchange rate, and on external competitiveness, and widened external imbalances. The inflows have also fueled a rapid credit expansion by banks. Fiscal balances have improved substantially, shifting from an average deficit of 3 percent of GDP over 2003-05 to a surplus of $2 \frac{1}{2}$ percent of GDP in 2006 and a projected surplus of 51/2 percent of GDP in 2007. In particular, VAT revenues collected at customs have boomed in the wake of FDI-driven imports (Figure III.2). At the same time, tax rates have been lowered. Personal income tax was reduced in early 2007, and the number of goods for preferential VAT treatment has been expanded. In 2008, social contribution rates will be lowered and the authorities plan to continue the reduction of these rates and the personal income tax in coming years. Furthermore, discretionary spending is increasing, in particular wage-related spending and capital outlays. While these policy changes may have their own merit, for example, by lowering the overall tax burden and 
increasing the attractiveness of the public sector, an important question for policy makers in Montenegro is to what extent recent benevolent fiscal outcomes can be expected to continue.

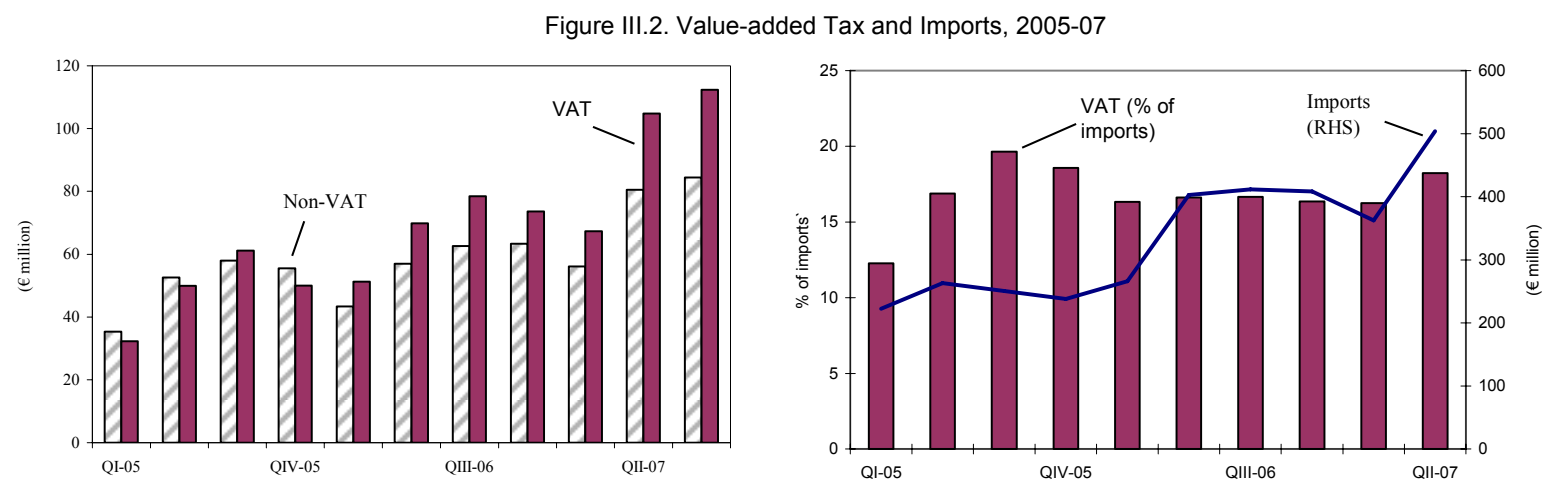

Sources: Montenegrin authorities; and Fund staff estimates and calculations.

75. Fiscal outcomes are the result of direct budgetary decisions (discretionary policy), underlying growth potential, and demand pressures (cyclical impact). The cyclical component is determined by the deviation of economic activity from underlying trends and of the degree to which budgetary components react to such fluctuations. The structural balance is a measure of the fiscal position at underlying trends and is derived by removing the temporary impact. Typically, the analysis involves the estimation of the output gap and the sensitivity of budget components to this (i.e. the automatic stabilizers). There are, however, other temporal movements that also can have significant impact on the fiscal position. In particular, large external imbalances manifested through increasing current accounts deficits imply a large increase of domestic absorption over production that, in particular, would stimulate indirect taxation (Jaeger, 2007).

\section{Despite many limitations, analysis of the cyclicality of fiscal policy in transition} economies can be useful. The structural shifts in the economy associated with transition distort economic patterns making it difficult to identify underlying economic trends, and lack of longer consistent economic time series can restrict the analysis. However, identifying basic relationships can inform policy makers and help them take advantage of economic circumstances (IMF 2005b). When economic growth is above its underlying potential and stability risks are intensifying, as indicated by real exchange rate appreciation and asset price inflation, a fiscal tightening would offset private sector pressures on resources. Also, revenue surges during such periods are often not structural and should be allowed to be offset through the automatic stabilizers generating fiscal surpluses. By treating such factors as temporary improvements in the fiscal balances, policy makers can signal prudence to financial markets and bolster their ability to take on down-turns. 


\section{The structural budget balance in Montenegro is assessed by estimating the} impact of the internal and external imbalances on the budget. The internal imbalance is approximated by the output gap, the difference of actual and potential output, and the absorption gap is used as a proxy for the external imbalance. ${ }^{31}$ While the output gap in Montenegro is in line with regional experiences, the absorption gap increases sharply in 2006, mirroring the capital inflow induced expansion of the current account (Figure III.3). The structural balance is estimated by adjusting the overall balance by the effect of the imbalances. It is assumed that the cyclical effects of the output gap primarily affect direct taxes and social contributions, and that the absorption gap mainly affects indirect and trade taxes. As a first approximation, it is also Output Gap in Selected Countries, 2003-06 assumed that expenditures have a negligible cyclical component as unemployment benefits and social transfers merely constitute $2 \frac{1}{2}$ percent of overall (In percent of potential GDP) expenditures.

\begin{tabular}{lrrrr}
\multicolumn{4}{c}{ (In percent of potential GDP) } \\
\hline & 2003 & 2004 & 2005 & 2006 \\
\hline Bulgaria & -3.0 & -1.0 & 0.1 & 0.7 \\
Czech Rep. & -3.9 & -3.5 & -1.5 & 0.0 \\
Hungary & -0.9 & -0.3 & -0.2 & -0.2 \\
Montenegro & -0.1 & 0.6 & -0.5 & 0.7 \\
Romania & -3.6 & -0.2 & -1.2 & 0.8 \\
Slovakia & -0.5 & -0.5 & -0.3 & -0.1 \\
Slovenia & -0.6 & -0.2 & -0.3 & 0.8 \\
\hline
\end{tabular}

Sources: IMF staff reports and country desk information.

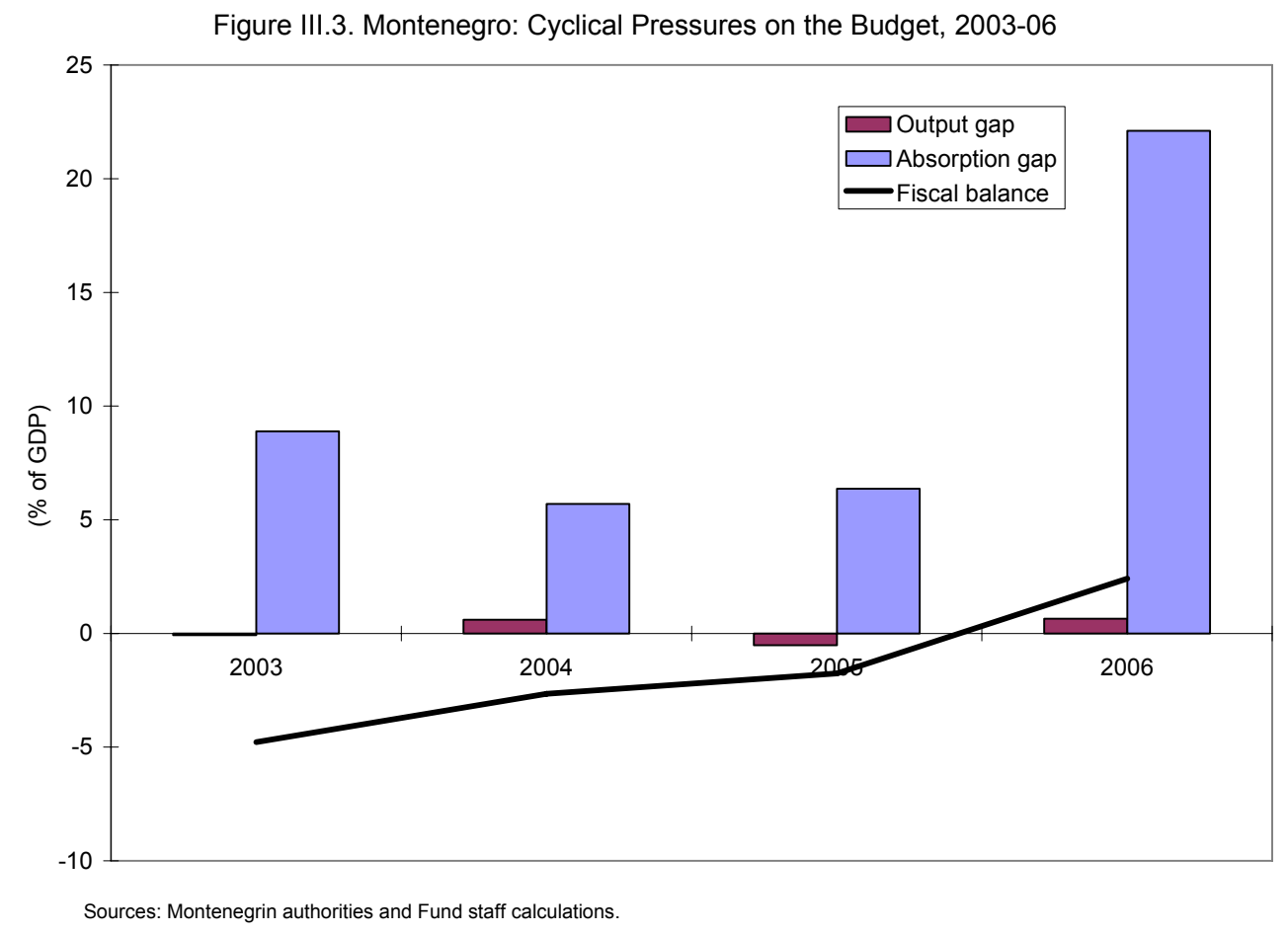

${ }^{31}$ Appendices I and II provide details on the derivations of the gaps. 
78. The analysis suggests that, structurally, fiscal policy in Montenegro turned procyclical in 2006. A number of combinations of tax elasticities to the output and absorption gaps were simulated to assess the impact on the structural budget balance in Montenegro (Table III.2). Restrictive expenditure policies indicate a withdrawing of fiscal stimulus in 2004-05. In 2006, nominal

Table III.2. Structural Budget Balance, 2003-06

revenues increased (In percent of GDP; unless otherwises specified)

substantially, and while expenditure also jumped, the overall nominal balance shifted from a deficit of 1.8 percent of GDP to a surplus of 2.4 percent of GDP. However, adjusting for the possible cyclical impact of real growth above potential and large external inflows, the structural balance indicates an expansionary fiscal impulse in 2006, ranging from 0.1 percent of GDP to 1 percent of GDP. While data quality is limited and the results partly could be affected by the structural transformation of the economy, the substantial impact on primarily indirect taxes from the external gap indicates that the improvement in the overall balance is largely temporary.

79. Looking forward, the revised budget for 2007 and projections based on announced policy changes for $\mathbf{2 0 0 8}$ indicate a substantial increase in fiscal stimuli of the economy. Despite strong adjustments of the primary balance, planned increases of public sector wages, tax cuts and reductions of social contribution rates, are estimated to contribute to domestic demand by
Structural Balance, 2006-08 (in percent of GDP)

\begin{tabular}{lrrr}
\hline & 2006 & $\begin{array}{r}2007 \\
\text { Rev. }\end{array}$ & 2008 \\
& Prel. & Budget & Proj. \\
\hline Overall balance & 2.4 & 3.0 & 2.3 \\
Primary balance & 3.6 & 4.4 & 3.3 \\
Cyclical adjustment & 5.5 & 8.0 & 7.7 \\
Primary balance (structural) & -1.9 & -3.1 & -4.0 \\
Fiscal impulse & 0.4 & 1.1 & 3.6 \\
\hline Sources: Montenegrin authorities; and Fund staff \\
estimates and projections.
\end{tabular}


1 and $3 \frac{1}{2}$ percent of GDP in 2007 and 2008, respectively. With the strong revenue performance likely to continue over the next couple of years, the political pressures on the budget envelope will intensify. To alleviate these pressures Montenegro should consider a more restrictive fiscal rule to limit the adverse impact of the temporary upswing of the economy.

\section{Many countries have adopted explicit fiscal commitments to strengthen} discipline and to relieve policymakers from short-term political pressures. The purpose of such fiscal rules is, in many cases, to reduce the discretionary element and minimize the uncertainty of fiscal policy. Fiscal commitments can take the form of relative simple rules on the nominal budget balance,

for example a no-deficit rule. The fiscal authorities can also commit to various forms of expenditure limits, or, more involved, to limits on the non-cyclical elements of the fiscal stance.

International experience indicate that cyclical upswings are usually Fiscal Rules in Selected Countries

\begin{tabular}{lll}
\hline & Budget balance rules & Expenditure rules \\
\cline { 2 - 3 } $\begin{array}{l}\text { Argentina } \\
\text { Brazil }\end{array}$ & Overall budget balance & Primary expenditure ceilings \\
Denmark & Limit on average stuctural balance & Real expenditure ceilings \\
Ecuador & Numerical limit on deficit & Primary expenditure ceilings \\
Finland & Structural balance & Real expenditure ceiling \\
Peru & Numerical limit on deficit & Primary expenditure ceilings \\
Sweden & Overall surplus over the cycle & Primary expenditure ceilings \\
Switzerland & Balanced structural budget & Spending ceilings adjusted for \\
& & cyclical position \\
United Kingdom & Golden rule: balanced current & Nominal expenditure ceilings \\
& account over the cycle & \\
\hline
\end{tabular}

Sources: Danninger (2002) and Kopitz (2004). associated with a fiscal pro-cyclical bias, but also that deficits have been reduced following the introduction of balanced budget rules (Debrun, 2007).

\section{The design of an appropriate fiscal rule is not without trade-offs. Limits on} budget balances, although clear and easy to communicate, do not address the problem of procyclicality. Nor do nominal and real expenditure ceilings per-se take into account short-term demand management considerations, and, in addition, can lead to rigid adjustments without priority consideration of spending needs. The primary drawback of structural targets is the difficulty in finding undisputable methods for deriving the output and absorption gaps, in particular, in emerging market economies with lack of consistent time series and quality data.

\section{Montenegro should, nevertheless, consider adopting an explicit fiscal rule, to} supplement the debt target. Faced with competing priorities for short-term demand management and spending needs, coupled with long-term fiscal sustainability considerations, the government would strengthen macroeconomic policy implementations by pre-committing to a rule-based fiscal framework. A fiscal rule should be consistent with the medium-term debt target, but would also need to take into account the effects of short-term economic fluctuations. Thus, a combination of an officially adopted debt target together with explicit limits on expenditures would likely be the most appropriate framework for the current situation in Montenegro. 
83. The adoption of any fiscal rule in Montenegro should, however, be underpinned by credible policy commitments and enforcement mechanisms. Any merits of a rule can easily be undermined without a clear justification of the rule. In addition, an explicit and detailed medium-term expenditure framework would increase credibility, and any revenue declines due to tax rate reductions should be made clear to the public. All entities of government operations need to be brought into the budget framework to avoid shifting costs to local governments or public enterprises. To enhance accountability, any breach of the rule should be made public.

\section{Strengthening the Fiscal Framework-Conclusions and Policy Considerations}

84. Montenegro has come a long way in establishing credible and functioning budget institutions, but a lack of explicit fiscal commitments could undermine private sector confidence. Public debt is on a sustainable path and privatization revenues have boosted government deposits. Budget transparency has shown a remarkable improvement since independence and more reforms are underway. And fiscal policy has largely remained neutral during large political upheavals. However, challenges remain and many could be addressed by reducing the ad-hoc element of fiscal policy making. Strong and explicit commitments regarding fiscal objectives and goals would strengthen private sector confidence in public policy and enhance predictability.

85. Public debt sustainability is currently not a concern, but is undermined by large uncertainties. This could be remedied by, one, official adoption of a medium-tem debt target subject to parliamentary approval and, two, clarification, to the extent possible, of all potential liabilities, in particular of public enterprises. In addition, the credibility of the target would be strengthened by a laying out, in detail, of the future borrowing intentions and limits that the government will apply.

\section{Independence provides an excellent opportunity for Montenegro to assert its}

policy intentions. The authorities have responded forcefully by spelling out a strategy aiming at speeding up the transformation towards a market-based economy and closer integration with the European Union. However, policy reforms still lag neighboring countries, and external assessments are weakened by lacking, lagging or frequently revised key economic data. Key uncertainties prevail. To continue to improve expectations, efforts need to be applied to improving basic economic and fiscal data. Most importantly, control and accountability of, in particular, local governments and public enterprises need to be strengthened.

\section{Fiscal policy management of the on-going demand boom is becoming more} challenging. Tentative calculations indicate that a substantial part of the improvement of the fiscal balances is explained by temporary factors and that the fiscal position is contributing to the expansion of domestic demand. Recent tax cuts and wage rate hikes are likely to further weaken the underlying fiscal position, fueling demand and making the management of a 
cyclical reversal more difficult to handle. Letting the stabilizers work during the upturn of the economy would provide some restraint on the boom. A strengthening of the fiscal balance, net of temporary deviations would both counteract private sector pressures on competitiveness and provide for fiscal space when the economy cools off. 


\section{References}

Danninger, Stephan, 2002, “A New Rule: The Swiss Debt Brake,” IMF Working Paper No. 02/18.

Debrun, Xavier, Manmohan S. Kumar, 2007 “The Discipline-Enhancing Role of Fiscal Institutions: Theory and Empirical Evidence,” IMF Working Paper No. 07/171.

EBRD, 2008, “Transition Report 2008,” forthcoming (London: European Bank for Reconstruction and Development).

European Commission, 2003, "Expenditure Rules in EU Member States," in Public Finance in EMU, 2003 (Brussels: European Commission).

— 2006, "National Numerical Fiscal Rules and Institutions for Sound Public Finances," in Public Finance in EMU, 2006 (Brussels: European Commission).

Hagemann, Robert, 1999, “The Structural Budget Balance: The IMF's Methodology,” IMF Working Paper No. 99/95 (Washington: International Monetary Fund).

Horton, Mark, 2005, "Role of Fiscal Policy in Stabilization and Poverty Alleviation," in Post Apartheid South Africa-The First Ten Years, ed. by Michael Nowak and Luca Antonio Ricci (Washington: International Monetary Fund).

International Finance Corporation, 2007, “Doing Business 2008,” Washington DC.

IMF, 2005 a, Fiscal Responsibility Laws, unpublished, Washington DC.

- 2005 b, Cyclicality of Fiscal Policy and Cyclically Adjusted Fiscal Balances, unpublished, Washington DC.

—, 2005 c, Promoting Fiscal Discipline Over the Business Cycle, unpublished, Washington DC.

Jaeger, Albert, Alexander Klemm, 2007, “Assessing The Fiscal Stance During Absorption Booms" in Selected Issues: 2007 Article IV Consultation for Bulgaria, Country Report No. 07/390. (Washington: International Monetary Fund).

Kumar, Manmohan S., Teresa Ter-Minassian, Promoting Fiscal Discipline (Washington: International Monetary Fund). 
Reinhart, Carmen M., Kenneth S. Rogoff, and Miguel A. Savastano, 2003, "Debt Intolerance," Working Paper No. 9908, National Bureau of Economic Research.

Szekely, Istvan, 2005, "What Should Be the Level of Public Debt in Poland?" in Selected Issues: 2005 Article IV Consultation for Poland, Country Report No. 05/264. (Washington: International Monetary Fund).

Transparency International, 2006, 2007, "Global Corruption Report”.

Tuladhar, Anita, 2007, "Strengthening the Fiscal Framework," in Selected Issues: 2007 Article IV Consultation for Czech Republic, Country Report No. 07/85. (Washington: International Monetary Fund).

Watson, Max, 2006, "Financial Stability during Convergence: What can Fiscal Policy Contribute?" in Fiscal Policy Surveillance in Europe, ed. Peter Wierts, Servas Deroose, Elena Flores and Alessandro Turrini.

World Bank, 2006, "Republic of Montenegro: Public Expenditure and International Review," Washington DC.

World Economic Outlook 2003 (Washington: International Monetary Fund).

Yläoutinen, Sami, 2004, "Fiscal Frameworks in the Central and Eastern European Countries,” Discussion Paper No. 72 (Helsinki: Central Bank of Finland). 


\section{Appendix III.1. Estimating Potential GDP and the Output Gap}

1. The output gap is defined as the difference between actual GDP and potential GDP as a percent of potential GDP:

$$
\operatorname{Ygap}_{t}=\left(\left(Y_{t}-Y_{t}^{*}\right) / Y_{t}^{*}\right)
$$

where $\mathrm{Y}$ is nominal GDP and $\mathrm{Y}^{*}$ is potential nominal GDP. Potential GDP is considered as the highest level of GDP that is consistent with stable inflation.

2. There are three common methodologies to estimate the potential GDP; using Hodrick-Prescott filter, a production function approach, and vector autoregression analysis. The Hodrick-Prescott filter is used to extract GDP in a smooth trend component. The remainder is a cyclical one-off component. The main drawback of using the HP-filter to derive potential GDP is the lack of economic information that enters into the algorithm. This is, however, an advantage in countries where data on, in particular, the capital stock is deficient. The production function methodology builds on an economically consistent basis, but is more demanding in terms of data requirement, and, as such, is more vulnerable to statistical mismeasurements.

3. A number of caveats regarding the Montenegro GDP statistics need, however, to be applied. Primarily, it is widely believed that official GDP estimates understate the true size of the economy, due to the presence of a large grey sector. Also, the statistical methodology in compiling the national account is weak. Furthermore, since the data span available in Montenegro is relatively short, the methodologies applied here are limited by the lack of sufficient cyclical pattern of economic activity and by the fact that a large component of the variation could be due to a structural shift. Nevertheless, the recent rapid upturn of the economy is likely to be temporary, and a quantification of this part could be useful as a guide to short-term fiscal policy.

\section{Measuring the GDP gap using the Hodrick-Prescott Filter}

4. In Montenegro, only unofficial quarterly estimates of nominal GDP exist (2002:Q1-2006:Q4). A monthly GDP series was generated using a quadratic matching sum interpolation, which was then seasonally adjusted using the Census X12 method. A visual inspection indicates that GDP growth picked up substantially at end-2006.

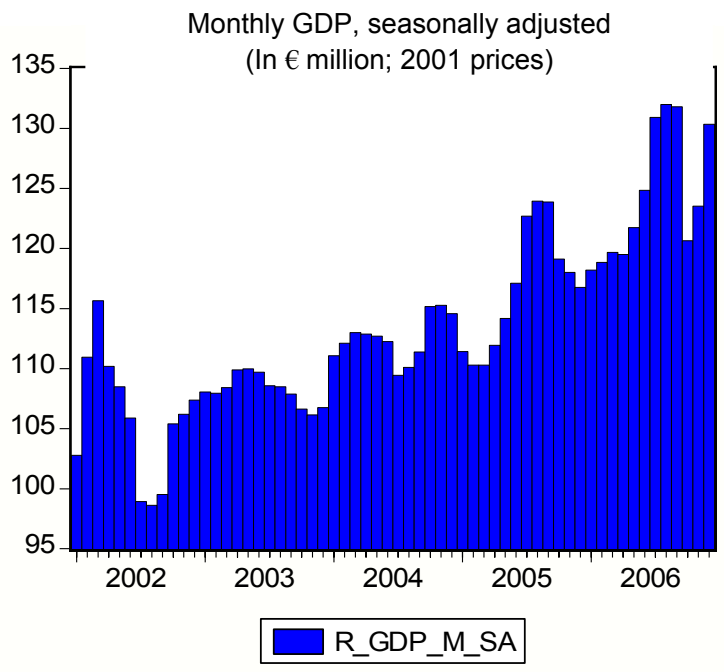


5. The next step is to use the Hodrick-Prescott filter to remove the cyclical components of real GDP. The Hodrick-Prescott filter is applied according to:

$$
Y_{t}^{r}=Y_{t}^{*}+Y_{t}^{c} \quad \mathrm{t}=1, \ldots, \mathrm{T}
$$

where real GDP $\left(Y_{t}^{r}\right)$ is the sum of smooth trend $\left(Y_{t}^{*}\right)$ and cyclical $\left(Y_{t}^{c}\right)$ components. The smooth path of real GDP is derived through least squares augmented with a smoothing function that penalizes for large changes in the trend component of GDP:

$$
\min _{\left\{Y_{t}^{*}\right\}_{t=-1}^{T}}\left\{\sum_{t=1}^{T}\left(Y_{t}^{r}-Y_{t}^{*}\right)^{2}+\lambda \sum_{t=1}^{T}\left[\left(Y_{t}^{*}-Y_{t-1}^{*}\right)-\left(Y_{t-1}^{*}-Y_{t-2}^{*}\right)\right]^{2}\right\}
$$

6. The estimate of potential GDP depends on the "smoothing" variable $\lambda$; the greater the value the larger is the extracted cyclical component. The value of $\lambda$ for monthly data is recommended at 14,400 (Hodrick-Prescott 1997), but it can be argued that with larger presence of structural shifts in the economy the value could be lower. However, the data are not very sensitive to variations of the "smoothing" factor
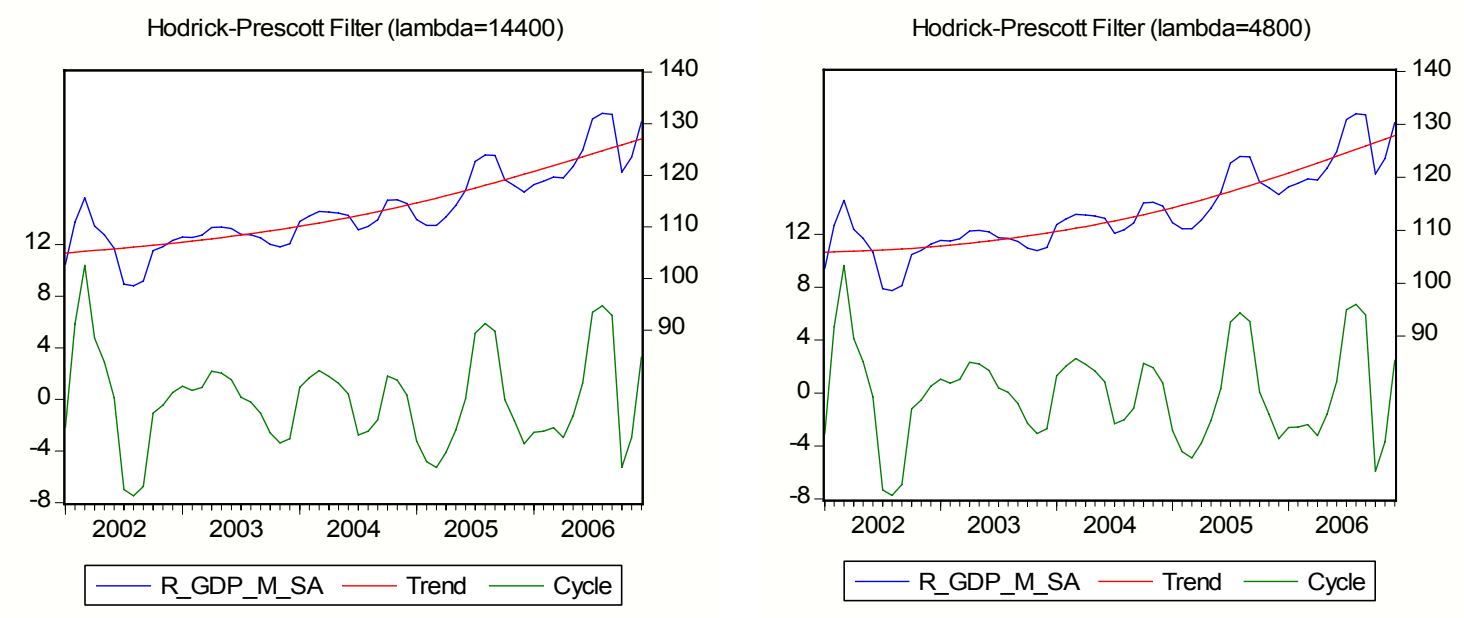

Source: IMF staff calculations. 


\section{Appendix III.2. Cyclical Impact on the Budget-Estimating the Effects of Output and Absorption Gaps}

7. The budget effect of the output gap is calculated as:

$$
\left(\frac{S B B}{Y^{*}}\right)_{t}=\left(\frac{B B}{Y}\right)_{t}-(\varepsilon Y g a p)_{t}
$$

and the effect of the absorption gap is calculated as:

$$
\left(\frac{S B B}{Y^{*}}\right)_{t}=\left(\frac{B B}{Y}\right)_{t}-(\alpha A g a p)_{t}
$$

where SBB is the structural budget balance, BB the actual budget balance, Y nominal GDP and $\mathrm{Y}^{*}$ the potential GDP. The coefficients $\varepsilon$ and $\alpha$ denote the elasticity of the budget with respect to the output and absorption gaps.

8. The absorption gap is defined as:

$$
\operatorname{Agap}_{t}=\left(A_{t}-A_{t}^{*}\right) / Y_{t}^{*}
$$

where absorption is estimated by $A_{t}=Y_{t}-C A_{t}+I T$. Potential Absorption, $\mathrm{A}^{*}$, is considered as the sustainable level of absorption and the equilibrium value of the current account, $\mathrm{CA}^{*}$, is derived from staff's analysis of external stability risk (Staff report, Box 3):

$$
A_{t t}^{*}=\left(Y_{t}^{*}-C A_{t}^{*}+I T_{t}\right)
$$

where IT is the balance of incomes and transfers from abroad.

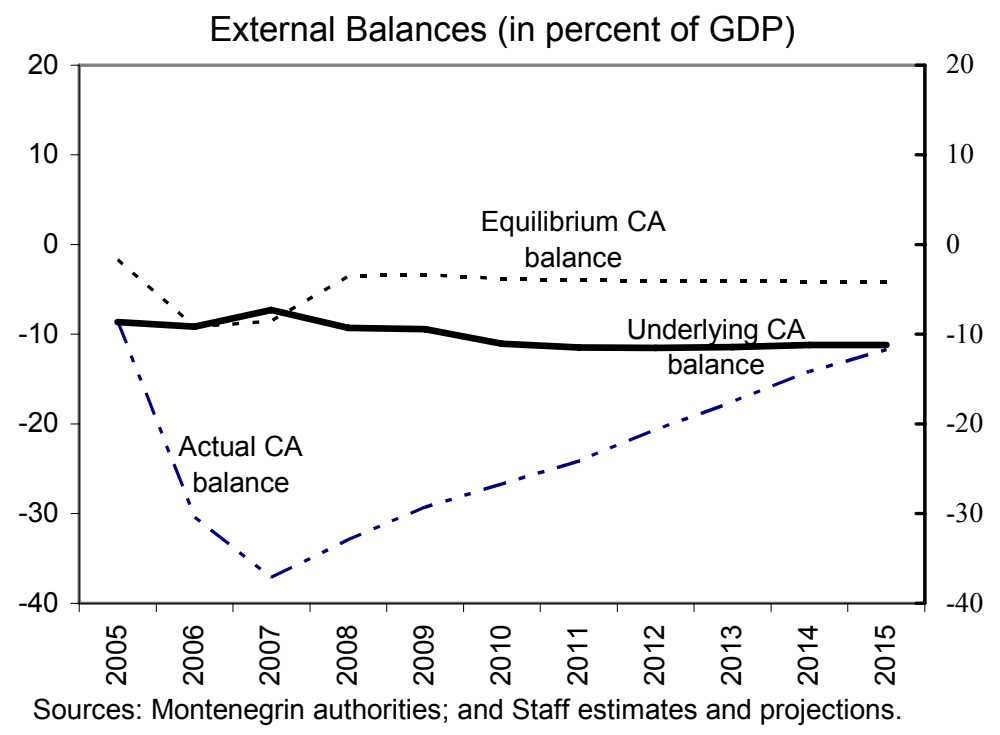




\section{The Banking Sector of IMontenegro: Risks DURing the Transition Path TOWARDS THE E $\mathbf{U}^{32}$}

\section{Introduction}

88. In Montenegro, credit growth has been increasing very rapidly since 2005. Rapid credit growth is a normal feature of the financial sector development process underway in many Central and Eastern European (CEE) countries, including Montenegro. ${ }^{33}$ Montenegro is probably the most recent country in the region to have experienced a massive capital inflow, most of which has been channeled through the banking system (Box IV.1).

89. Financial deepening can not be captured solely by the rate of growth of credit. While the amount of credit in the economy is a common indicator of financial depth and its growth rate a key signal of excessive speed, cross-country analysis generally fails to take into account the overall degree of sophistication of the financial sector. ${ }^{34}$

90. The paper's main contribution is to look at several dimensions of financial deepening from the point of view of bank balance sheets, including credit growth. The analysis suggests that the speed at which financial deepening has been proceeding in Montenegro is among the fastest so far experienced within peer countries.

\section{The risks of an exuberant catching-up process, which includes rapid credit} growth, have generally been grouped in two categories: ${ }^{35}$

- Macroeconomic risks. These risks can be summarized as "overheating", which translates into pressures on inflation, current account, foreign indebtness, and the exchange rate. The relevance of these risks is necessarily related to the magnitude of the capital flows involved.

- $\quad$ Prudential risks. The key concept is "financial stability", which relates to the ability of the financial sector (mainly the banking sector) to healthily meet the growing demand of the economy for deeper financial intermediation, while remaining sound.

92. To contain risks and reduce vulnerabilities, several policy instruments have been adopted by CEE countries over the years. ${ }^{36}$ These instruments strictly depend on available policy options: macroeconomic instruments rely on fiscal, monetary and exchange rate

\footnotetext{
${ }^{32}$ Prepared by Christian Capuano.

${ }^{33}$ IMF (2006), Enoch et al. (2007).

34 This is a difficult task, as data availability and comparability among different countries is often prohibitive.

${ }^{35}$ Hilbers et al. (2005), BIS et al. (2006), and Otker-Robe et al. (2007), among many.

${ }^{36}$ Appendix II presents a summary of policy instruments and their impact.
} 
measures; prudential instruments broadly focus on making sure financial intermediaries are well positioned to withstand negative shocks by strengthening supervision and risk management capabilities; and administrative instruments refer to cruder measures with a direct impact on financial sector developments, such as credit ceilings or capital controls.

93. The common goal of these policies is to slow down the pace of credit growth by influencing the structure and development of the banking (and non-banking) sector's balance sheet. Macroeconomic policies indirectly affect the banking sector's balance sheet, as they modify the incentive structure of the private sector to access financial intermediaries (ex: fiscal and interest rate tightening). Prudential instruments may impact the balance sheet both directly (such as higher capital requirements) or indirectly (such as closer on/off site inspections are expected to lead to more prudent lending practices); and administrative measures are generally closely targeted to the balance sheet (such as bank-by-bank credit limits).

94. Part $\mathbf{A}$ of this paper investigates the extent of financial deepening in Montenegro, by analyzing the structure of the banking sectors in CEE countries and comparing Montenegro to its peers. Part A answers the following questions:

- $\quad$ Are the banking sectors of CEE countries converging to the EU?

- What are the cross-sectional differences in the banking sectors of CEE countries?

- Is Montenegro converging or diverging? At what speed is Montenegro's banking sector developing with respect to its peers?

95. Part B describes the risks of a too rapid converging process, and proposes some policy options for Montenegro, drawing from a selection of policy responses adopted over the years by CEE countries.

\section{A. The Structure of Banking Sector: Assessing Balance Sheet Convergence}

96. To analyze convergence, we look at the time-variation of balance sheet and income statement variables in the banking system of CEE countries. The past several years have seen dramatic structural changes in the banks of CEE countries. Unprofitable and often state-controlled banks have turned into mostly privately-owned engines for economic growth. Furthermore, policies have often been implemented to influence the pace of banking sector development. The structure of the banks' balance sheets and income statements should reflect these changes and are likely to have gone through major modifications over the years. 


\section{Box IV.1. Credit Growth from an International Perspective}

Credit growth in Montenegro has advanced rapidly in the past three years, in line with the experience in other transition economies. At about 79 percent at 2007 Q3, the credit/GDP ratio has already reached a level comparable to that in the Baltic countries, and notwithstanding a fast pace of increase, credit could continue to grow rapidly for a number of years.

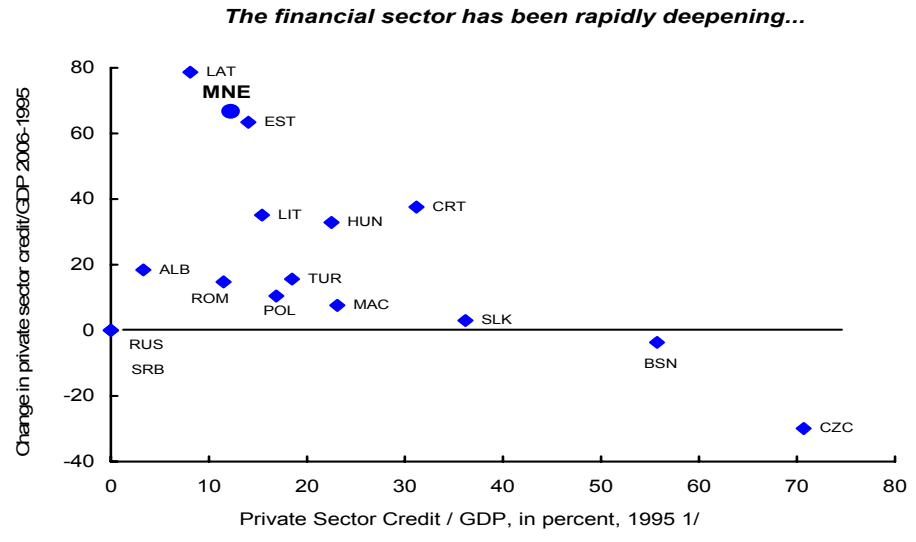

Source: IMF, International Financial Statistics. 1/ MNE 2003-07, and SRB 1998-2007. .....but there is still room for further growth in credit.

\begin{tabular}{lrrrrr}
\multicolumn{6}{c}{ Credit to the Private Sector / GDP, during Selected Credit Boom Episodes 1/ } \\
\hline Country & Start of Boom & End of Boom & Duration & Credit at Start & Credit at End \\
\hline Crisis Countries & & & & & \\
Argentina & 1990 & 1995 & 6 & 9.2 & 19.7 \\
Brazil & 1993 & 1995 & 3 & 13.3 & 47.0 \\
Mexico & 1987 & 1994 & 8 & 12.3 & 38.7 \\
Philippines & 1988 & 1998 & 11 & 16.1 & 48.0 \\
Turkey & 1995 & 2000 & 6 & 18.5 & 23.7 \\
Uruguay & 1992 & 2002 & 11 & 25.2 & 65.9 \\
Non-crisis countries & & & & & \\
Greece & 1995 & ongoing & 12 & 31.9 & 88.7 \\
Indonesia & 1984 & 1993 & 10 & 14.2 & 44.3 \\
Ireland & 1995 & ongoing & 12 & 61.1 & 182.6 \\
Portugal & 1987 & ongoing & 20 & 61.4 & 157.0 \\
Spain & 1998 & ongoing & 9 & 84.1 & 164.4 \\
Booms in selected CEE countries & & & & & \\
Hungary & 1994 & ongoing & 13 & 26.4 & 55.9 \\
Latvia & 1997 & ongoing & 10 & 9.7 & 78.3 \\
Lithuania & 1998 & ongoing & 9 & 11.0 & 43.2 \\
Macedonia & 1999 & ongoing & 8 & 20.9 & 29.7 \\
Ukraine & 1997 & ongoing & 10 & 2.4 & 47.3 \\
Montenegro & ongoing & $\mathbf{2}$ & $\mathbf{1 8 . 2}$ & $\mathbf{7 9 . 0}$ \\
\hline 1/Adapted and updated from Hilbers et al (2005) & & & &
\end{tabular}

How fast is too fast? At 2007 Q3, an out-of-sample estimation of the long-run equilibrium level of the private sector credit to GDP ratio suggests that credit-to-GDP in Montenegro exceeds its equilibrium level for the current stage of development. The banking sector's Z-score, has been declining, although not significantly. Due to data availability, results should nonetheless be cautiously interpreted.

Change in Z-score in selected CEE countries, 2001-07 1/

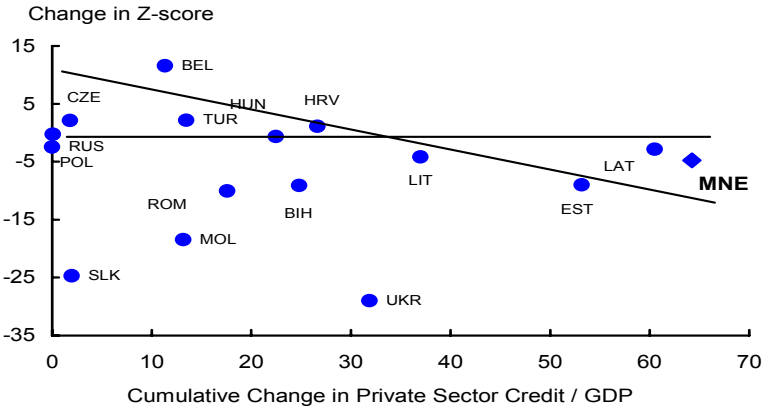

Sources: IFS, MCM database on FSIs; and IMF staff calculations. $1 /$ The $Z$-score computes the number of standard deviations the return to capital must fall for equity to be depleted. It is measured by $Z=(k+m) / s$, where $\mathrm{k}$ is equity capital as percent of assets, $\mathrm{m}$ is average return as percent on assets, and $\mathrm{s}$ is the standard deviation of the return on assets. A lower score is associated with a higher probability of insolvency risk.
Private Sector Credit / GDP in Selected Transition Economies

\begin{tabular}{lrrrrrr}
\hline Country & Actual & Predicted $^{1 /}$ & Deviation & Change $^{2 /}$ & Predicted $^{3 /}$ & Excess \\
\hline Estonia & 77.4 & 80.8 & -3.4 & 12.9 & 7.3 & 5.5 \\
Latvia & 86.8 & 75.3 & 11.4 & 13.6 & 6.9 & 6.6 \\
Romania $^{\text {Montenegro }}{ }^{4 /}$ & 26.3 & 49.6 & -23.3 & 4.0 & 4.8 & -0.8 \\
& 62.4 & 46.1 & 16.3 & 15.4 & 5.2 & 10.1
\end{tabular}

Source: IFS, WEO. Based on Schadler et al. (2005); IMF staff calculations.

1/ Based on VECM of credit/GDP, log of GDP per capita at PPP and real interest rate

${ }^{21}$ Actual average change in credit/GDP in 2003-07

${ }^{3 /}$ Average predicted short-run change in 2003-07

${ }^{4 /}$ 2005-07 data, adjusted for the underground economy and the wealth effect from assets sales. 


\section{Convergence is established in relation to some fastly growing European} economies - Greece, Ireland, Spain and Portugal (GISP). These are countries whose financial sectors grew rapidly in the 90's and that have successfully entered the European Union (EU). They represent a natural benchmark for CEE countries, whose medium or longterm goal is to join the EU. This is valid for Montenegro, in particular.

98. We measure convergence as the distance between key balance sheet and income statement variables in CEE and GISP countries. We assume convergence if the distance between CEE and GISP countries in the chosen balance sheet (or income statement) variable decreases over time.

99. The focus is on a set of balance sheet variables: the ratio of capital to assets (CA), ratio of private sector credit to deposits (PSCD), and ratio of foreign liabilities to assets (FLA). These ratios capture key developments in CEE banking sectors, which have been the direct or indirect objective of considerable policy efforts (Box IV.2). Capital is the natural buffer banks hold to withstand unexpected, negative shocks and absent information on the ratio of capital to risk-weighted assets - which better reflects the amplitude of the risks faced by banking system - CA is regularly monitored by supervisory authorities. PSCD measures how much of this growth is financed by deposits. While deposits would also include foreign residents deposits, these are generally of a second order when compared to the bulk of deposits. PSCD captures how much of the asset expansion has been financed locally. Symmetrically, FLA explores foreign interlinkages, a common feature of CEE banking sectors, by measuring how much of the asset expansion has been foreign financed, thus capturing asset growth dependence on external sources of funds.

100. Income statement variables analyzed are: return on assets (ROA), return on equity (ROE) and the interest rate spread (IR). ${ }^{37}$ These capture key efficiency and profitability developments in CEE banking sectors. ROA and ROE measure the profitability of investing in the banking sector, while IR focuses on the cost of accessing credit and is related to the degree of competition and efficiency of the banking industry. Monetary policy tightening through an increase in interest rates would lead to an increase in the cost of borrowing and should be reflected in IR. The same is true for tighter prudential measures that affect the cost of lending, i.e., tighter provisioning requirements. Administrative measures that limit asset expansion also influence profitability, depending on price and volume elasticities in the credit market.

\footnotetext{
${ }^{37}$ Measured by the difference between lending and deposit rate.
} 


\section{Convergence in Comparator Countries}

\section{Why should these variables for CEE countries converge to some EU reference}

level? To provide some perspective, we first look at the behavior of some fast growing EU economies in recent years, namely the GISP countries.

\section{Box IV.2. Balance Sheet Analysis}

Policy instruments tend to influence the pace of financial deepening by affecting the expansion of either side of the banking sector's balance sheet. In general, on the assets side, macroeconomic policies, such as an increase in interest rate, tend to make borrowing more expensive, providing saving incentives to the private sector, and should lead to a decrease in private sector credit. Prudential measures such as closer on/off site inspections are generally aimed at making lending approval standards tighter, also constraining credit. Finally, administrative credit ceilings directly impose a maximum limit. On the liabilities side, monetary policies such as higher reserve requirements aim at constraining the amount of credit financed by deposits. Administrative measures tend to affect both the amount and the composition of liabilities, for example by imposing limits on foreign borrowing. Finally, prudential measures often target the relationship between assets and liabilities, such as higher capital requirements or net-open FX limits, with the aim to obtain, ceteris paribus, a lower asset expansion. The chosen balance sheet ratios, CA, PSCD and FLA exactly capture these relationships.

Simplified Balance Sheet

\begin{tabular}{l|l} 
Assets & Liabilities \\
\hline $\begin{array}{l}\text { Private Sector Credit } \\
\text { Other Assets }\end{array}$ & $\begin{array}{l}\text { Deposits } \\
\text { Foreign Liabilities } \\
\text { Other Liabilities } \\
\text { Capital }\end{array}$ \\
\hline Total Assets & Total Liabilities
\end{tabular}

Deposits (PSCD)

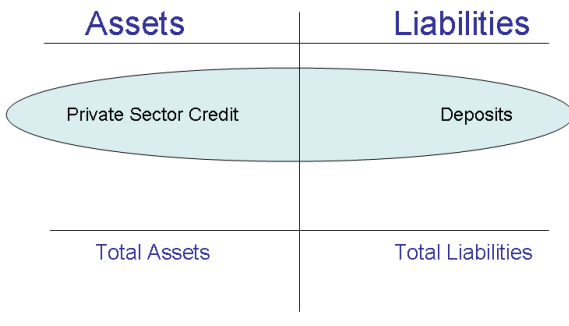

Capital in percent of Assets (CA)

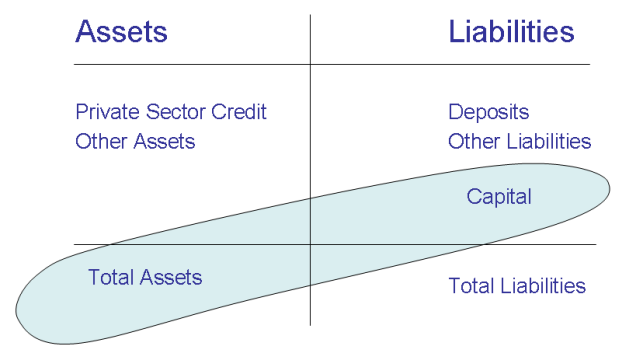

Foreign Liabilities to Total Assets (FLA)

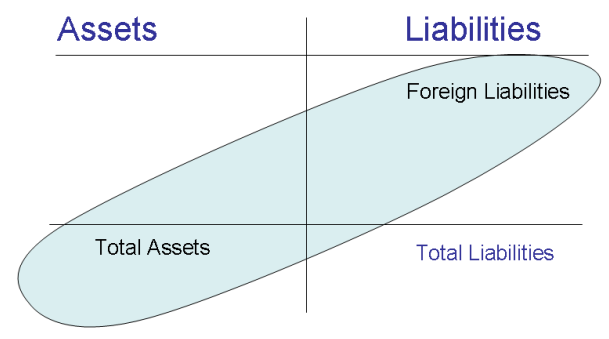


102. Figure IV.1 indicates that the GISP CA ratio and interest rate spread have been converging to EU levels over time. ${ }^{38}$ GISP CA has been declining on average, converging towards the EU mean. While minimum capital requirements are strictly regulated by the supervisor authority, persistent higher CA ratios signal an inefficient use of resources, as capital is left sitting unutilized. Figure IV.1 suggests that GISP banking sector efficiency has been improving, converging to EU levels.

Figure IV.1. Capital in Percent of Assets and Interest Rate Spread: GISP Countries
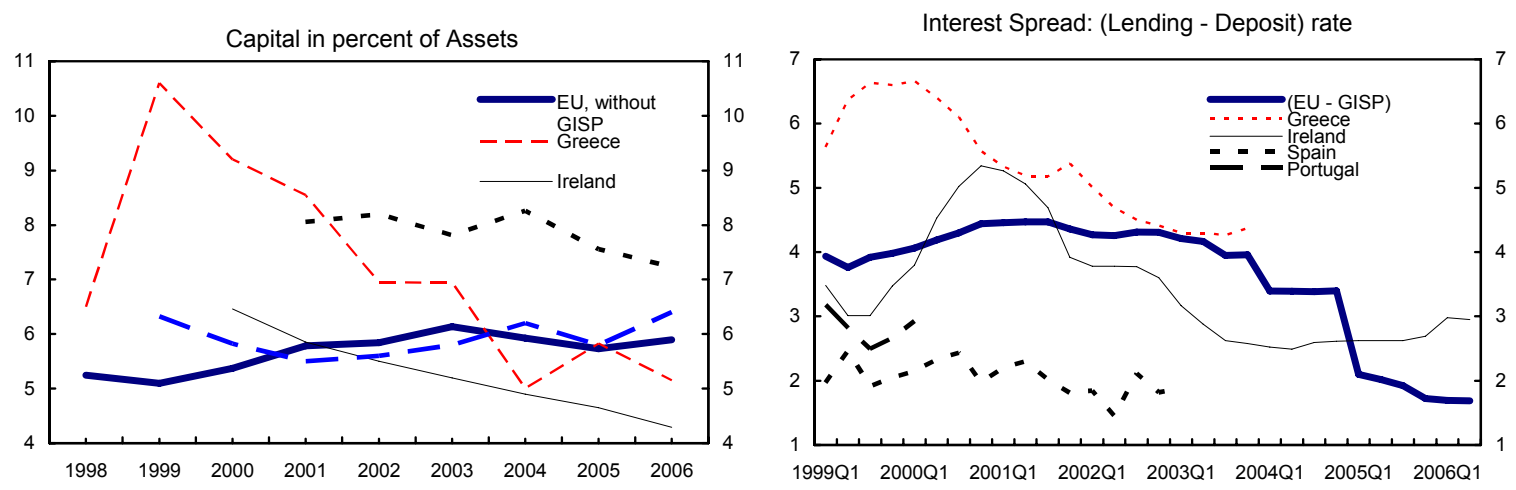

Sources: IMF, Global Financial Stability Report (2007) and International Financial Statistics.

103. Balance sheet developments indicate that GISP countries have on balance been converging to EU levels (Figure IV.2). While the convergence appears more pronounced for PSCD, some differences emerge when analyzing FLA, with Portugal and Greece displaying a more intense convergence than Ireland and Spain, in the face of a less volatile FLA ratio in EU.

\footnotetext{
${ }^{38}$ Interest rate spread information should be cautiously interpreted, as this tend to be often revised by the authorities.
} 
Figure IV.2. Balance Sheet Developments: GISP Countries
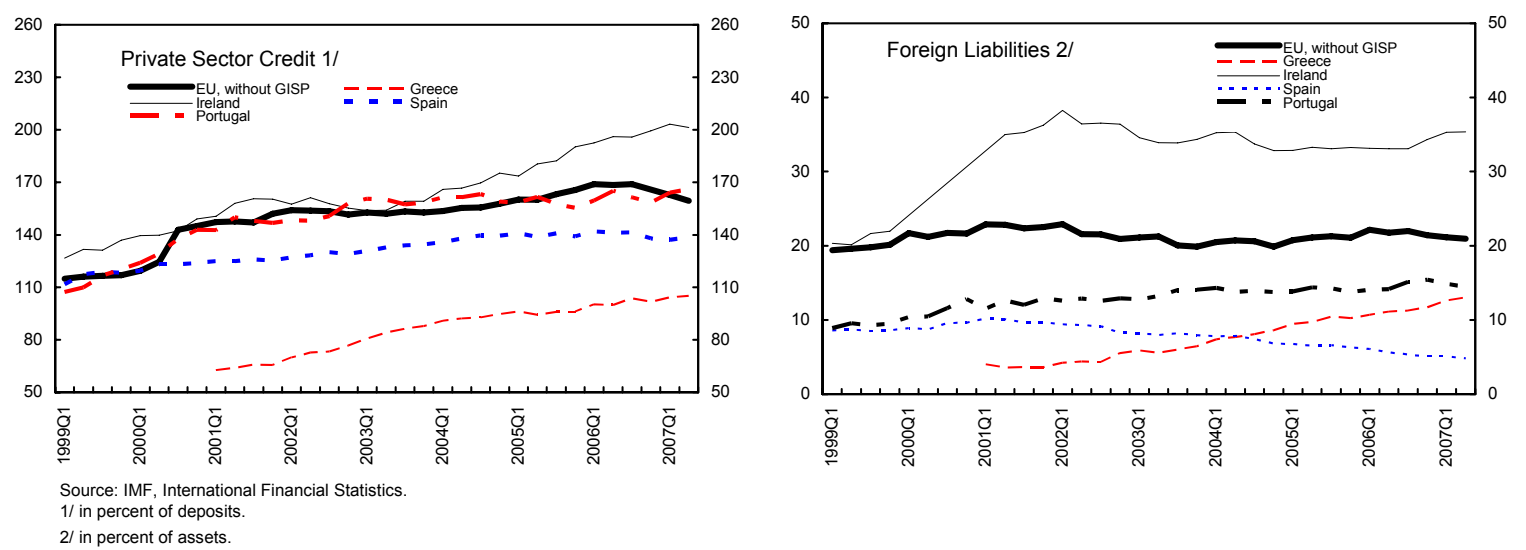

104. Profitability developments, measured by ROA and ROE, point to a somewhat stronger convergence of GISP countries to EU levels (Figure IV.3). Time-series variation in profitability indicators are rather good signals of convergence towards the EU-norm. As markets integrate and the banking sector deepens, one would expect to see capital flow into more profitable countries and to flow-out of less profitable countries. This pattern should hold for the banking sector as well, and indeed seems to be the case for GISP countries. ${ }^{39}$

Figure IV.3 Measures of Profitability: GISP Countries
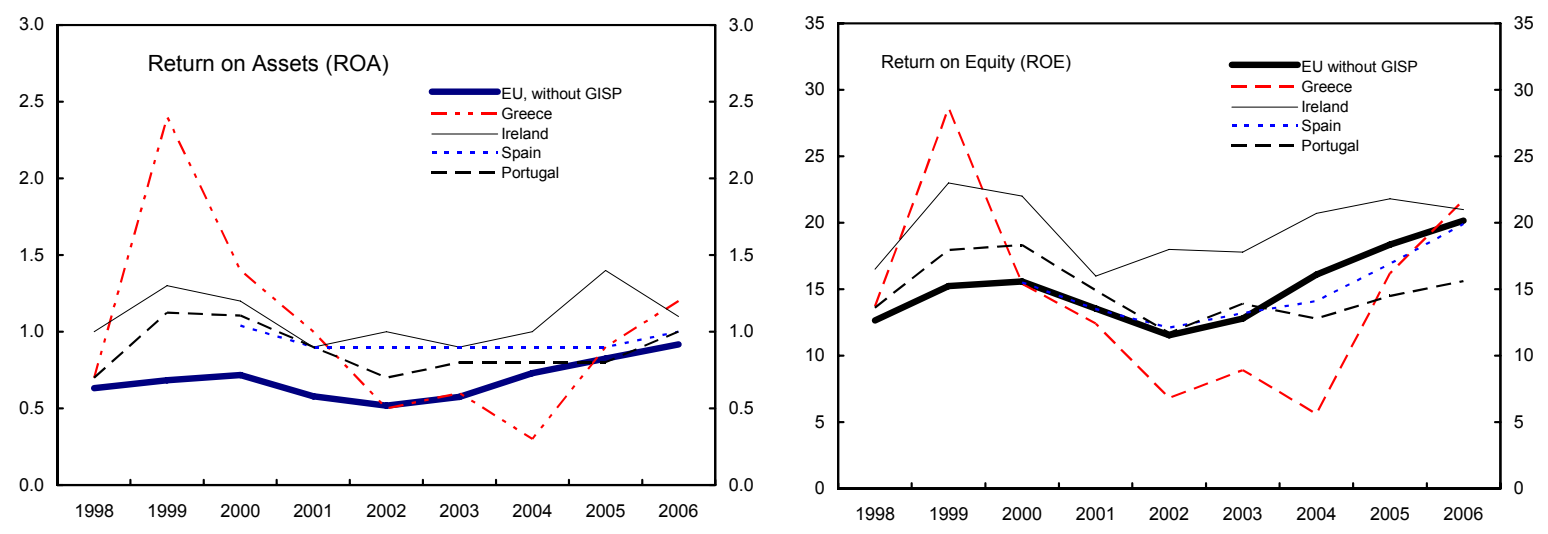

Source: IMF, International Financial Statistics.

\footnotetext{
${ }^{39}$ One might argue that differences in profitability should reflect different degrees of riskiness of the banking sector, i.e., one should observe convergence in risk-adjusted returns. As such, Figure IV.3 suggests that converging nominal returns would also indicate EU convergence in risk-profiles, at least for the aggregate banking system.
} 


\section{Montenegro's Development Path Towards EU Standards}

105. To investigate on the dynamics of the selected variables and analyze convergence of CEE banking sectors, we propose a methodology that integrates graphical analysis with formal statistical and econometric tests. We analyze 19 CEE countries during 200207. ${ }^{40}$ Not all variables are available. Econometric specifications provide complementary evidence, with the usual caveats that estimated coefficients may be contaminated by all sorts of statistical problems.

106. We analyze cross-sectional differences within CEE countries and compare Montenegro's performance to that of its peers. To this end, we use the average change in selected variables and focus on the changes in the entire CEE distribution of these variables.

107. This section presents a comprehensive analysis of convergence for $\mathrm{CA}$ ratio. A summary table will summarize the results of the same analysis for the remaining variables: PSCD, FLA, ROA, ROE, and IR. A detailed convergence analysis for the remaining balance sheet and income statement variables is found in Appendix IV.1.

108. CEE Capital buffers seem to have been converging to GISP levels during 200207 (Figure IV.4). The convergence appears much more dispersed than indicated by Figure IV.1 (for GISP countries).

Figure IV.4. Capital in Percent of Assets, CEE Countries
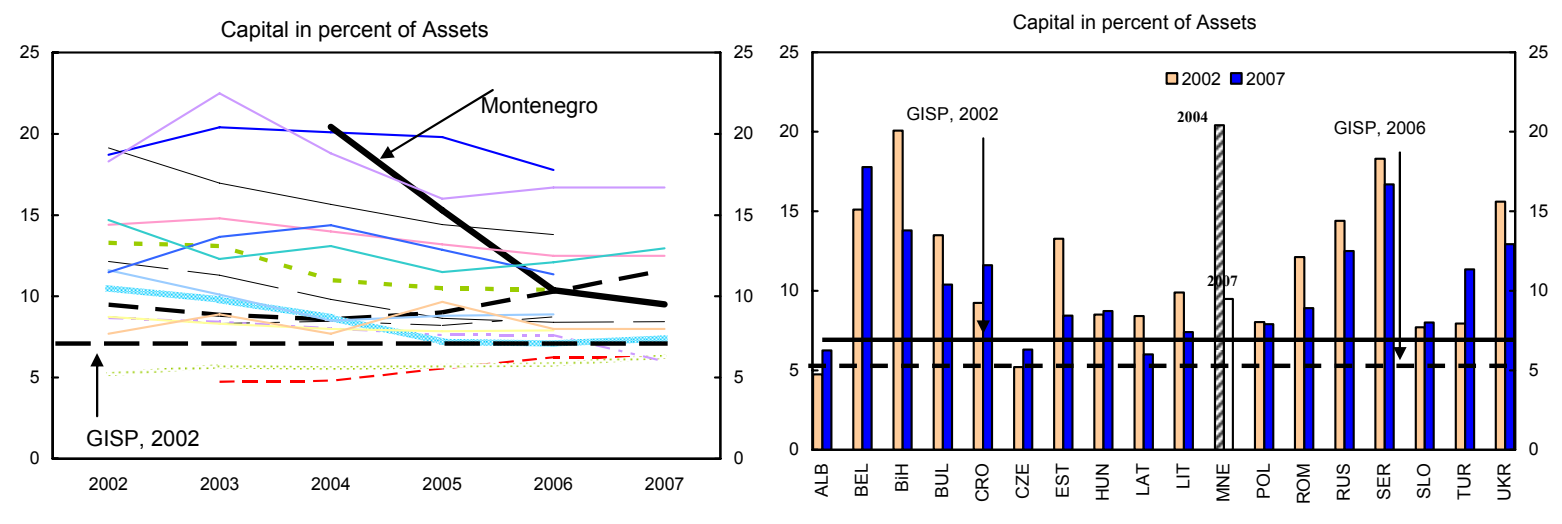

Source: IMF, Global Financial Stability Report (2007).

109. Figure IV.5 presents the CA distribution for CEE countries for 2002-07. In the left panel, 75 percent of the distribution is presented in a shaded box. Inside the box, the figure displays the median value on a horizontal line. The maximum and minimum values are indicated as horizontal lines outside the box. Finally, the bolded horizontal line indicates the 2002 GISP value, while the shaded bolded line presents the 2006 GISP value. Montenegro's pattern is indicated. The panel on the right decomposes the CA distribution. One column displays the absolute difference between the mean of the CA distribution for CEE countries

\footnotetext{
${ }^{40}$ The latest available information is used for 2007.
} 
and that of GISP countries. ${ }^{41}$ This column provides information on the average change of the $\mathrm{CA}$ distribution over time. The second and a third columns display the absolute difference between the mean of the highest (lowest) quintile of the CA distribution for CEE countries and the mean of GISP countries. These two columns investigate whether the convergence to GISP level has been uniform within CEE countries. The right panel suggests that CA convergence, if any, is mainly due to the highest 20 percent of the CA distribution, whose absolute difference with respect to GISP levels has been declining over time. The left panel indicates that the CA distribution has become less dispersed during 2002-07, with median values converging towards GISP levels. Montenegro's CA has been converging very rapidly.

Figure IV.5. Capital to Assets Distribution for CEE Countries
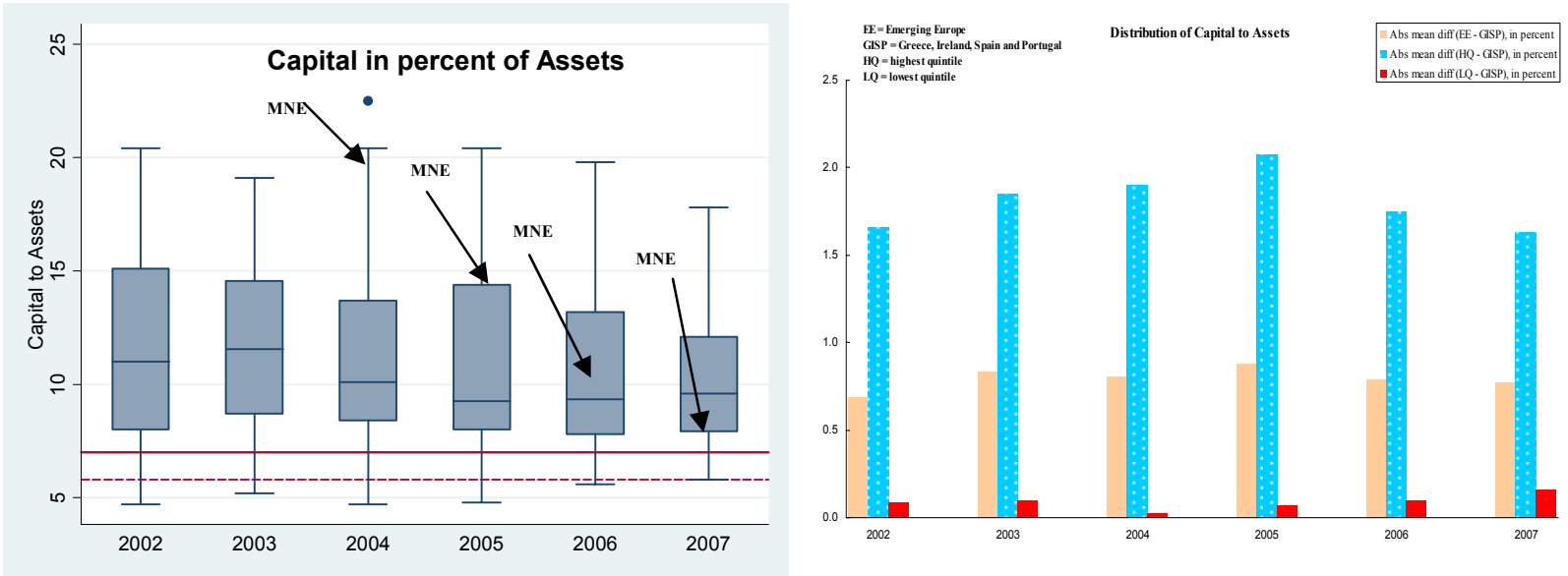

110. The convergence of CA ratios is confirmed by econometric estimation. The following specification draws from the macroeconomic growth literature, Sala-i-Martin (1995) among many. We are interested in determining the sign of the beta coefficient in:

$$
\mathrm{y}_{\mathrm{i}, \mathrm{t}}=\alpha_{\mathrm{i}}+\beta \times\left(\mathrm{yy}_{\mathrm{i}, \mathrm{t}-1}-\mathrm{yy}^{*}\right)+\varepsilon_{\mathrm{i}, \mathrm{t}}
$$

where $\mathrm{yy}_{\mathrm{i}, \mathrm{t}-1}$ is the variable of interest (CA in this case) in the previous period, $\mathrm{yy}^{*}$ is the target level to which we will measure convergence (the 2002 GISP level in this paper) and $\mathrm{y}_{\mathrm{i}, \mathrm{t}}$ is the percentage growth rate in CA, currently observed. The beta coefficient measures whether - and the rate at which - there is convergence towards the GISP level. A negative sign indicates convergence, as countries whose CA ratios fall below (above) the target level in the previous period would grow faster (slower) in the current period, a positive sign indicates divergence. Table IV.1 presents the fixed and random effects panel regression beta coefficient, for both CEE and GISP countries ${ }^{42}$.

\footnotetext{
${ }^{41}$ For GISP countries, 2006 values have been used also in 2007, due to lack of more recent information.

${ }^{42}$ In the GISP estimation, $y^{*}{ }^{*}$ is the average CA value for EU countries excluding GISP countries in 2002-06.
} 
Table IV.1. CA Fixed and Random Effects Panel Regression

\begin{tabular}{ccccc}
\hline \multirow{2}{*}{ CA } & \multicolumn{2}{c}{ CEE countries } & \multicolumn{2}{c}{ GISP countries } \\
\cline { 2 - 5 } & Fixed & Random & Fixed & Random \\
\hline \multirow{2}{*}{ BETA } & -0.035 & -0.008 & -0.077 & -0.001 \\
& $(-4.9)$ & $(-1.9)$ & $(-2.9)$ & $(-0.0)$ \\
CONST & 0.143 & 0.015 & 0.014 & -0.03 \\
& $(4.3)$ & $(0.6)$ & $(0.6)$ & $(-0.9)$ \\
& & & & \\
Obs & 85 & 85 & 20 & 20 \\
R-square & 0.3 & 0.2 & 0.4 & 0.1 \\
F-stats 1/ & 0.00 & 0.07 & 0.01 & 0.9 \\
\hline t-stats in parenthesis & & & \\
1/ p-values & & & &
\end{tabular}

\section{Results indicate that CEE capital buffers, as measured by CA, have been} converging towards GISP levels. Results also show that convergence has proceeded at a somewhat slower pace than observed between CA ratios in GISP countries and EU levels. This evidence suggests that further convergence in CEE CA levels should be expected in the future.

\section{After having established convergence on average, we highlight cross-sectional} differences and compare Montenegro's performance to its peers. To this end, we let changes in the CA distribution be tested by way of stochastic dominance. Tests of first-order (FOSD) and second-order stochastic dominance (SOSD) allow us to determine whether the convergence to GISP level is valid for the entire distribution, or applies only to a subset of $\mathrm{CEE}$ countries. Furthermore, we rank each CEE country by computing the change in the absolute difference between CA levels in 2002 and 2007, to identify countries that have been converging more rapidly to GISP levels.

\section{We apply the "q-approach to dominance" (Davidson and Duclos, 2000) and} express the measures of stochastic dominance in terms of quintiles. If one indicates the CA cumulative distribution function in $2002(2007)$ by $\mathrm{F}_{02}(\omega)\left(\mathrm{F}_{07}(\omega)\right)$, then $\mathrm{F}_{02}(\omega)$ firstorder stochastically dominates (FOSD) $\mathrm{F}_{07}$ if and only if $\mathrm{F}_{02}(\omega) \leq \mathrm{F}_{07}(\omega)$. Convergence to the GISP level is equivalent to determining whether the $2007 \mathrm{CA}$ distribution is closer to the GISP level than the 2002 distribution. ${ }^{43}$

\footnotetext{
${ }^{43}$ That is, whether $\mathrm{F}_{02} \mathrm{FOSD} \mathrm{F}_{07}$, which for q-th quintile implies to verify that the absolute difference (in percent) between the average CA value and the GISP target value in 2002 is greater than the same absolute difference in 2007, $\Delta_{07}(\mathrm{q}) \leq \Delta_{02}(\mathrm{q})$. SOSD is implied by FOSD and calls to determine whether $\mathrm{C} \Delta_{07}(\mathrm{q}) \leq \mathrm{C} \Delta_{02}(\mathrm{q})$, for each quintile (q), where $\mathrm{C} \Delta$ indicates the mean cumulative absolute difference between the average $\mathrm{CA}$ value and the GISP target up to the q-th quintile.
} 
114. Figure IV.6 indicates that convergence to GISP has been uniform within the entire CA distribution of CEE countries. For all quintiles, the 2007 CA distribution is closer to GISP level than in 2002, implying convergence.

Figure IV.6. Convergence to GISP: Capital in Percent of Assets
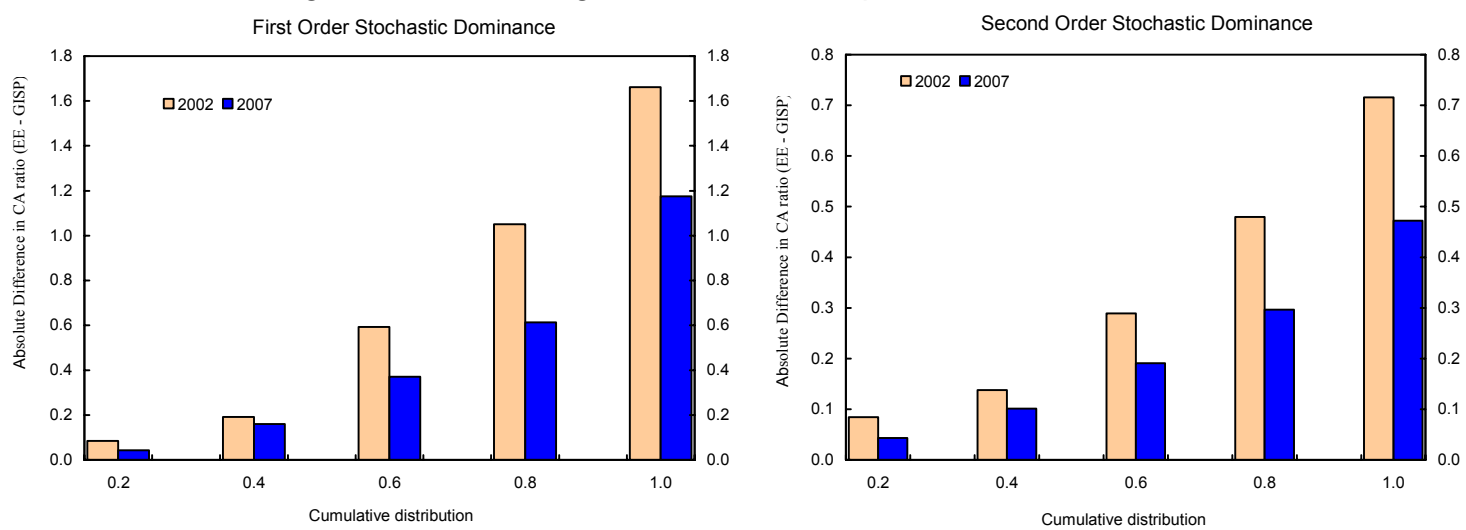

115. In the sample period, Montenegro has been the fastest converging country to GISP level, in terms of capital to assets ratio, Table IV.2. The rapid speed of Montenegro CA convergence is visible in Figure IV.5. While convergence in CA is welcome, it also signals a very rapid asset expansion which should be continuously monitored to ensure financial stability is preserved by making sure the banking sector stays sufficiently capitalized.

Table IV.2. Capital to Assets Ranking

\begin{tabular}{lcccc}
\hline & Distance from GISP & Distance from GISP & Change & Rank 2/ \\
& 2002 1/ & 2007 1/ & & 10 \\
\hline Albania & 0.3 & 0.1 & -0.2 & 17 \\
Belarus & 1.2 & 1.5 & 0.4 & 2 \\
Bosnia and Herzegovina & 1.9 & 1.0 & -0.9 & 6 \\
Bulgaria & 0.9 & 0.5 & -0.4 & 16 \\
Croatia & 0.3 & 0.5 & 0.1 & 12 \\
Czech Republic & 0.3 & 0.2 & -0.1 & 3 \\
Estonia & 0.9 & 0.2 & -0.7 & 14 \\
Hungary & 0.2 & 0.2 & 0.0 & 11 \\
Latvia & 0.2 & 0.1 & -0.1 & 7 \\
Lithuania & 0.4 & 0.0 & -0.4 & 1 \\
Montenegro 3/ & 1.9 & 0.5 & -1.4 & 13 \\
Poland & 0.2 & 0.1 & 0.0 & 5 \\
Romania & 0.7 & 0.3 & -0.5 & 8 \\
Russia & 1.1 & 0.8 & -0.3 & 9 \\
Serbia & 1.6 & 1.4 & -0.2 & 15 \\
Slovak Republic & 0.1 & 0.1 & 0.0 & 18 \\
Turkey & 0.1 & 0.6 & 0.5 & 4 \\
Ukraine & 1.2 & 0.7 & -0.5 & \\
& & & & \\
\hline
\end{tabular}

1/ Absolute value of [CA(i) - 2002 GISP mean]/2002 GISPmean, for each country i

2/ According to the change in distance from GISP mean

3/ data for 2004-07 
116. Table IV.3 summarizes the results of the analysis of convergence for all selected variables. The banking sectors of CEE countries are converging towards GISP levels, and Montenegro is one of the most rapid converging countries. In the sample of $19 \mathrm{CEE}$ economies, we found convergence in CA, PSCD and IR, while we rejected convergence for FLA, ROA and ROE. Montenegro, when compared to its peers, has been one of the fastest converging countries, particularly for $\mathrm{CA}$, ROA and ROE, while some slower convergence has occurred according to PSCD, IR and FLA.

Table IV.3. Summary of Results

\begin{tabular}{lcc}
\hline Variable & CEE & Montenegro \\
& Are CEE converging? & How fast is MNE converging? \\
\hline & Yes & 1 \\
CA 1/ & Yes & 9 \\
PSCD 2/ & No & 7 \\
FLA 2/ & No & 2 \\
ROA 1/ & No & 5 \\
ROE 1/ & Yes & 8 \\
IR 3/ & & \\
& & \\
\hline 1/ CEE includes 18-countries & & \\
2/ CEE includes19-countries & & \\
3/ CEE includes 15-countries & &
\end{tabular}

\section{B. Risks from Rapid Convergence in Montenegro and Policy Options}

\section{Risks for Montenegro}

117. Many European countries have been and are still dealing with high capital inflows, typically channeled through the banking system. This process has interested CEE for more than a decade, Otker-Robe et. al. (2007). Capital inflows have led to considerable financial deepening and rapid growth in many CEE countries. Authorities have tried to manage this process in order to maintain financial stability by applying different measures, typically grouped into macroeconomic, prudential and administrative measures, Hilbers et. al. (2005). ${ }^{44}$

118. Montenegro is not different from other CEE economies. After opening up its economy to foreign investors, Montenegro has benefited from enormous capital inflows, which have mostly been entering the economy through the banking system. Banks themselves have been the target of capital inflows with increased foreign participation, which

\footnotetext{
${ }^{44}$ Appendix II presents a table summarizing policy reponses to capital inflows adopted in selected CEE countries.
} 
controls about 79 percent of banking system capital at end-2006. Coupled with a positive business cycle and a renewed trust in the banking sector, this has led to a very fast financial deepening process on both sides of banks balance sheet, with deposit and lending growing at triple digits.

119. For Montenegro, the risks of this very rapid catching up process are twofold: macroeconomic and prudential. The main macroeconomic risk is price pressure. While Euro adoption essentially isolates the country from external shocks, it does not prevent price hikes in the non-tradable sectors. Rapid credit growth is inducing a consumption boom, mostly directed to tradable goods. Nevertheless, part of the consumption is devoted to nontradable goods, inducing price pressures in the local markets. The surge in real-estate prices is such an example. Furthermore, credit is at times directed at financing long positions in the local stock market, contributing to its sky-rocketing performance in 2006-07. From the prudential perspective, the risks reside on the balance sheet of banks. The most relevant of these risks is credit risk. As financial deepening continues, loans are extended to less creditworthy customers, exposing banks to credit risk. Furthermore, for Montenegro, an intrinsic funding risk is tied-up with unilateral euroization. Liquidity risk is somewhat mitigated by the high percentage of foreign owned banks, whose parent institutions have easy access to Euro money market.

\section{Policy Options for Montenegro}

120. In Montenegro, the macroeconomic risk of overheating will have to be dealt with appropriate fiscal policies. ${ }^{45}$ Furthermore, public sector interference in the banking sector, while decreasing, should be fully eliminated and public deposits removed from commercial banks, other than relating to normal activity, to achieve a better asset diversification in the balance sheet of Montenegro and level the playing field among banks.

121. Prudential risks will have to be dealt with strong and pro-active supervision. A strategy to preserve financial stability, geared to Montenegro's financial sector characteristics, requires the involvement of all interested players: ${ }^{46}$

- $\quad$ Risk management is, in primis, the banks' responsibility. Banks need to improve their risk management practices, adopting, inter-alia, stress-testing analysis to accurately assess potential risks and appropriately provision for them;

- The Central Bank of Montenegro's (CBM) main responsibility is to make sure that banks that take on more risks are the ones that are better able to

\footnotetext{
${ }^{45}$ See chapter III.

${ }^{46}$ For a complete description of the financial sector of Montenegro, see the Financial System Stability Assessment.
} 
handle them. CBM should favor risk-based supervision, by focusing on detecting weaknesses in banks' risk management practices, through horizontal thematic reviews of banks and stress-testing analysis, and applying bank-specific remedial actions (such as higher provisions, capital or risk weighting requirements or different mortgage loan to value or debt service to income ratios) when needed. CBM should also look for banks' cooperation, involvement and participation in periodic stress-testing exercises, by issuing stress-testing guidelines and recommendations on growing risks. In this regard, it will be necessary to adopt the new Law on Banks, granting CBM all necessary risk-based tools to efficiently manage growing vulnerabilities;

- $\quad$ Public awareness of credit-risk should be raised. In particular, the monitoring of private sector indebtedness should be strengthened. Furthermore, the Securities and Exchange Commission (SEC) should work to limit risks associated with the highly capitalized domestic stock market, focusing on:

- Improving transparency and raising the quality of audited financial statements of listed companies;

- Regulatory structure and supervision for fair trading;

- Measures to ensure that emerging pension funds are adequately diversified, with strictly limited exposure to the domestic market.

- A comprehensive, reliable, and fully operational credit registry would greatly facilitate risk management. Banks could be allowed to access the registry on a cost recovering fee-basis, to better assess credit risk and improve risk-management practices;

- Within the CBM, a contingency plan for emergency liquidity situations should be developed, following the adoption of the Central Bank Law to address potential funding needs of banks;

- National statistics should be strengthened. To address measurement concerns regarding the economic cycle, CBM should take charge to develop a real estate price index and compile the statistics on private external debt;

- Administrative measures to contain credit growth should not be excluded. Should total credit in the banking system reach unsustainable growth rates, CBM should tighten mandatory reserve requirements, by widening the base for reserve calculation, including all on-balance sheet liabilities, as well as allowing for differentiation by deposit maturity. Should overall off-balance sheet liabilities growth disproportionately increase as a consequence, they should also be included in the base for reserve calculation. 


\section{Conclusions}

122. This paper has presented a dynamic analysis of the structure of the banking sector of CEE countries. Results indicate that the structure of banking sector in CEE, as measured by several balance sheet and income statement variables, has been significantly evolving during 2002-07 and is starting to resemble the same structure observed in some fastly growing European economies, namely Greece, Ireland, Spain and Portugal.

\section{Convergence has been detected for CA, PSCD and IR, while it has not been} proven for ROA, ROE and FLA. This indicates that while on a converging path, the average CEE banking sector has yet to fully converge to EU levels. Structural changes are likely to continue in the future, as the banking sector further matures and financial deepening intensifies. Foreign investors will continue to play a key role in this process by transferring know how in the banking industry, particularly on risk management. This should help render the system more resilient and efficient. On the other hand, deep foreign interlinkages necessitate comprehensive cooperation agreements with home supervisors to monitor the activity of conglomerate financial groups.

124. Montenegro banking sector has been developing very rapidly, but is not different from its CEE peers. The financial sector, in particular the banking sector, has positively contributed to real growth. Increased foreign participation has meant increased competition in the banking industry, reducing access costs to banking services, and renewed trust in the sector. The resulting liquidity, coupled with growing investment opportunities in the country has led to rapid financial deepening.

\section{The structure of the banking sector in Montenegro has been changing as well,} and converging in several dimensions to that observed in GISP economies. Results indicate that convergence has been more pronounced for CA, ROA and ROE, while less for PSCD, IR and FLA. Benign global market conditions have seen western European banks eager to enter the country to grasp profitable opportunities. The difficult task is to ensure that the young banking sector is sufficiently strong to withstand a slowdown in economic conditions.

126. In Montenegro, important roles will have to be played by both the public and private sector to decrease banking sector vulnerabilities. The public sector role resides in prudent and counter-cyclical fiscal policies and risk-based supervision. Prudent fiscal policies should aim at reducing overheating pressures, while supervisors remain responsible for making sure that riskier banks are appropriately provisioned to face unexpected negative shocks. The foreign participation of Montenegrin banks also implies reaching cooperation agreements with home supervisors. The private sector's role is to develop risk management tools appropriate for the rapid development of the financial sector of Montenegro. 


\section{Appendix IV.1. Detailed Analysis of Convergence}

1. Appendix IV.1 applies the analysis of convergence presented in Section A to all the remaining balance sheet and income statement variables: PSCD, FLA, ROA, ROE, and IR.

2. CEE credit to the private sector, in percent of deposits, appears to have been converging to the GISP level. On the one hand credit has been rapidly expanding in CEE countries as a result of financial deepening Hilbers et al. (2005), IMF (2006), and Enoch and Otker-Robe (2007). In addition, the opening up of the banking sector to foreign capital has triggered additional funds for credit expansion. This abundant and cheap liquidity has meant that credit growth has outpaced deposit growth in recent years.

\section{Private Sector Credit in Percent of Deposits, CEE Countries}
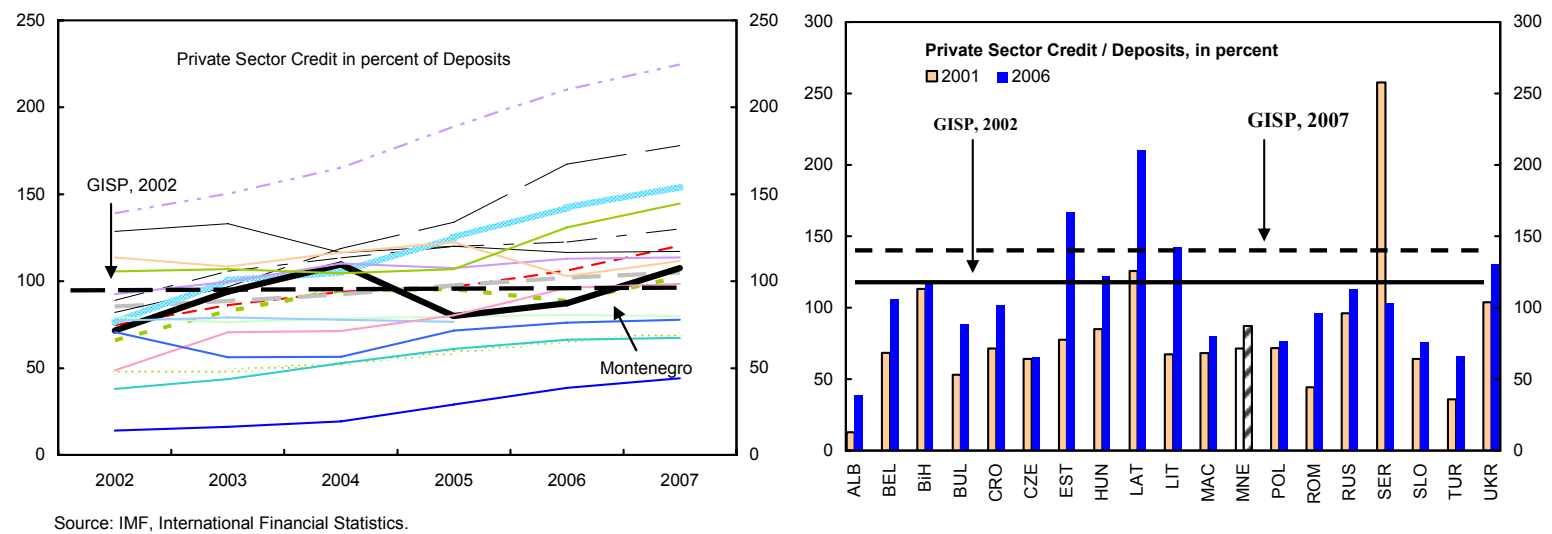

3. The decomposition of the PSCD distribution presents clear evidence of convergence. In the left panel, 75 percent of the distribution has been moving upward towards the GISP level, with an increased median, while the right panel indicates that the distance between the 2002 GISP level and the mean, top and bottom quintiles have been decreasing over time.

Private Sector Credit to Deposits Distribution for CEE Countries
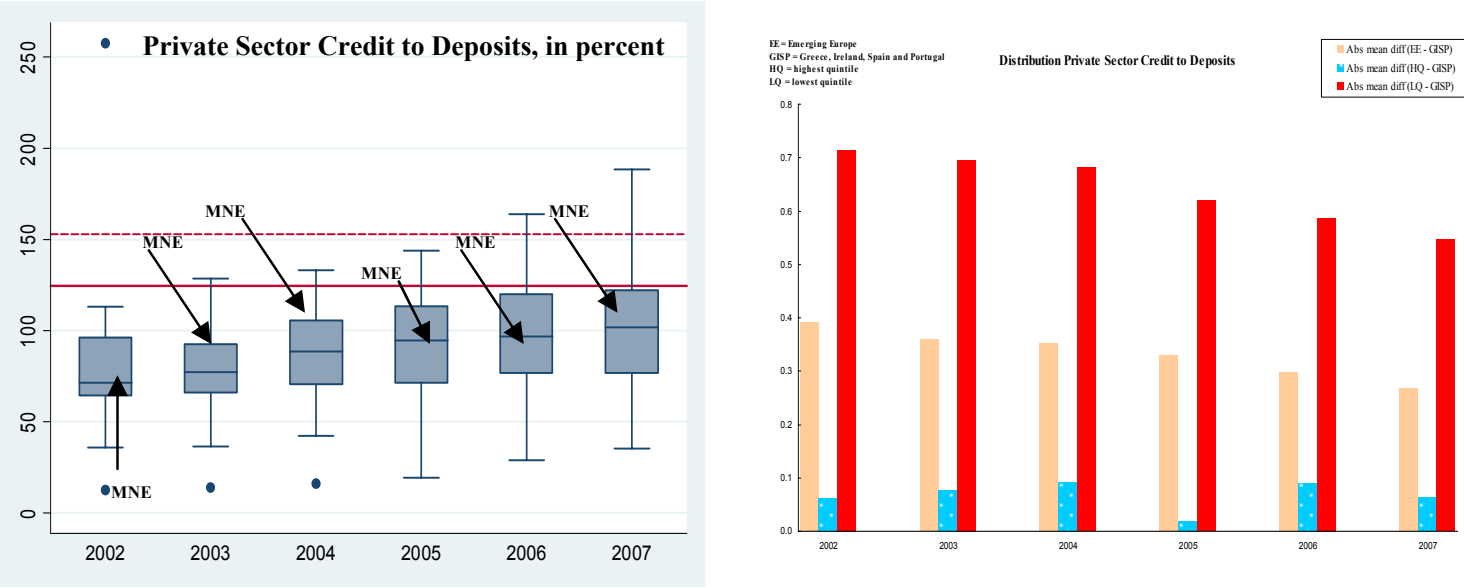
In this case, Montenegro has also been converging to GISP level. While both credit and deposits have continuously expanded in 2004-07, credit growth has recently started to outstrip deposit growth, with the increased ability of the banking system to obtain nondeposit sources of funding. This has led to a higher PSCD ratio, which is likely to grow in the future as well.

\section{The estimation of equation (1) confirms that PSCD has been converging to the} GISP level in 2002-07. The magnitude of the convergence coefficient for CEE is comparable to the GISP coefficient, signaling that CEE countries have been able to finance asset growth. While increased confidence in the banking sector and monetization of the economy have played a central role in providing local funding, including in Montenegro, the period from 2002 to 2007 has been characterized by benign global liquidity conditions in capital markets, which have helped finance the enormous asset growth in CEE countries.

\begin{tabular}{ccccc}
\multicolumn{5}{c}{ PSCD Fixed and Random Effects Panel Regression } \\
\hline \multirow{2}{*}{ PSCD } & \multicolumn{3}{c}{ CEE countries } & \multicolumn{2}{c}{ GISP countries } \\
\cline { 2 - 5 } & Fixed & Random & Fixed & Random \\
\hline \multirow{2}{*}{ BETA } & -0.033 & -0.001 & -0.002 & -0.001 \\
& $(-5.1)$ & $(-2.5)$ & $(-2.0)$ & $(-1.6)$ \\
CONST & -0.046 & 0.027 & 0.009 & 0.03 \\
& -1.7 & $(1.0)$ & $(0.5)$ & $(1.9)$ \\
& & & & \\
Obs & 95 & 95 & 20 & 20 \\
R-square & 0.3 & 0.3 & 0.2 & 0.6 \\
F-stats 1/ & 0.00 & 0.02 & 0.06 & 0.24 \\
t-stats in parenthesis & & & & \\
1/ p-values & & &
\end{tabular}

\section{FOSD and SOSD criteria indicate that convergence to the GISP level has been} almost uniform within CEE countries. The left panel points to a weak rejection of FOSD criterion, as FOSD does not hold for the top quintile of the distribution. The right panel is in accordance with SOSD, as the mean cumulative distance consistently decreases across the entire distribution. 
Convergence to GISP: Private Sector Credit in percent of Deposits
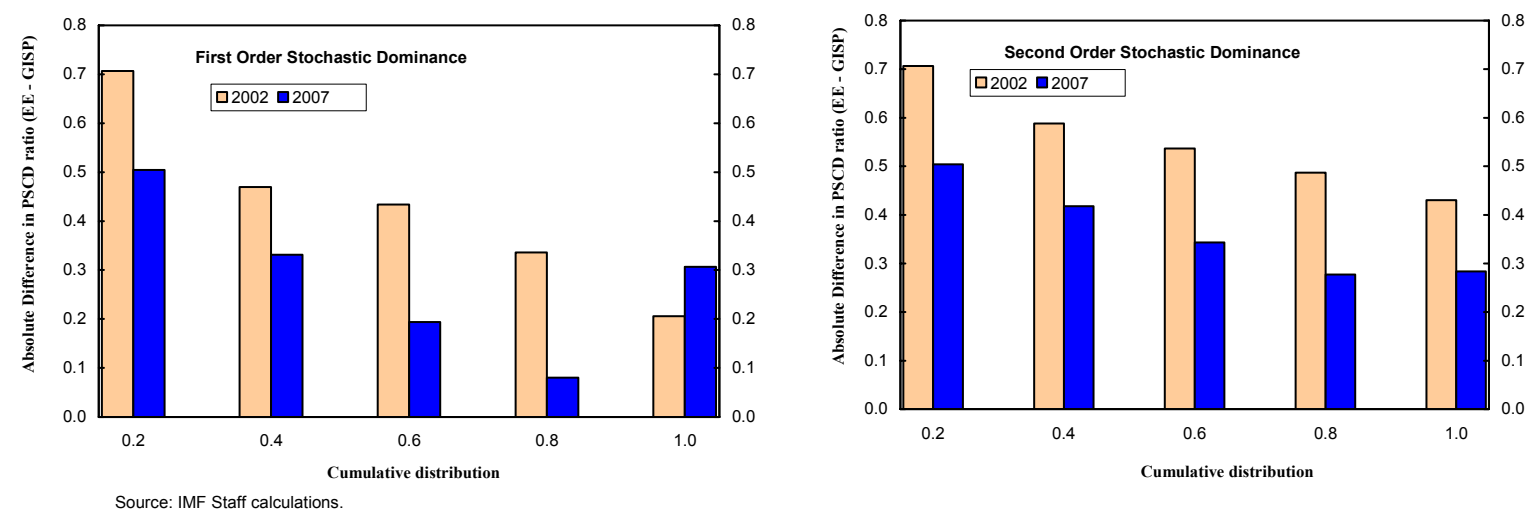

6. Montenegro's PSCD convergence to GISP level has been average, when compared to its peers (Table IV.A1) during 2004-2007 Q2. Montenegro has experienced both a rapid growth in credit and in deposits. This has essentially resulted from of a surge in asset sales along the coast. Increased foreign ownership of banks has also increased confidence in the banking sector and remonetization of the economy. More recently, this pattern has changed with deposit growth slowing down, and credit continuing to increase rapidly, financed by non-deposit funds.

Table IV.A1. Private Sector Credit to Deposits Ranking

\begin{tabular}{|c|c|c|c|c|}
\hline Country & $\begin{array}{c}\text { Distance from GISP } \\
20021 /\end{array}$ & $\begin{array}{c}\text { Distance from GISP } \\
20071 /\end{array}$ & Change & Rank 2/ \\
\hline Albania & 0.9 & 0.7 & -0.2 & 10 \\
\hline Belarus & 0.5 & 0.1 & -0.3 & 4 \\
\hline 'Bosnia and Herzegovina & 0.1 & 0.1 & 0.0 & 17 \\
\hline Bulgaria & 0.6 & 0.3 & -0.3 & 6 \\
\hline Croatia & 0.4 & 0.2 & -0.2 & 7 \\
\hline Czech Republic & 0.5 & 0.5 & 0.0 & 18 \\
\hline Estonia & 0.4 & 0.3 & 0.0 & 16 \\
\hline Hungary & 0.3 & 0.0 & -0.3 & 5 \\
\hline Latvia & 0.2 & 0.5 & 0.3 & 19 \\
\hline Lithuania & 0.5 & 0.1 & -0.3 & 3 \\
\hline Macedonia & 0.5 & 0.4 & -0.1 & 13 \\
\hline Montenegro 3/ & 0.4 & 0.2 & -0.2 & 9 \\
\hline Poland & 0.4 & 0.4 & 0.0 & 15 \\
\hline Romania & 0.6 & 0.2 & -0.4 & 2 \\
\hline Russia & 0.2 & 0.1 & -0.1 & 11 \\
\hline Serbia & 1.1 & 0.2 & -0.9 & 1 \\
\hline Slovak Republic & 0.5 & 0.4 & -0.1 & 14 \\
\hline Turkey & 0.7 & 0.5 & -0.2 & 8 \\
\hline Ukraine & 0.2 & 0.1 & -0.1 & 12 \\
\hline
\end{tabular}

1/ Absolute value of [PSCD(i) - 2002 GISP mean]/2002 GISPmean, for each country i

2/ According to the change in distance from GISP mean

3/ data for 2004-2007 Q2 


\section{CEE Foreign Liabilities in percent of Assets (FLA) do not seem to have been} converging to the GISP level (Figure IV.A2). Over time, the distance between the average FLA ratio and GISP level has not been consistently declining. While starting below the GISP level in 2002, CEE FLA has been increasing over time. With easy access to cheap parent bank liquidity, foreign financing has been a first-order contributor to CEE asset expansion. For Montenegro, the left panel shows that while it was below CEE average in 2002, FLA has increased, reaching the CEE average in 2007.

Figure IV.A2. Foreign Liabilities in percent of Assets, CEE Countries
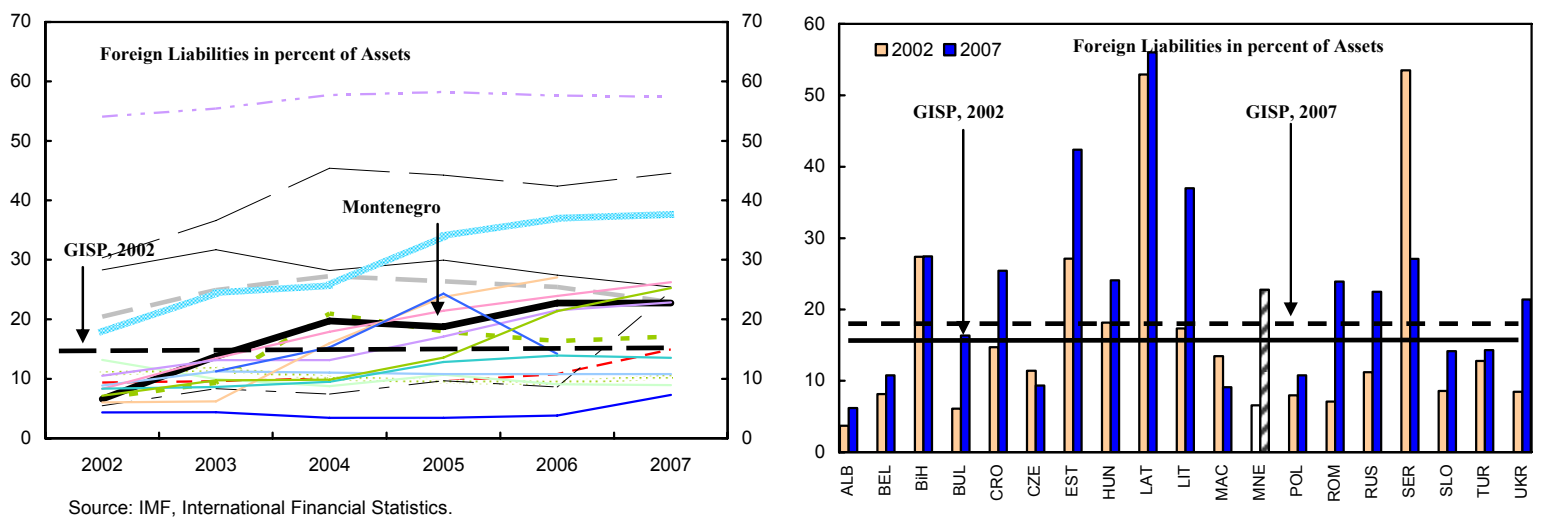

8. The decomposition of the distribution confirms that the FLA ratio has not been converging to the GISP level in 2002-07 (Figure IV.A3). The left panel highlights that Montenegro has become more similar to other CEE countries over the years, as FLA has been increasing. The right panel suggests that some convergence to GISP level may have occurred for the lowest quintiles of the distribution.

Figure IV.A3. Foreign Liabilities in Percent of Assets Distribution for CEE Countries

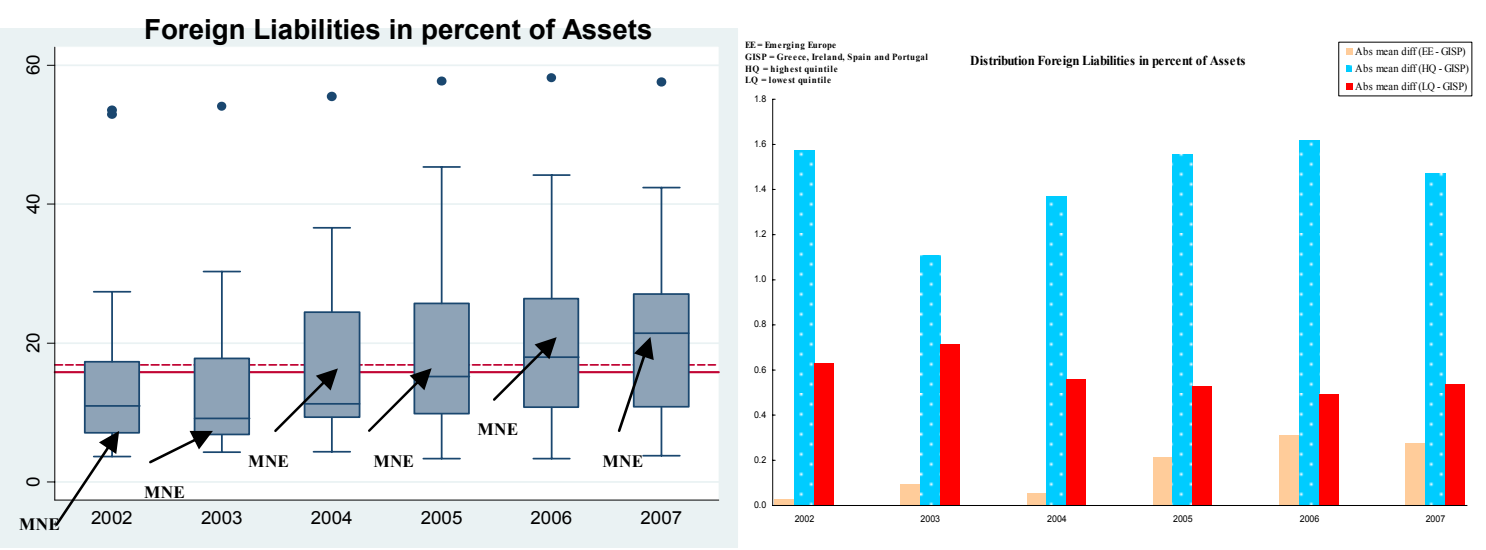

9. The coefficient estimates of equation (1) should be carefully interpreted, as they suggest some mis-specification. While the fixed effect (within estimator) panel regression indicates significant convergence to GISP level, this result is in contrast with the random effect model (between estimator) whose specification is actually rejected by the data. This 
difference in results points to a specification problem, at least for FLA ratio. GISP estimation delivers similar results.

\begin{tabular}{ccccc}
\multicolumn{5}{c}{ FLA Fixed and Random Effects Panel Regression } \\
\hline \multirow{2}{*}{ FLA } & \multicolumn{3}{c}{ CEE countries } & \multicolumn{2}{c}{ GISP countries } \\
\cline { 2 - 5 } BETA & Fixed & Random & Fixed & Random \\
& -0.031 & -0.001 & -0.027 & -0.003 \\
CONST & $(-6.3)$ & $(-0.5)$ & $(-2.5)$ & $(-0.4)$ \\
& 0.179 & 0.125 & -0.144 & 0.02 \\
& $(6.2)$ & $(4.4)$ & -1.9 & $(0.2)$ \\
Obs & & & & \\
R-square & 93 & 93 & 20 & 20 \\
F-stats 1/ & 0.4 & 0.1 & 0.3 & 0.1 \\
t-stats in parenthesis & 0.00 & 0.64 & 0.02 & 0.73 \\
1/ p-values & & & &
\end{tabular}

10. Stochastic dominance tests confirm that FLA has not been converging to the GISP level.

Convergence to GISP: Foreign Liabilities in percent of Assets
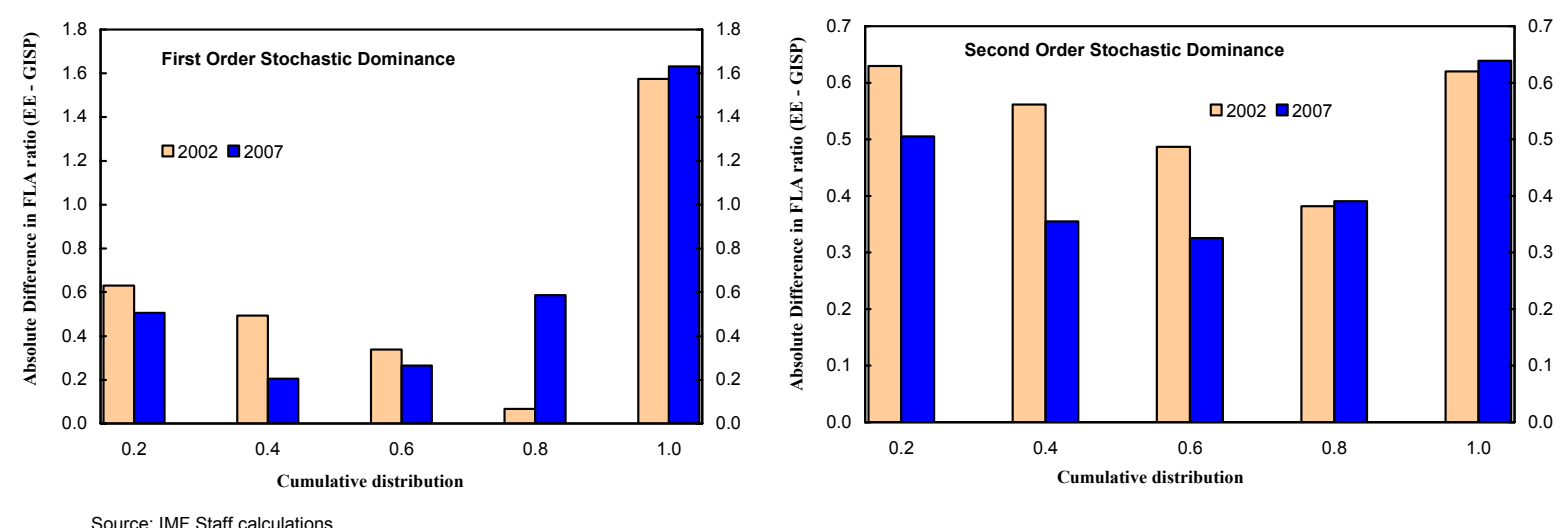

11. Montenegro's FLA ratio has been increasing over time, converging to its peers.

The sources of funding have been changing. When Montenegro opened up to foreign investors, foreign capital bought controlling stakes in several domestic banks. However, the bulk of banks balance sheet growth was financed by a surge in local deposits, resulting from asset sales along the coast and renewed trust in the banking system, coupled with remonetization and legalization of the grey economy. More recently, banks competing for market share have turned to the cheap parent bank liquidity to continue to finance credit expansion, with deposits growing at a lower pace. This resembles the developments observed in several other CEE countries, namely in the Baltic region. 
Foreign Liabilities to Assets Ranking

\begin{tabular}{lcccc}
\hline \multicolumn{1}{c}{ Country } & $\begin{array}{c}\text { Distance from GISP } \\
2002 \text { 1/ }\end{array}$ & $\begin{array}{c}\text { Distance from GISP } \\
2007 \text { 1/ }\end{array}$ & Change & Rank 2/ \\
\hline Albania & 0.8 & 0.8 & 0.0 & 11 \\
Belarus & 0.5 & 0.3 & -0.2 & 5 \\
Bosnia and Herzegovina & 0.8 & 0.8 & 0.0 & 12 \\
Bulgaria & 0.6 & 0.0 & -0.6 & 2 \\
Croatia & 0.1 & 0.6 & 0.6 & 17 \\
Czech Republic & 0.3 & 0.4 & 0.1 & 14 \\
Estonia & 0.7 & 1.7 & 1.0 & 18 \\
Hungary & 0.6 & 0.4 & -0.1 & 6 \\
Latvia & 2.4 & 2.7 & 0.3 & 16 \\
Lithuania & 0.1 & 1.4 & 1.3 & 19 \\
Macedonia & 0.1 & 0.4 & 0.3 & 15 \\
Montenegro 3/ & $\mathbf{0 . 6}$ & $\mathbf{0 . 5}$ & -0.1 & $\mathbf{7}$ \\
Poland & 0.5 & 0.3 & -0.2 & 4 \\
Romania & 0.5 & 0.5 & 0.0 & 10 \\
Russia & 0.3 & 0.4 & 0.1 & 13 \\
Serbia & 2.4 & 0.7 & -1.7 & 1 \\
Slovak Republic & 0.4 & 0.1 & -0.4 & 3 \\
Turkey & 0.2 & 0.1 & -0.1 & 9 \\
Ukraine & 0.5 & 0.4 & -0.1 & 8 \\
& & & & \\
\hline 1/ Absolute value of [FLA(i) -2002 GISP mean]/2002 GISPmean, for each country i & \\
2/ According to the change in distance from GISP mean & & & \\
3/ data for 2004-2007 Q2 & & & & \\
& & & & \\
& & & & \\
\end{tabular}

\section{CEE ROA has been increasing in 2002-07, exceeding the GISP level}

(Figure IV.A4). The profitability of the CEE banking system has been rapidly increasing in 2002-07. High margins coupled with fast financial deepening in many countries have attracted foreign interest in the banking sector. Montenegro has been one of the latest targets, and its profitability is starting to reach levels comparable to those of its peers.

Figure IV.A4. Return on Assets, CEE countries
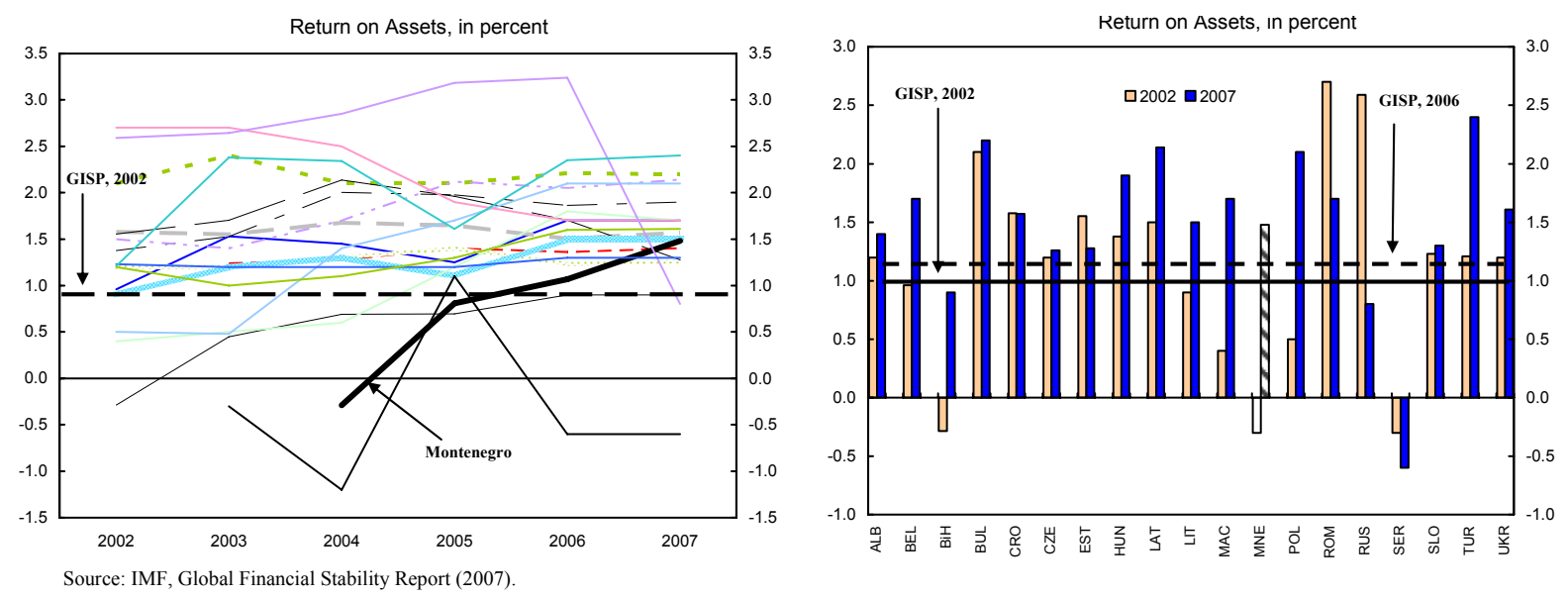
13. ROA has increased in all CEE countries, during 2002-07, including Montenegro (Figure IV.A5). The left panel suggests that the CEE ROA level has been increasing without converging to GISP level. This is confirmed in the right panel where the distance between CEE ROA distribution and GISP level has volatile. Montenegro's ROA has constantly increased in 2005-07, turning positive. Profitability has been driven by high margins coupled with increased credit demand and financial deepening. Increased competition for market shares will continue to deliver tough price competition and should generate some efficiency gains.

Figure IV.A5. Return on Assets Distribution for CEE Countries

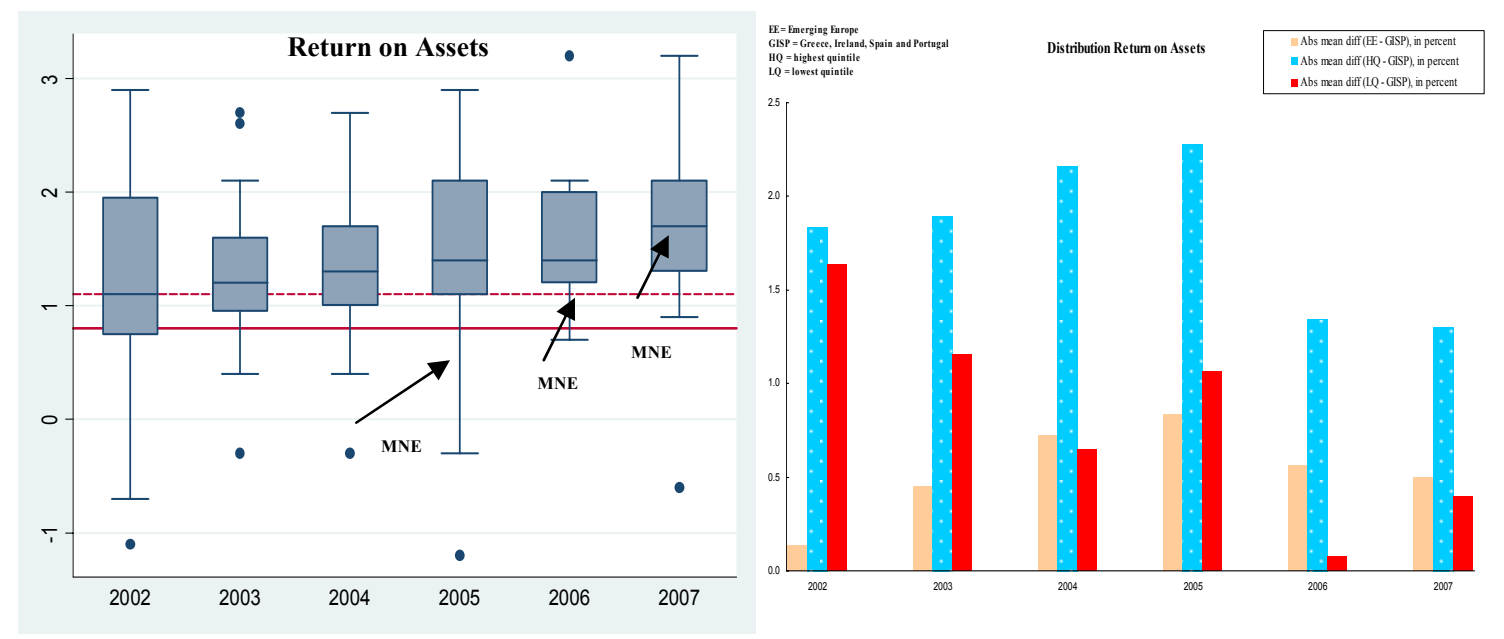

14. The estimation of equation (1) confirms the graphical analysis and the distribution decomposition: ROA has not been converging to the GISP level (Table IV.A2). As higher profitability is mainly reflecting fat intermediation margins, the evidence suggests that financial deepening is likely to continue in the future. Growing competition driven by foreign capital in the search for profitable returns should drive margins down, leading ROA to converge to GISP and EU levels. This should also be the case for Montenegro. 
Table IV.A2. ROA Fixed and Random Effects Panel Regression

\begin{tabular}{ccccc}
\hline \multirow{2}{*}{ ROA } & \multicolumn{2}{c}{ CEE countries } & \multicolumn{2}{c}{ GISP countries } \\
\cline { 2 - 5 } & Fixed & Random & Fixed & Random \\
\cline { 3 - 5 } BETA & 0.577 & 0.247 & -1.848 & -0.611 \\
& $(2.4)$ & $(1.9)$ & $(-3.1)$ & $(-1.5)$ \\
CONST & -0.311 & -0.191 & 0.568 & 0.258 \\
& $(-2.1)$ & $(-1.7)$ & $(3.2)$ & $(2.2)$ \\
& & & & \\
Obs & 87 & 87 & 20 & 0.5 \\
R-square & 0.1 & 0.2 & 0.4 & 0.27 \\
F-stats 1/ & 0.02 & 0.07 & 0.00 & \\
t-stats in parenthesis & & & \\
1/ p-values & & & &
\end{tabular}

15. Tests of stochastic dominance confirm the previous analysis (Figure IV.A6). The left panel indicates that we should reject convergence according to the FOSD criterion, at least for the central part of the ROA distribution.

Figure IV.A6. Convergence to GISP: Return on Assets
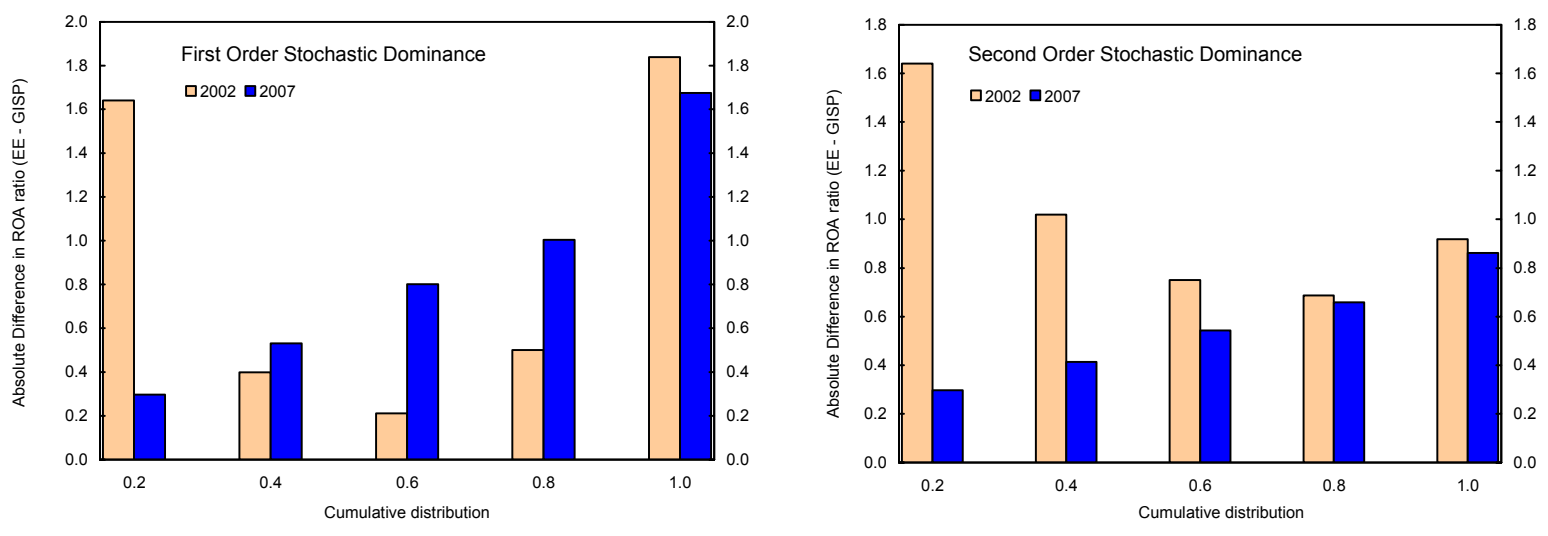

Source: IMF Staff calculations.

16. Montenegro's ROA has been rapidly increasing in 2004-07, making it the second fastest converging to the GISP level (Table IV.A3). Montenegro's growth potential, open banking sector and relatively underdeveloped financial system, have made it an attractive target for foreign investors. This has led to considerable financial deepening and credit expansion, with decreasing intermediation costs. 
Table IV.A3. Return to Assets Ranking

\begin{tabular}{|c|c|c|c|c|}
\hline Country & $\begin{array}{c}\text { Distance from GISP } \\
20021 /\end{array}$ & $\begin{array}{c}\text { Distance from GISP } \\
20071 /\end{array}$ & Change & Rank 2/ \\
\hline Albania & 0.3 & 0.5 & 0.2 & 9 \\
\hline Belarus & 0.2 & 0.8 & 0.7 & 16 \\
\hline Bosnia and Herzegovina & 2.2 & 0.0 & -2.1 & 1 \\
\hline Bulgaria & 2.1 & 1.4 & -0.7 & 6 \\
\hline Croatia & 0.0 & 0.6 & 0.6 & 14 \\
\hline Czech Republic & 0.2 & 0.3 & 0.1 & 8 \\
\hline Estonia & 1.9 & 0.8 & -1.0 & 3 \\
\hline Hungary & 0.4 & 1.0 & 0.6 & 15 \\
\hline Latvia & 0.6 & 1.2 & 0.6 & 13 \\
\hline Lithuania & 1.2 & 0.6 & -0.6 & 7 \\
\hline Macedonia & 1.8 & 0.9 & -0.8 & 5 \\
\hline Montenegro $3 /$ & 1.3 & 0.2 & -1.1 & 2 \\
\hline Poland & 0.1 & 1.3 & 1.2 & 18 \\
\hline Romania & 1.7 & 0.8 & -0.9 & 4 \\
\hline Russia & 1.6 & 2.5 & 0.9 & 17 \\
\hline Serbia & 1.3 & 1.6 & 0.3 & 11 \\
\hline Slovak Republic & 0.1 & 0.4 & 0.3 & 10 \\
\hline Turkey & 0.3 & 1.5 & 1.2 & 19 \\
\hline Ukraine & 0.3 & 0.7 & 0.4 & 12 \\
\hline
\end{tabular}

1/ Absolute value of [ROA(i) - 2002 GISP mean]/2002 GISPmean, for each country $i$

2/ According to the change in distance from GISP mean

3/ data for 2004-07

17. ROE has been increasing in CEE, without showing a strong convergence pattern to the GISP level in 2002-07 (Figure IV.A7). Both profitability and equity capital have generally increased in 2002-07. While profitability reflects high intermediation margins, equity has augmented to allow a very rapid expansion of balance sheets. Montenegro ROE started out low in 2004, but has been gradually increasing since.

Figure IV.A7. Return on Equity, CEE Countries
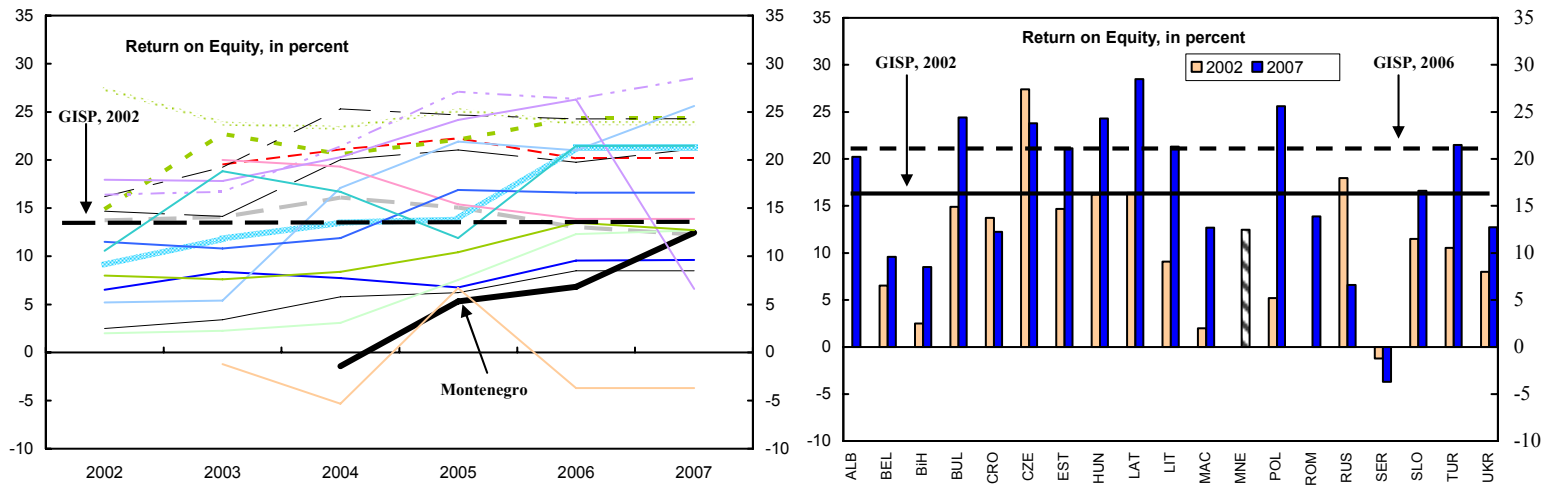

Source: IMF, Global Financial Stability Report (2007). 
18. The decomposition of ROE distribution shows an uneven pattern, with some convergence to GISP level for parts of the CEE distribution (Figure IV.A8). While increasing, Montenegro ROE remains well below CEE average in 2007.

Figure IV.A8. Return on Equity Distribution for CEE Countries
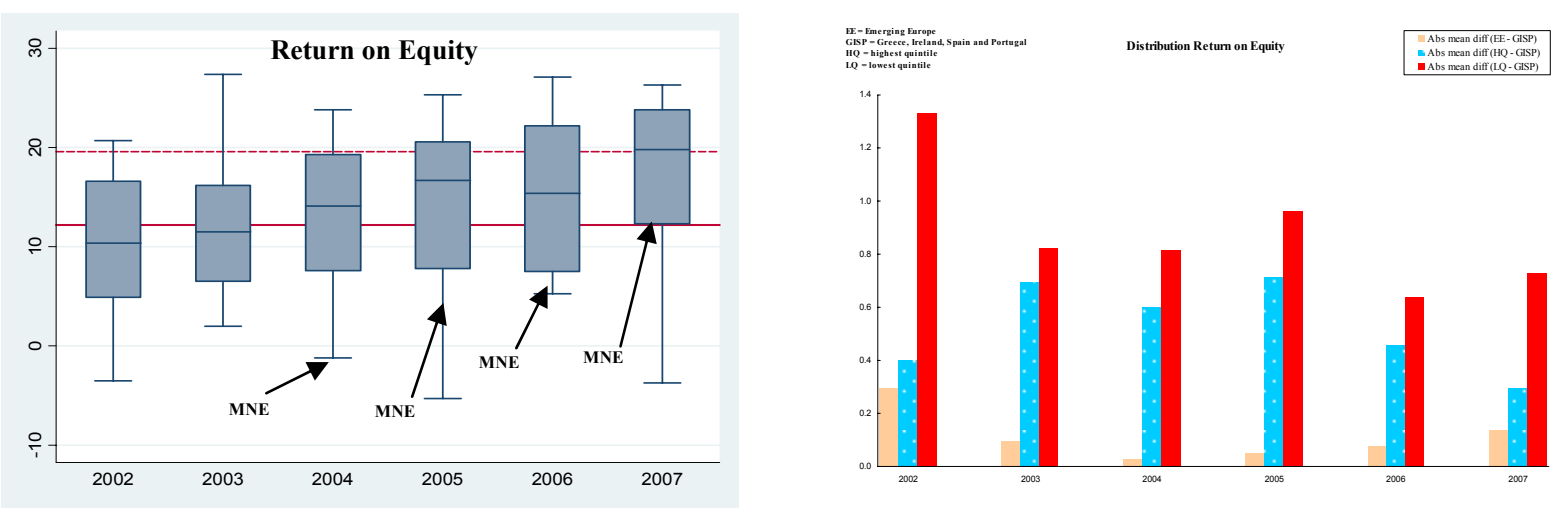

19. An estimation of the beta coefficient in equation (1) does not indicate convergence in ROE (Table IV.A4). While these results seems consistent with the graphical evidence on CEE countries, there are possible specification problems when applied to GISP countries, as GISP ROE has been converging to EU levels (Figure IV.3).

Table IV.A4. ROE Fixed and Random Effects Panel Regression

\begin{tabular}{ccccc}
\hline \multirow{2}{*}{ ROE } & \multicolumn{2}{c}{ CEE countries } & \multicolumn{2}{c}{ GISP countries } \\
\cline { 2 - 5 } & Fixed & Random & & Random \\
\hline \multirow{2}{*}{ BETA } & 0.065 & 0.031 & -0.078 & -0.031 \\
& $(1.9)$ & $(1.7)$ & $(-1.7)$ & $(-1.4)$ \\
CONST & 0.053 & -0.043 & 0.151 & 0.145 \\
& $(0.4)$ & $(-0.3)$ & $(1.4)$ & $(2.3)$ \\
& & & & 19 \\
Obs & 85 & 85 & 19 & 0.5 \\
R-square & 0.1 & 0.1 & 0.2 & 0.31 \\
F-stats 1/ & 0.05 & 0.11 & 0.11 & \\
t-stats in parenthesis & & & \\
1/ p-values & & & & \\
\end{tabular}

20. Tests of stochastic dominance are consistent with the graphical analysis, suggesting a partial convergence of ROE (Figure IV.A9). The FOSD test indicates that some convergence might have occurred for the low quintiles of the distribution, but not for the higher quintiles. 
Figure IV.A9. Convergence to GISP: Return on Equity
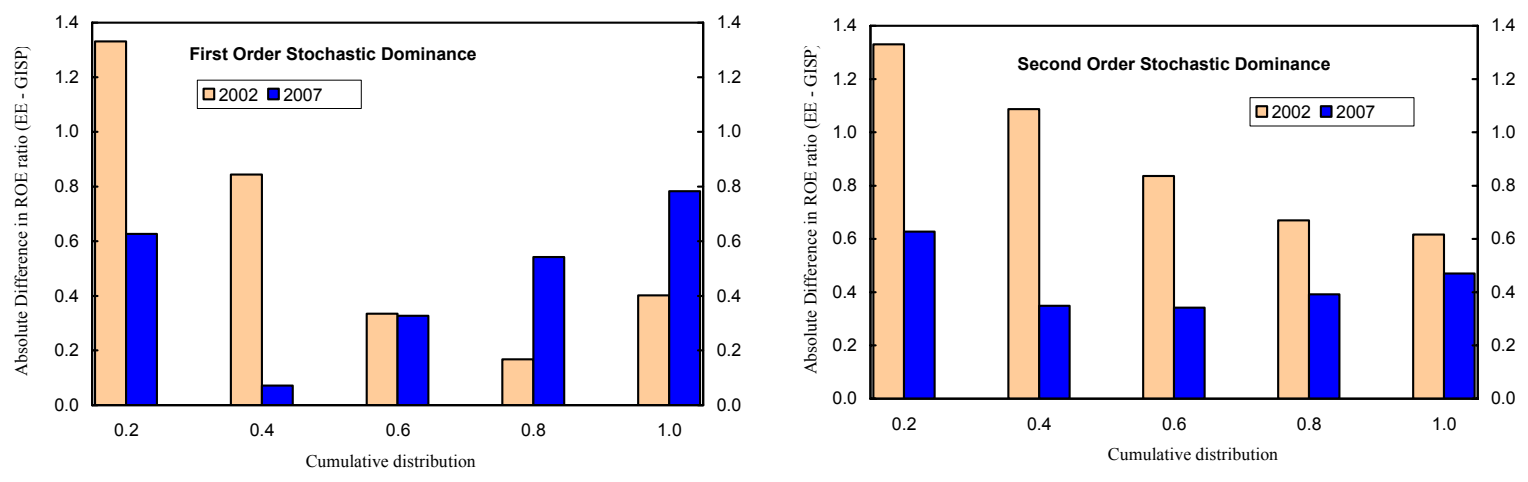

Source: IMF Staff calculations.

21. Among CEE countries, Montenegro's convergence has been pronounced,

Table IV.A5. Montenegro's ROE remains too low and an increase in profitability, possibly through efficiency gains is needed.

Table IV.A5. Return to Equity Ranking

\begin{tabular}{lcccc}
\hline \multicolumn{1}{c}{ Country } & $\begin{array}{c}\text { Distance from GISP } \\
\mathbf{2 0 0 2} \mathbf{~ 1 /}\end{array}$ & $\begin{array}{c}\text { Distance from GISP } \\
\mathbf{2 0 0 7} \mathbf{~ / /}\end{array}$ & Change & Rank 2/ \\
\hline Albania & 0.4 & 0.4 & 0.0 & 12 \\
Belarus & 0.7 & 0.3 & -0.3 & 9 \\
Bosnia and Herzegovina & 1.2 & 0.4 & -0.8 & 3 \\
Bulgaria & 0.0 & 0.7 & 0.7 & 19 \\
Croatia & 0.5 & 0.1 & -0.5 & 6 \\
Czech Republic & 0.2 & 0.7 & 0.5 & 16 \\
Estonia & 0.5 & 0.4 & -0.1 & 11 \\
Hungary & 0.1 & 0.7 & 0.6 & 18 \\
Latvia & 0.3 & 0.9 & 0.5 & 17 \\
Lithuania & 1.1 & 0.5 & -0.6 & 4 \\
Macedonia & 1.2 & 0.1 & -1.1 & 2 \\
Montenegro 3/ & $\mathbf{1 . 1}$ & $\mathbf{0 . 5}$ & $\mathbf{0 . 6}$ & $\mathbf{5}$ \\
Poland & 0.1 & 0.5 & 0.4 & 14 \\
Romania & 0.4 & 0.0 & -0.4 & 8 \\
Russia & 0.4 & 0.9 & 0.5 & 15 \\
Serbia & 1.1 & 1.3 & 0.2 & 13 \\
Slovak Republic & 0.4 & 0.2 & -0.3 & 10 \\
Turkey & 1.7 & 0.5 & -1.2 & 1 \\
Ukraine & 0.5 & 0.0 & -0.4 & 7 \\
& & & & \\
\hline
\end{tabular}

1/ Absolute value of [ROE(i) - 2002 GISP mean]/2002 GISPmean, for each country i

$2 /$ According to the change in distance from GISP mean

3/ data for 2004-07 
22. Interest rate spreads (lending minus deposit rate) indicates a convergence pattern for CEE countries in 2002-07 (Figure IV.A10). Increased competition in the banking sector, often resulting from foreign banks entering local markets, has led to a reduction of spreads. This is a positive development for CEE countries that foster financial deepening by facilitating access to credit. Furthermore, it points to increased efficiency in channeling savings to investment opportunities.

Figure IV.A10. Lending Minus Deposit Rate, CEE Countries
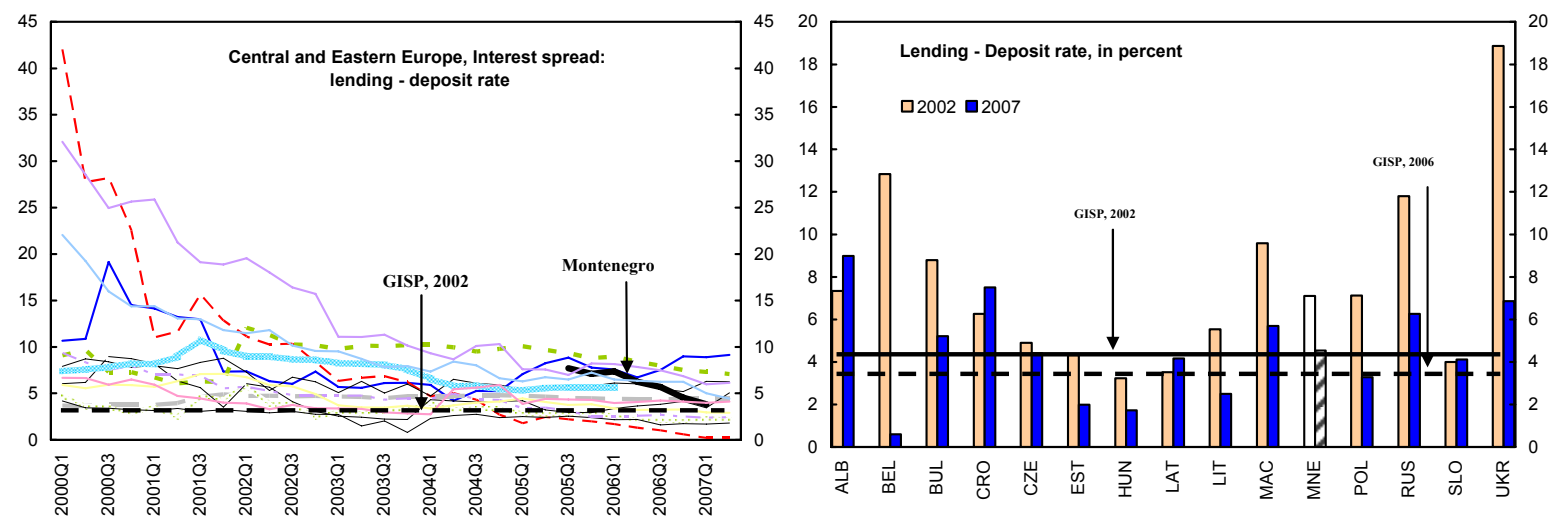

Source: IMF, International Financial Statistics.

23. The decomposition of the CEE distribution highlights a somewhat homogeneous convergence of CEE spread towards GISP level. In the left panel, Montenegro appears to have been converging quite rapidly to the GISP level, while the right panel suggests that convergence is underway at both extremes of the distribution.

Interest Rate Spread Distribution for CEE Countries
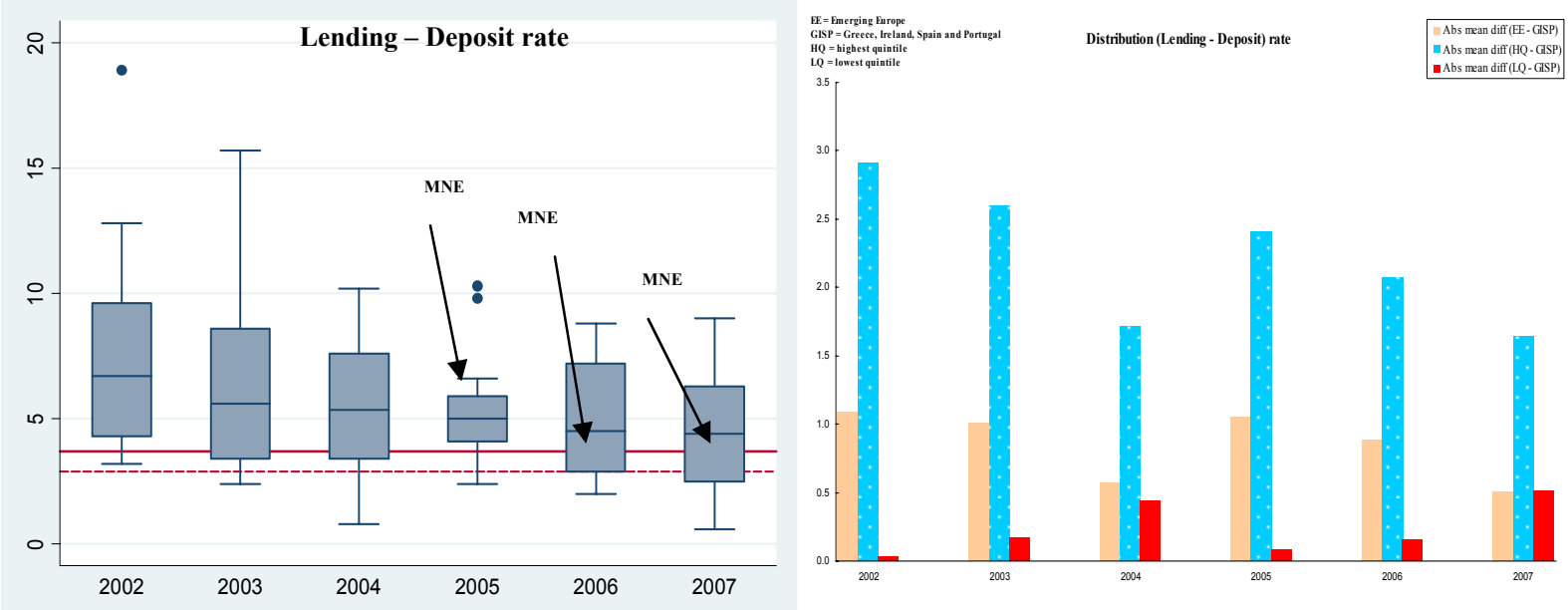


\section{The estimated beta coefficient in equation (1) is not conclusive, but evidence}

points to some convergence (Table IV.A6). Results do not exclude convergence, but some contradictory evidence across different specifications (fixed and random effects) is suggestive of potential specification problems. Considering the graphical analysis favoring convergence, the panel regression does provide some supporting evidence for convergence.

Table IV.A6. IR Fixed and Random Effects Panel Regression

\begin{tabular}{ccccc}
\hline \multirow{2}{*}{ IR } & \multicolumn{2}{c}{ CEE countries } & \multicolumn{2}{c}{ GISP countries } \\
\cline { 2 - 5 } & Fixed & Random & Fixed & Random \\
\hline BETA & -0.049 & -0.022 & n.a. & n.a. \\
& $(-2.0)$ & $(-1.4)$ & & \\
CONST & 0.056 & -0.021 & n.a. & n.a. \\
& $(0.8)$ & $(-0.4)$ & & \\
Obs & & & & \\
R-square & 0.1 & 71 & & \\
F-stats 1/ & 0.05 & 0.1 & & \\
t-stats in parenthesis & 0.17 & & \\
1/ p-values & & & & \\
\end{tabular}

\section{Convergence is essentially confirmed by tests of stochastic dominance}

(Figure IV.A11). The distance between the distribution of CEE countries and GISP level has been decreasing over time, and uniformly across the distribution. A slightly different pattern is signaled for the lowest quintile of the distribution.

Figure IV.A11. Convergence to GISP: Interest Rate Spread
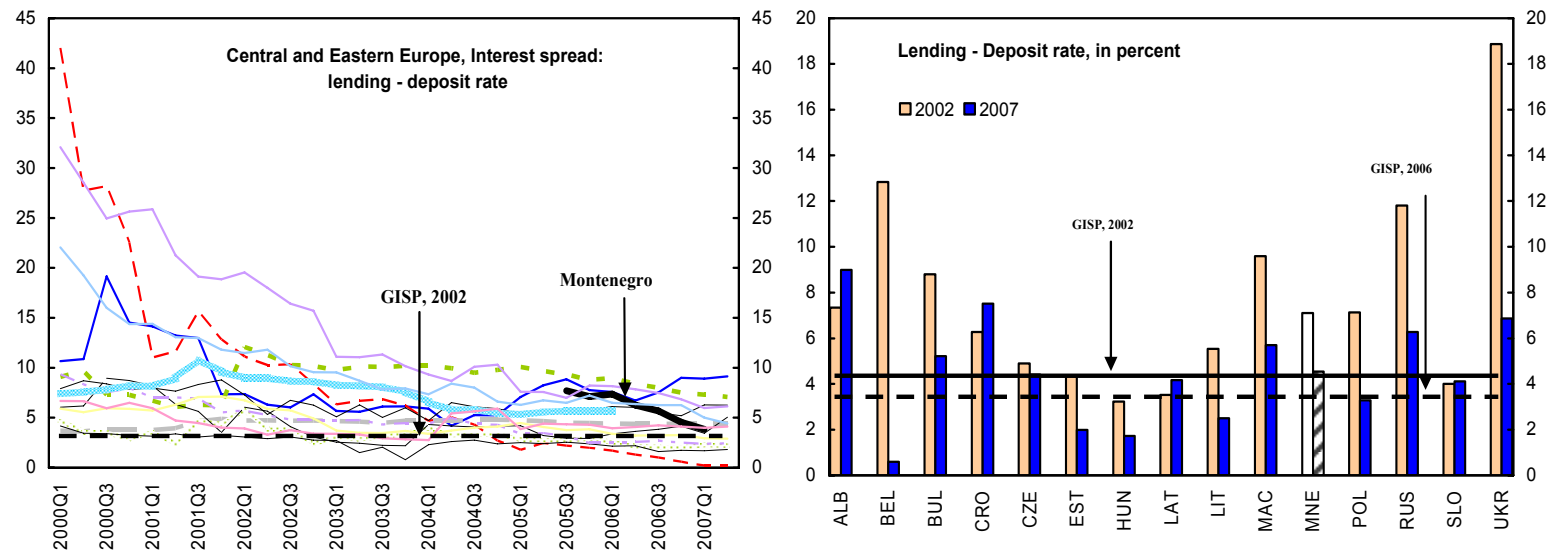


\section{Montenegro convergence pattern is so far comparable to those experienced by}

its peers (Table IV.A7). While limited information does not allow a deep comparison, Montenegro's interest spread has been rapidly converging towards the GISP level, signaling healthy competition in the banking sector and easier access to credit.

\begin{tabular}{lcccc}
\multicolumn{5}{c}{ Table IV.A7. Interest Rate Spread Ranking } \\
\hline \multicolumn{1}{c}{ Country } & $\begin{array}{c}\text { Distance from GISP } \\
\text { 2002 1/ }\end{array}$ & $\begin{array}{c}\text { Distance from GISP } \\
\mathbf{2 0 0 7} \mathbf{~ 1 /}\end{array}$ & Change & Rank 2/ \\
\hline Albania & 1.0 & 2.3 & 1.4 & 15 \\
Belarus & 2.5 & 0.8 & -1.7 & 2 \\
Bulgaria & 1.4 & 0.9 & -0.4 & 6 \\
Croatia & 0.7 & 1.8 & 1.1 & 14 \\
Czech Republic & 0.3 & 0.6 & 0.3 & 11 \\
Estonia & 0.2 & 0.3 & 0.1 & 9 \\
Hungary & 0.1 & 0.4 & 0.2 & 10 \\
Latvia & 0.0 & 0.5 & 0.5 & 13 \\
Lithuania & 0.5 & 0.1 & -0.4 & 7 \\
Macedonia & 1.6 & 1.0 & -0.6 & 5 \\
Montenegro 3/ & $\mathbf{0 . 9}$ & $\mathbf{0 . 7}$ & $\mathbf{0 . 2}$ & $\mathbf{8}$ \\
Poland & 0.9 & 0.2 & -0.7 & 4 \\
Russia & 2.2 & 1.3 & -0.8 & 3 \\
Slovak Republic & 0.1 & 0.5 & 0.5 & 12 \\
Ukraine & 4.1 & 1.6 & -2.5 & 1 \\
& & & & \\
\hline 1/ Absolute value of [IR(i) - 2002 GISP mean]/2002 GISPmean, for each country i & \\
2/ According to the change in distance from GISP mean & & \\
3/ data for 2005-2007 & & &
\end{tabular}




\section{Appendix IV.2. Policy Responses to Capital Inflows in Selected European Countries}

\section{Selected European Countries: Policy Responses to the Capital Inflows}

\begin{abstract}
Policy Responses
. Financial sector reforms (legal and institutional framework for foreign investment made EU compatible, and strengthening the prudential and supervisory framework.

. Appropriate information systems for financial flows integrating all foreign investments, statistical tools to gather information on cross-border financial flows, and reporting requirements on financial institutions, legal entities, and physical persons.
\end{abstract}

. Liberalization of FX and capital account regime from 2000 and acceleration of trade liberalization from 1997. . Credible and consistent macroeconomic policy mix (including transparent monetary policy based on CBA). . Supervisory, monetary, and administrative measures to slow down the pace of rapid credit growth financed largely by inflows intermediated by the banking system (e.g., raising the level and broadening the coverage of reserve requirements to liabilities previously exempted; further tightening of prudential and supervisory regulations; moral suasion to convince banks to reduce credit growth; credit controls in the form of a nonremunerated reserve requirement on excessive credit

growth) (2004-06).

. Debt management measures: The authorities shifted from

foreign to domestic borrowing sources; bought back outstanding Brady discount bonds; government deposits were transferred to the central bank; and the Deposit Insurance Fund was instructed to invest its cash balances and maturing repos in government debt to deal with the liquidity impact of inflows.
Bulgaria (1997-2006)

Impact

. These measures helped in managing the capital flows, including by increasing the financial system's absorption capacity of the inflows. In particular, it provided greater freedom to banks in managing their open foreign currency positions, including those associated with capital flows, while obligating them to develop internal risk management systems in line with best international practices.

. May have helped somewhat reduce net FX inflows into the domestic economy.

. Helped limit potential adverse consequences of increased inflows.

. These measures were taken not to limit capital inflows per se, but to deal with their implications through expansion of credit funded by such inflows. Overall, moral suasion was ineffective (given the dominance of foreign banks operating under home country regulations); tighter reserve requirements mainly served as a warning; while the supervisory, administrative measures helped slow credit growth, they also resulted in some disintermediation and circumvention efforts that transferred some of the activity to potentially riskier funding of borrowers; the latter required in turn a widening of the scope of the measures and efforts to strengthen nonbank financial sector supervision. . Helped deal with the liquidity impact of the inflows.

Croatia (1993-2006)

\section{Policy Responses}

\section{. Limited scale sterilization initially through reserve}

requirements and 'obligatory' $C B$ bills (remunerated at above deposit rates but below standard $\mathrm{CB}$ bill rates), later through foreign currency denominated CB bills (at market rates).

. FX market liberalization in 2001, including by allowing banks full access to the FX market (including to hold foreign currency in their accounts, and not only when justified by

import needs as previously) and extension of surrender requirement period for conversion of $\mathrm{FX}$ receipts of the corporate sector.

. Introduction of Chilean type of controls in early 1998, in the form of a requirement to deposit (in kuna) 30 percent of the shortterm credits from abroad and 5 percent of longer-term

credits at the CB for all financial credits taken for conversion into domestic currency; a requirement to deposit (in kuna) 10 percent of the guarantees on credits for conversion into kunas; and a requirement to deposit 15 percent of foreign

\section{Sterilization efforts have been thwarted by a high degree of}

euroization preventing effective development of monetary policy instruments; obligatory CB bills were introduced, because standard bills did not attract enough liquidity.

. The measures have helped i) better manage corporate FX risks (by enabling companies to freely decide on the currency composition of their portfolio holdings); ii) deepen and broaden

the relatively shallow foreign exchange market (in turn facilitating better management by all market participants of the risks associated with capital flows), iii) improve financial intermediation of the capital inflows (together with the efforts to

strengthen the banking system following the banking crisis of 1998-2000, including through opening the sector to foreign capital and strengthening its supervision and regulation).

. Initially, the controls were instrumental in decreasing the share of short-term inflows; controls on longer term financial credits and deposits were abolished soon (in late 1998 following

international market turbulences). 
exchange deposits of foreign banks (in kuna) in a separate account with the $\mathrm{CB}$.

. Debt management measures: The authorities shifted from foreign to domestic borrowing sources.

. Fiscal adjustment and a mix of prudential, supervisory, and administrative measures to reduce capital inflows, with a view to limiting the accumulation of external debt and expansion of credit, where the exchange rate stability objective and high euroization of the economy limited the capacity to use traditional monetary instruments:

\section{. (Unremunerated) marginal reserve requirement (MRR)}

on banks' new foreign borrowing (7/2004) to slowdown bankrelated portion of capital inflows that has funded much of the bank credit expansion; the rate was increased several times (to 55 percent currently) and the base was broadened in 2005 (e.g., to include banks' guarantees to companies/individuals who directly borrow from abroad, and deposits received by banks from leasing companies not related to them, and to introduce a special reserve requirement of 55 percent for issued securities for $F X$ related liabilities); the MRR is in addition to the overall reserve requirement (RR) of 17 percent on banks' $F X$ and kuna liabilities (domestically and from abroad);

. Moral suasion: the HNB warned banks on a few occasions that it would relax or tighten some of its instruments depending on their foreign borrowing, and issued guidelines for management of currency induced risks and credit risk from household lending;

. Supervisory and administrative measures to slow down the pace of rapid credit growth financed largely by bank borrowing from abroad (e.g., further tightening of the prudential and supervisory framework; raising risk weights on unhedged FX linked borrowing; reporting requirements for unhedged FX loans; FX liquidity requirements and broadening of their base to include FX-indexed as well as FX-denominated instruments; and credit controls in the form of obligatory purchases of low yielding HNB bills for banks extending excessive credit in 2003 and end-2006).
. Helped cope with the implications of the inflows on the liquidity of the financial system.

. The prudential, supervisory, and administrative measures (including reserve requirements on bank borrowing) as a whole aimed at dealing with the external and financial sector vulnerability implications of the inflows, and have not so far had a significant impact on bank borrowing or credit growth. . The preliminary indications suggest that banks are unwilling to raise their lending rates to offset the rising cost of lending imposed by these measures so as to keep their market shares. .While the MRR on banks' external borrowing seems to have resulted in some scaling down of their borrowing plans after the rate was raised to 55 percent, an upturn in borrowing has already been observed, reportedly to comply with the broadening of the FX liquidity requirements from late 2006 . Banks also evidently seek other ways to overcome the regulations (e.g., by financing activity through retained earnings, injection of capital by, or directing clients to, parent banks, intensifying efforts to attract domestic deposits, etc). . Moral suasion has had limited effectiveness given the significant share of foreign banks in the system.

. FX linked lending seems to have slowed down somewhat recently, reflecting the change in the 32 percent liquidity requirement (to broaden its base) as well as higher risk weights for FX lending to unhedged customers.

. Banks' circumvention efforts led to several attempts by the HNB to close loopholes by widening the scope of the existing regulations; a unified nonbank supervisory agency was also established to strengthen nonbank supervision and thereby limiting the room for circumvention by switching to borrowing from nonbank financial institutions.

\begin{tabular}{|l}
\hline \\
Policy Responses
\end{tabular} Czech Republic

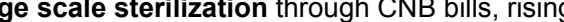

unremunerated reserve requirements (1994-1997), and automatic conversion of government privatization revenues at the CNB.

\section{. Liberalization of capital outflows (1995).}

. Administrative measures, such as limits on short-term open positions with nonresidents and margin fees on FX transactions with the CNB (1995).

. Greater exchange rate flexibility through a widening of the exchange rate band (from 0.5 to 7.5 percent) in early 1996 followed by a forced exit to a floating regime.

. Interest rate cuts, occasional interventions, and set up of a

government account at the CNB for conversion of privati-zation proceeds under free float and IT regime after 1998.

Estonia (mainly since 2000)

\section{Policy Responses}

In responding to the inflows and credit growth financed by them,. capital or credit controls have been ruled out, given the desire to avoid policy reversals and inconsistencies with the EU directive, they were not expected to have an impact in a system dominated by large conglomerates and foreign banks. CBA ruled out an
Impact

.Was moderately effective in providing some monetary policy

autonomy under the pegged exchange rate in short-term, but involved substantial quasi-fiscal and real costs. Overall they were not helpful in preventing a slower disinflation process.

. Arguably helped reduce net inflows. . Had only a limited effect in extending the maturity of the inflows, as they were easily circumvented.

. Temporarily successful in reversing short-term flows in 1996, providing a greater room for monetary policy maneuvering by introducing a degree of exchange rate variability.

. Helped reduce the appreciation pressure that was feeding into undershooting of inflation targets (especially after the 2001-0 2 appreciation episode). 
independent interest rate policy. The scope for tighter prudential limits was also limited by the risk of disintermediation.

. Monetary measures took the form of: delays in the relaxation of the reserve requirement to the Euro area levels, and including foreign liabilities in the reserve base on gross basis while abolishing vault-cash deductibility from the base.

. Fiscal measures: tightening fiscal policy further has been difficult; the authorities attempted to reduce borrowing incentives by limiting mortgage interest rate deductibility that encourages real estate related borrowing.

. Prudential and supervisory measures: Given the limited monetary tools available and difficulty to influence foreign bank behavior, the authorities' supervisory effort has been focused on risks from rapid credit growth, particularly in the real estate sector. Measures included: maintaining the higher capital adequacy requirement; increasing risk weightings of mortgage loans from 50 percent to 100 percent (March 2006); promoting better understanding of risks associated with excessive credit growth (hence to reduce lending and borrowing exuberance), especially in the mortgage loan market; and enhancing cooperation between home/host supervisors.

. Communication or "moral suasion" tools: the BoE recommended that the government abolish certain tax relief and guarantee schemes in the mortgage market so as not to interfere in market developments; "moral suasion" letters were sent to banks, their Scandinavian owners, and to respective regional supervisory authorities.
- Capital inflows and rapid credit growth has continued with a peak in the annual growth in real sector credit at more than $50 \%$ at the end of 2005 . The measures in the last four years have not yet had any visible impact to slow down credit growth.

- Government reluctance to make unpopular decisions to abolish the relevant tax reliefs and existing state guarantee schemes in the housing loan market has continued to provide incentives for rapid credit growth.

-The authorities have found that the large presence of foreign banks with easy access to funds, though beneficial for many reasons, has limited their ability to influence bank behavior by regulation. Moral suasion tool has also not been helpful since foreign banks have paid more attention to instructions from parents and strong competition has prevented banks from slowing credit growth so as not to lose market share.

\section{Hungary (1995-2006)}

\section{Policy Responses}

. Large sterilized interventions, when the exchange rate band was narrow (until 2001).

. Greater exchange rate flexibility through a widening of the crawling band (from \pm 2.25 to \pm 15 percent) in 2001 , though intra-marginal interventions provided limited de facto flexibility.

. Adjustment in exchange rate regime parameters, e.g., by reducing monthly rates of crawl to slow down the depreciation of the currency (to accommodate the appreciation pressures). . Gradual decrease in interest rates permitted by disinflation; . Cautious liberalization of the capital account (with controls on certain transactions-e.g., derivative transactions and lending to nonresidents in domestic currency maintained). . Debt management tools: Early repayment of foreign public debt through privatization receipts and shifting the denomination of the debt in favor of the domestic currency. . Moral suasion: Possibility to impose measures and controls against destabilizing capital inflows under extraordinary circumstances, as well as threats to impose stricter reserve requirements to stem the inflows and to reduce remuneration on reserve requirements if banks' on-balance sheet open positions exceeded 30 percent of their capital (never used). . Strengthening of prudential and reporting environment to help monitor and manage risks associated with capital flows.

\section{. Risk awareness campaigns by the central bank to warn}

against the risks associated with unhedged FX lending of foreign borrowing by banks to borrowers with limited FX earnings and hedging against FX risks.

\author{
. Helped address partly the appreciation pressures on the \\ currency. \\ . Played a role in limiting speculation against the forint and \\ potential adverse consequences of a reversal of the interest \\ sensitive portfolio inflows. \\ . Helped cope with the implications of the inflows on the \\ liquidity of the financial system.
}

. Possibility to impose extraordinary measures could have played

a signaling effect. However, moral suasion in general had limited effectiveness in an environment of highly integrated international financial markets and in the presence of large foreign banks which have easy access to foreign funds and are supervised and regulated by parent bank supervisors. .While helpful, the effectiveness may be limited in the absence of efforts to strengthen cross-border coordination of parent and host bank supervisors.

. These measures have been aimed not at limiting capital inflows per se, but at dealing with their implications for facilitating FX lending; effectiveness of these measures have been likely limited given the persistent strength of FX lending. 
Israel (1988-1998)

\section{Policy Responses}

. Sterilized interventions to defend the exchange rate band and prevent excessive appreciation that undermine competitiveness . Adjustment of exchange rate band parameters and practices (e.g., abandonment of an 'inner' band and/or adjustment of the rate of crawl).

. Greater exchange rate flexibility by widening the bands and introducing asymmetric bands.

\section{. Careful sequencing of capital account liberalization:}

. Deferral of further inflow liberalization at times of strong inflows and liberalization of capital outflows;

. Liberalizing inflows and long-term flows before outflows and short-term flows, and foreigners' and business sector flows before domestic and household sector flows;

. Continuous development of domestic money and capital markets; increased range and sophistication of monetary operations available; and strengthening bank supervision and regulation.
Impact

. Large quasi-fiscal costs that forced seeking other policy options over time.

. Provided some temporary relief from the impossible trinity dilemma by introducing more exchange rate flexibility.

. Decisive factor in resolving the holy trinity dilemma by introducing two-way exchange rate risks.

. Worked well in reducing the market pressure on exchange rate band limits (thereby also limiting the need to intervene and sterilize). markets to absorb and effectively manage the inflows.

\begin{tabular}{|cc}
\hline & Policy Responses \\
\hline Monetary measures: Increase in the main refinancing rate on
\end{tabular}

. Monetary measures: Increase in the main refinancing rate on

several occasions to keep rates $1 \frac{1}{2}-2$ percentage points above ECB rate, phased increase in the reserve requirement $(7 / 2004$, $6 / 2005$ ) and a broadening in the reserve base to include banks' foreign liabilities with shorter maturities.

\section{. Prudential and supervisory measures: increase in} supervisory reporting requirements-tightening of onsite/ offsite inspections, introduction of a rating system for banks, periodic stress testing activities, increased supervision of banking groups on a consolidated basis (2004); dialog and exchange of information between home and host supervisors. The latter was seen as a way to mitigate the threat to stability that would arise from a slowdown in capital inflows from the large foreign banks. Various MoUs have been signed at the Baltic or bilateral levels.

- Moral suasion: periodic consultations with individual banks and bank association; communication of BoL's concerns about rapid credit growth to banks (through letters to and meetings with banks) and the media; efforts to raise public awareness (e.g., through conferences) have been used to raise public awareness of the risks associated with rapid credit growth and its associated risks. Administrative controls have not been used as they were seen as a step backward and a last resort.

\section{Policy Responses}

\section{Lithuania (mid-late 1990s and 2002-present)}

Measures taken to respond to the implications of the inflows for the rapid growth of credit, and not to reduce the growth rate per se but to limit the risks involved, including by addressing the factors that may be stimulating credit and excessive risk taking:
Impact

. The phased increase in reserve requirements has achieved some

limited success in slowing credit growth, by tightening lats liquidity conditions which also exerted some temporary upward pressure on money market rates. Since remuneration rates are below banks' funding costs, higher and more broadly applicable reserve requirements acted to raise bank lending rates on both lats- and euro-denominated loans. In general however, monetary measures were not sufficient to put persistent downward pressure on lending growth, which has remained very strong throughout (2002-2006), though the term structure of banks' borrowing abroad improved. Reasons for limited effectiveness include: lack of independent monetary policy; high euroization; high foreign ownership, and hence unlimited access to funding sources; and competition and profitability in the banking sector.

. The immediate impact of these measures have not yet been observed, with credit growth supported by the inflows having remained persistent. Regulatory options to contain the buildup in vulnerabilities have in general been constrained in the EU context. In a setting where banking services may be offered by local banks, foreign branches, and cross-border providers, domestic prudential regulations that are stricter than elsewhere in the EU have been viewed to be easily evaded by booking loans offshore.

\section{Impact}

Credit growth and inflows have remained very strong throughout

(2002-2005). Raising foreign direct investment levels_including by attracting foreign investors-will require further improvements in the investment climate. 


\begin{abstract}
- Monetary measures: with limited interest rate policy under the CBA, the measures took the form of postponing the planned reduction in reserve requirements to euro zone levels. - Prudential/supervisory measures: tightening of capital adequacy requirements in 2006; continued bank monitoring measures with frequent inspections and ongoing efforts to increase information disclosure under pillar 3 of Basel II; greater cooperation with home supervisors of foreign banks to facilitate supervisory and crisis management cross-border arrangements (agreements concluded with Sweden, Latvia, and Estonia).

- Moral suasion/risk awareness/market development measures: collection of comprehensive information in the credit registry for risk assessment/management; policies for better understanding of risks; moral suasion letters to banks; public statements on risks related to housing boom; talks with banks and internal ratings based risk assessment measures.

- Attracting long term investments through improving business and investment climate: Lithuania's relatively low level of FDI and its recent outflow of FDI are causes for concern. Some efforts have been put into improving the investment climate and improving climate for doing business.
\end{abstract}

\begin{tabular}{|c|c|}
\hline \multicolumn{2}{|c|}{ Poland (1991-2005) } \\
\hline Policy Responses & Impact \\
\hline $\begin{array}{l}\text { Gradual increase in exchange rate flexibility and monetary } \\
\text { policy autonomy with an eventual move to a full float (2000) } \\
\text { and adoption of inflation targeting (1998). }\end{array}$ & $\begin{array}{l}\text { Provided time for development of other elements supporting } \\
\text { exchange rate flexibility and their sequencing with capital } \\
\text { account liberalization and implementation of inflation targeting. } \\
\text { Full monetary autonomy under a flexible exchange rate and IT } \\
\text { finally solved the problem of costly sterilized interventions and }\end{array}$ \\
\hline $\begin{array}{l}\text { Sterilized interventions and tighter monetary policy } \\
\text { (OMOs and reserve requirements increased in the second half } \\
\text { of the 1990s). }\end{array}$ & $\begin{array}{l}\text { economic overheating associated with capital flows earlier. } \\
\text { Not very effective in curbing domestic demand, as monetary } \\
\text { transmission of standard instruments through fragmented and } \\
\text { underdeveloped financial markets was limited and higher } \\
\text { interest rates continued to attract inflows. }\end{array}$ \\
\hline $\begin{array}{l}\text { Administrative measures: The NBP began attracting } \\
\text { household deposits directly to drain excess liquidity in the } \\
\text { banking system and to encourage banks to adjust deposit rates. } \\
\text {. Liberalization of external trade, including the abolishment } \\
\text { of import surcharges and reduction of import tariffs (in }\end{array}$ & $\begin{array}{l}\text { Improved the CB control over market rates and helped reduce } \\
\text { overheating associated with the capital inflows in an } \\
\text { environment with weaknesses in monetary transmission. } \\
\text {. Limited growth of FX reserves, also through stimulating } \\
\text { imports. }\end{array}$ \\
\hline
\end{tabular}
connection with the requirements associated with WTO and EU accession), and elimination of a surrender requirement. . Possibility to impose temporary measures under special circumstances that may threaten monetary/financial stability was put in the Law after OECD related capital account liberalization (e.g., an obligation on residents or nonresidents to maintain noninterest bearing deposits in connection with their capital operations other than FDI, or obligation to resell foreign currency or obtain permit to engage in FX operations). . Delays in liberalization of the remaining capital controls at times of strong capital inflows and international financial market volatility (second half of the 1990s and early 2000s); . Mandatory liberalization of outflows (OECD obligations). . Indirect interventions: Setting up of a government account at the NBP for FX proceeds associated with privatization and Eurobond issues.

. Debt management measures: The authorities shifted from foreign to domestic borrowing sources; and used part of the privatization receipts to finance future debt service and buy back Brady bonds.

. Gradual strengthening of bank regulation and supervision and development of markets: Prudential regulation and supervision gradually strengthened up to the level comparable

. Never used. (As in the Czech and Hungarian cases, their mere presence could have acted as a deterrent to certain types of crisis prone flows)

. Helped prevent contagion of Asian and Russian crises.

Possibly contributed to reducing pressure from capital inflows. . Helped reduce appreciation pressure on the zloty by reducing the net inflow of FX in the market.

. Helped cope with the implications of the inflows on the liquidity of the financial system.

. Helped improve the resilience of the banking system and markets to absorb and effectively manage the inflows. 
and in some areas more restrictive than international standards throughout the 1990s, with tight qualification and provisioning criteria and limits on open positions since the early 1990s.

. Gradual development of money/FX markets (e.g.derivatives

for hedging) since mid-1990s, supported by a gradual increase

in exchange rate flexibility until 2000 . Effective capacity for

monetary operations was also in place since the late 1990s.

\begin{tabular}{|c|c|}
\hline \multicolumn{2}{|c|}{ Romania (2004-2006) } \\
\hline Policy Responses & Impact \\
\hline $\begin{array}{l}\text { Delays in liberalizing capital controls, including restrictions } \\
\text { on nonresident purchases of government securities and other } \\
\text { controls on short-term capital inflows until } 2005 \text {. } \\
\text { Allowing exchange rate flexibility (abandoning the crawling } \\
\text { band in November 2004) so as to help reduce the upward } \\
\text { pressure on inflation by allowing the lei to appreciate under the } \\
\text { inflation targeting regime adopted in July 2005); but reduction } \\
\text { in interest rates to discourage capital inflows through partial } \\
\text { sterilization of its interventions. From Late 2005, interventions } \\
\text { were reduced and subsequently abandoned, allowing greater } \\
\text { exchange rate flexibility and tighter monetary policy; the } \\
\text { policy rate was tightened (early } 2006 \text { ), and sterilization } \\
\text { operations intensified to reduce the policy rate gap. } \\
\text { Improvement in the fiscal balance (fiscal stance of broad } \\
\text { public enterprises tightened relative to GDP). } \\
\text { Administrative measures: Extending and raising the reserve } \\
\text { requirement on all foreign currency denominated liabilities } \\
\text { successively (2004-06), with a view to curtailing strong } \\
\text { foreign currency lending by the banking system and excessive } \\
\text { lending to unhedged household borrowers; these measures } \\
\text { were combined with the limits on exposures of credit } \\
\text { institutions lending in foreign currency to borrowers without } \\
\text { natural hedging, and refinement of loan classification and } \\
\text { provisioning requirements to take into account FX risks. }\end{array}$ & $\begin{array}{l}\text { Until } 2005 \text { interest rate sensitive inflows were limited by the } \\
\text { controls on short-term capital inflow, allowing some degree of } \\
\text { monetary autonomy under a de facto crawling band regime. } \\
\text {. The policy remained under pressure from the conflicting } \\
\text { objectives of inflation and competitiveness, which undermined } \\
\text { monetary policy credibility at times: The NBR continued to } \\
\text { intervene in the FX market to prevent lei appreciation and } \\
\text { reduced its sterilization efforts (September 2005); this caused its } \\
\text { effective interest rate (average rate at which it accepts bank } \\
\text { deposits) to diverge from the policy rate (until early 2006), } \\
\text { threatening the fulfillment of its inflation target. }\end{array}$ \\
\hline $\begin{array}{l}\text { Turkey (2003-present) } \\
\text { Policy Responses }\end{array}$ & Impact \\
\hline $\begin{array}{l}\text { Largely sterilized interventions (managing liquidity impacts } \\
\text { of inflows) limiting the extent and speed of nominal } \\
\text { appreciation in } 2003-04 \text { period. } \\
\text {. Reduction in interest rates (by more than } 10 \text { basis points } \\
\text { between early } 2004 \text { and early 2005). . Tighter fiscal policy (in } \\
\text { response to overheating and current } \\
\text { account concerns). } \\
\text { Debt management operations using capital inflows to over- } \\
\text { borrow and move to medium- and long-term domestic } \\
\text { borrowing using local currency instruments. }\end{array}$ & $\begin{array}{l}\text { Capital inflows have continued to come, with a significant } \\
\text { increase in equity and debt securities, as well as inflows to the } \\
\text { banking system. }\end{array}$ \\
\hline
\end{tabular}

Sources: Table 6, Otker-Robe et. Al. (2007). 


\section{References}

Bank for International Settlements, and others, 2006, Credit Growth: challenges for Financial Stability in Central and Eastern Europe, Note for a workshop of central banks and supervisory authorities in Frankfurt am Main on 12 December 2006.

Barro, R., and Sala-i-Martin, X., 1995, Economic Growth, The MIT Press, Cambridge Massachusetts.

Davidson, R., and J. Duclos, 2000, "Statistical Inference for Stochastic Dominance and for the Measurement of Poverty and Inequality," Econometrica 68-6, pp. 1435-64.

Enoch, C., and I. Ötker, 2007, Rapid Credit Growth in Central and Eastern Europe: Endless Boom or Early Warning? (Washington: International Monetary Fund).

Hilbers, P., I. Ötker, C. Pazarbasioglu,. and G. Jonhsen, 2005, “Assessing and Managing Rapid Credit Growth and the Role of Supervisory and Prudential Policies," IMF Working Paper No. 05/151 (Washington: International Monetary Fund).

International Monetary Fund, 2006, “Global Financial Stability Report”, September, Chapter II (Washington: International Monetary Fund).

_ , 2007, “Global Financial Stability Report,” September (Washington: International Monetary Fund).

Ötker, I., Z. Polanski, B. Topf, and D. Vavra, D., 2007, “Coping with Capital Inflows: Experiences of Selected European Countries," IMF Working Paper No. 07/190 (Washington: International Monetary Fund).

Schadler, S. and others, 2005, Adopting the Euro in Central Europe. Challenges of the Next Step in European Integration, IMF Occasional Paper No. 234 (Washington: International Monetary Fund). 